\title{
Impact of Salmonella enterica Type III Secretion System Effectors on the Eukaryotic Host Cell
}

\author{
Francisco Ramos-Morales \\ Departamento de Genética, Facultad de Biología, Universidad de Sevilla, Avenida Reina Mercedes 6, 41012 Sevilla, Spain \\ Correspondence should be addressed to Francisco Ramos-Morales, framos@us.es
}

Received 4 November 2012; Accepted 22 November 2012

Academic Editors: R. Botelho, G. C. Chen, N. Kataoka, and C. M. Wells

Copyright () 2012 Francisco Ramos-Morales. This is an open access article distributed under the Creative Commons Attribution License, which permits unrestricted use, distribution, and reproduction in any medium, provided the original work is properly cited.

Type III secretion systems are molecular machines used by many Gram-negative bacterial pathogens to inject proteins, known as effectors, directly into eukaryotic host cells. These proteins manipulate host signal transduction pathways and cellular processes to the pathogen's advantage. Salmonella enterica possesses two virulence-related type III secretion systems that deliver more than forty effectors. This paper reviews our current knowledge about the functions, biochemical activities, host targets, and impact on host cells of these effectors. First, the concerted action of effectors at the cellular level in relevant aspects of the interaction between Salmonella and its hosts is analyzed. Then, particular issues that will drive research in the field in the near future are discussed. Finally, detailed information about each individual effector is provided.

\section{Introduction: Type III Secretion Systems and Salmonella}

Gram-negative bacteria have evolved several machineries, known as secretion systems, for transport of substrates across their cell membranes in response to various environmental cues. Secretion of proteins is often essential for pathogenicity, biofilm formation, modulation of the eukaryote host, and nutrient acquisition. There are at least seven different secretion systems classified as type I (T1SS) to type VI (T6SS) and the CU (chaperone-usher) system. Two main mechanisms for transport operate in these secretion systems: the proteins can be exported directly from the cytoplasm out of the cell by a one-step process or by a two-step process where the protein is first exported through the inner membrane to the periplasm and then moved across the outer membrane. The T2SS, T5SS, and the CU transport substrates from the periplasm across the outer membrane. They are classified as two-step translocation pathways as they rely on the general secretory pathway, Sec, or the Tat pathway for the first step of transfer across the inner membrane. T1SS, T3SS, T4SS, and T6SS are one-step transport systems that carry out simultaneous translocation of substrates across both membranes without periplasmic intermediates [1].

Many Gram-negative bacterial pathogens of animals or plants, including members of the genera Salmonella, Shigella, Yersinia, Escherichia, and Pseudomonas, rely on T3SSs to inject proteins directly into the eukaryotic host cells. Substrates of T3SSs, known as effectors, are transported via a flagellum-like injectisome from the cytoplasm of the bacterial cell across the inner and outer membrane to the cytoplasm of a eukaryotic host cell. These complex nanomachines consist of at least 20 different subunits and are composed of a basal body residing in the inner membrane, periplasm and outer membrane of the bacterial cell, a needle, located in the extracellular space, and a channel-like translocon that inserts into the host plasma membrane. Effectors are targeted to the T3SS by a signal that is usually located within the $\mathrm{N}$-terminal 20 to 30 amino acids. These regions are structurally disordered and their amino acid sequences are not universally conserved, but they often share specific amino acid compositions or patterns. In addition to the $\mathrm{N}$ terminal T3S signal, translocation depends, at least in some cases, on a second protein region, located within the $\mathrm{N}$ terminal 50 to 100 amino acids of effector proteins, that 
provides the binding site for a T3S chaperone. Chaperones presumably promote the recognition of secreted proteins by components of the T3SS. Additional functions of the chaperones are preventing the premature degradation of T3SS substrates and contributing to impose a hierarchy on the translocation of effector proteins [2]. The diversity of functions of T3SS effectors as well as the lack of conserved sequences has hampered the comprehensive identification of candidate effectors. Collectively, these virulent factors contribute, in some cases redundantly, to remodel host cellular functions, subvert immunity, establish a survival niche, and promote pathogen proliferation. Completing the repertoire of effectors for different pathogens, as well as understanding the molecular functions, and identifying the host targets for every effector are subjects of intense research in the field of cellular microbiology. This recent discipline is at the interface between microbiology and cell biology and attempts to use pathogens as tools to tackle questions in cell biology and to employ cell biology methods to understand the pathogenicity of microbes [3].

Salmonella are predominantly pathogenic Gramnegative, rod-shaped, motile bacteria belonging to the family Enterobacteriaceae that probably diverged from a common ancestor with Escherichia coli about 100 million years ago. The genus Salmonella includes the species S. bongori and $S$. enterica. S. enterica is further divided into several subspecies and more than 2500 serovars. Serovars causing disease in humans and other warm-blooded animals mostly belong to $S$. enterica subspecies enterica, whereas $S$. bongori and the other subspecies of $S$. enterica are usually associated with cold-blooded animals. Salmonella can cause food poisoning, gastrointestinal inflammation, typhoid fever, and bacteremia, depending on the serovar and the host. For instance, S. enterica serovar Typhi causes typhoid fever in humans, whereas $S$. enterica serovar Typhimurium usually causes self-limited gastroenteritis in humans and a systemic typhoid-like disease in mice. S. enterica serovar Typhi is also an example of strict adaptation to a specific host, human, whereas S. enterica serovar Typhimurium has a wide range of hosts, including rodents, cattle, and mammals. Systemic infection usually starts with the ingestion of contaminated food or water. After crossing the intestinal mucosa, Salmonella infects macrophages and spreads via the blood to the liver and spleen where it multiplies intracellularly. The typical intracellular niche of Salmonella is a modified phagolysosome known as Salmonella-containing vacuole (SCV), but the mode of entry and the strategy to survive inside the target cells varies according to the type of cell and depends on the temporal expression of particular genes by Salmonella. Target cells include $\mathrm{M}$ cells, gut epithelial cells, macrophages, neutrophils, monocytes, dendritic cells, granulocytes, B cells, and T cells [4].

In addition to the flagella system, which is also considered a T3SS, S. enterica encodes two virulence-related T3SS, T3SS1 and T3SS2 (Figure 1), on Salmonella pathogenicity island 1 (SPI1) and Salmonella pathogenicity island 2 (SPI2), respectively [5-7]. Some T3SS substrates are encoded on SPI1 and SPI2, but many are encoded outside these pathogenicity islands, usually within DNA segments that exhibit features consistent with their horizontal acquisition. T3SS1 becomes active upon contact with epithelial cells in the intestine of the infected host and translocates effectors across the host cell plasma membrane. Some of these effectors are involved in induction of localized membrane ruffling and bacterial invasion. T3SS1 effectors also trigger activation of mitogen-activated protein kinase (MAPK) pathways, production of proinflammatory cytokines, recruitment of polymorphonuclear leukocytes (PMNs), and induction of acute intestinal inflammation. T3SS2 is found in all subspecies of S. enterica (but not in S. bongori). This system is expressed intracellularly in response to acidic $\mathrm{pH}$ and nutrient limitation found in the lumen of the SCV. It translocates effectors across the membrane of the SCV. These effectors are required for the modulation of the intracellular environment [8].

This paper summarizes our current knowledge about the functions of Salmonella T3SS effectors. First, because effectors often act cooperatively, sometimes redundantly or in opposite ways, it is important to consider their concerted actions on relevant steps of the infection process at the cellular level. The paper continues with an analysis of the issues that will drive future research in the field of Salmonella T3SS effectors. Finally, as a sort of glossary, detailed and up-to-date information is given about each particular effector with special emphasis in biochemical activities, host partners, and targeted cellular pathways and processes. This information is summarized in Table 1.

\section{Cellular Processes and Pathways Manipulated by Salmonella Effectors}

2.1. Actin Cytoskeleton and Invasion. Central to the pathogenesis of Salmonella is its ability to invade intestinal cells: M-cells, epithelial cells, and dendritic cells [9-11]. The best-characterized Salmonella invasion mechanism requires T3SS1 that initiates a process known as the "trigger" mechanism. It has been recently shown that Salmonella can also invade cells by a "zipper" entry process, typical of other pathogens like Listeria [12], through the Rck outer membrane protein, which induces a local accumulation of actin, leading to a discrete membrane alteration [13]. Another outer membrane protein, PagN, and the poreforming hemolysin HlyE also contribute to invasion by unknown mechanisms [14-16]. In addition, recent data indicate that other unknown entry routes may be used depending on the serotype, the host, and the cell-type considered $[17,18]$. However, given its relative importance and the scope of this review, the focus here will be on the T3SS1-dependent entry mechanism.

T3SS1-dependent invasion is a process with several steps [19], some of them common to other invasion mechanisms, that includes (i) movement in the gut lumen by passive diffusion and active motility and chemotaxis; (ii) transient interactions with the mucosal surface; (iii) reversible binding to target cells via adhesins; (iv) irreversible T3SS1-mediated docking; (v) translocation of bacterial effectors through T3SS1; (vi) manipulation of the host cells by effectors 


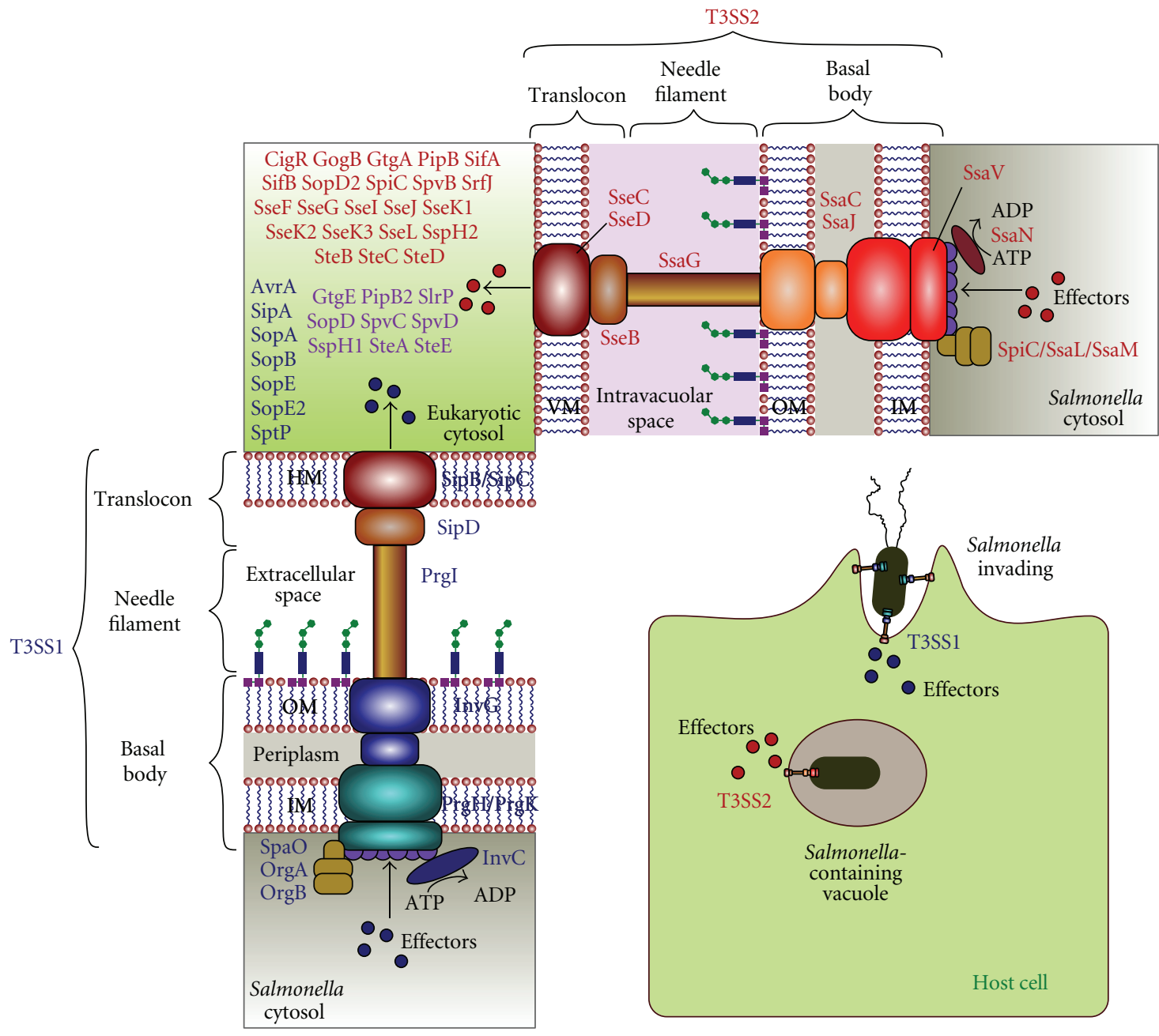

FIGURE 1: Schematic representation of Salmonella T3SS1 and T3SS2. HM: host plasma membrane; VM: vacuolar membrane; OM: outer membrane; IM: inner membrane. T3SS1 components and effectors are in blue. T3SS2 components and effectors are in red. Effectors translocated through both systems are in purple.

leading to rapid appearance of membrane ruffles; (vi) host cell invasion with formation of spacious vacuoles. Figure 2 summarizes the role of T3SS1 effectors in this process. At least six effectors induce remodeling of actin cytoskeleton: SipA, SipC, SopB, SopE, SopE2, and SptP. SipA and SipC directly bind to actin, cooperate to promote the formation of actin filaments at the site of bacterial adhesion, and prevent filament disassembly by host factors [20]. SipA modulates the actin-bundling activity of T-plastin [21] and inhibits the filament-depolymerizing factor ADF/cofilin and the filament capping and severin protein gelsolin [22]. SipC possesses distinct domains that are able to nucleate actin (central amino acid region) and to promote actin bundling (Cterminal region) $[23,24]$. SopE, SopE2, and SopB do not directly interact with actin but mediate the activation of small GTPases of the Rho family that are required for the formation of highly branched actin networks. As explained in the last section of this paper, SopE and SopE2 mimic mammalian guanine nucleotide exchange factors (GEFs) to activate the GTPases Rac1 and Cdc42 by catalyzing exchange of GDP for GTP $[25,26]$, whereas SopB indirectly activates RhoG targeting its GEF, SGEF [27]. After bacteria entry, membrane ruffling is terminated by the GTPase-activating protein (GAP) activity of SptP that inactivates Racl and Cdc42, reverting the actin cytoskeleton to its basal state after bacteria entry [28].

One important factor contributing to actin cytoskeleton reorganization and T3SS1-mediated Salmonella entry is tyrosine phosphorylation. Two host nonreceptor tyrosine kinases have been shown to be involved in invasion: Abl (Abelson tyrosine kinase) and FAK (focal adhesion kinase). Abl-mediated tyrosine phosphorylation of its substrates CrkII, an adaptor protein, and Abil, a component of the WAVE2 complex, is enhanced during host cell invasion, and inhibition of CrKII phosphorylation impairs bacterial entry [29]. The physical interaction between FAK and the scaffolding protein p130Cas is necessary for Salmonella internalization. Although phosphorylation of p130Cas is induced during Salmonella invasion, this is not required for bacterial internalization, but p130Cas appears to be necessary 


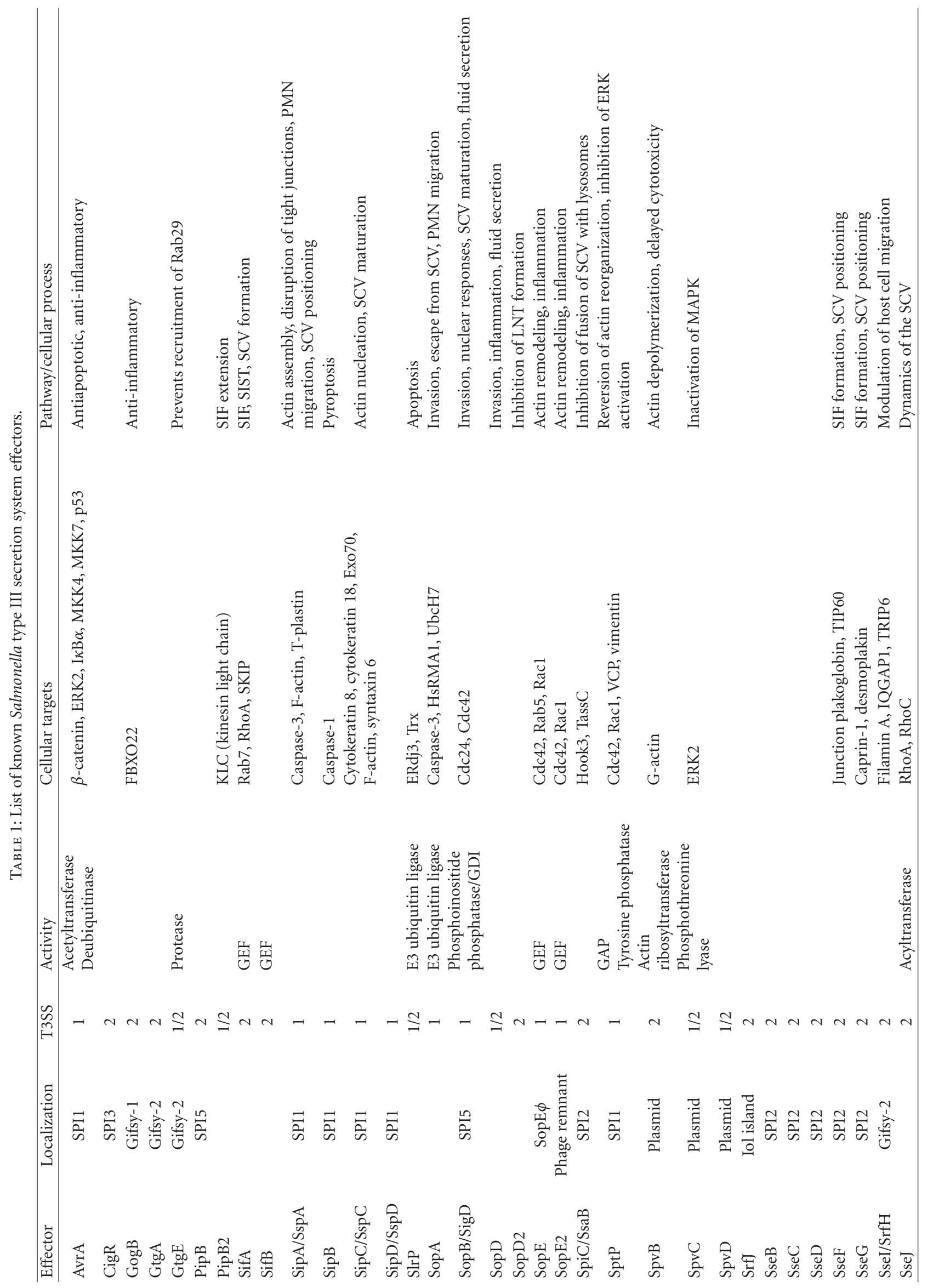




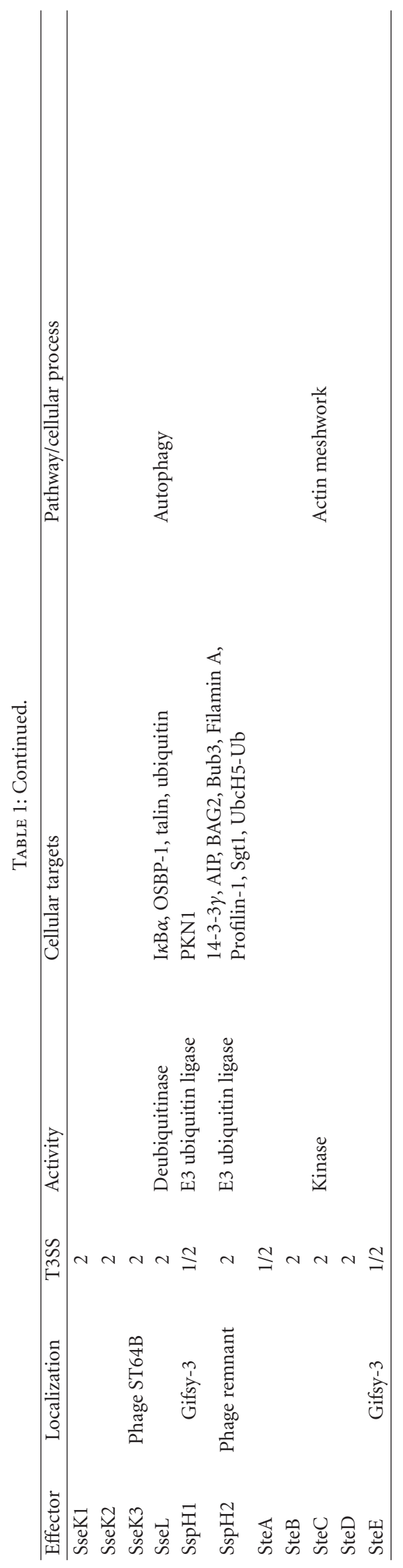




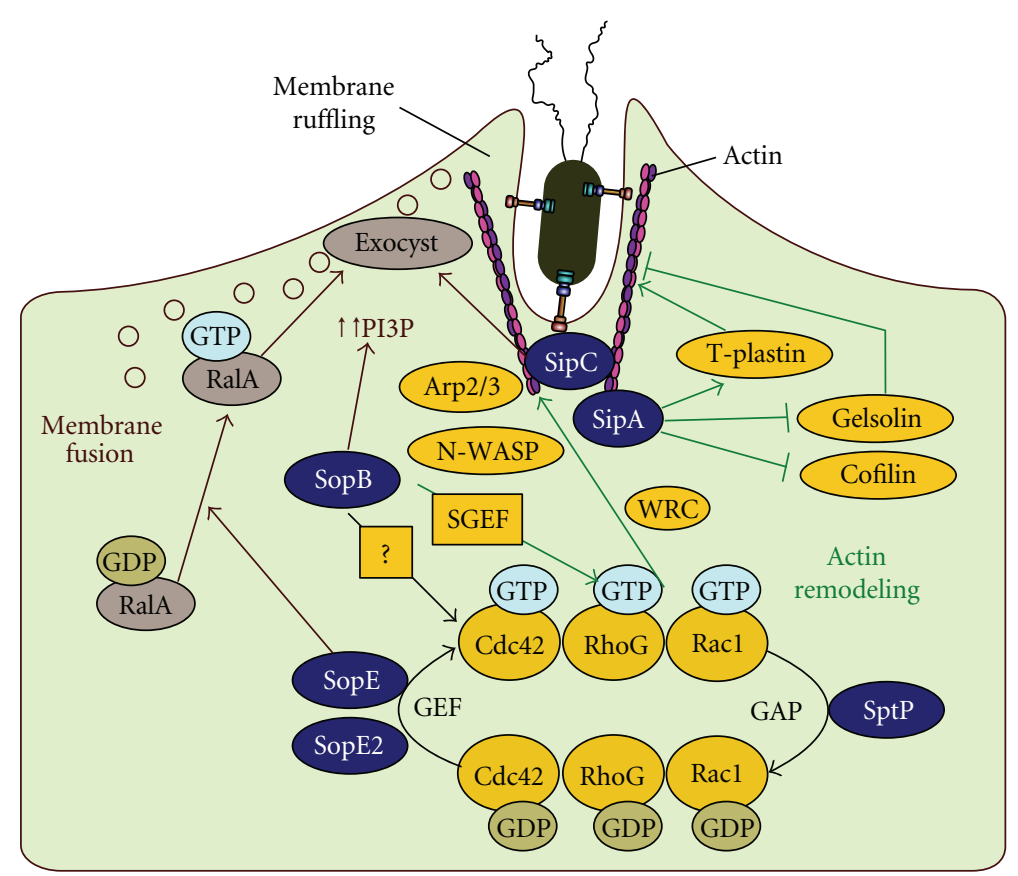

Figure 2: T3SS1-dependent invasion of eukaryotic cells. Salmonella triggers its own internalization into host cells using a mechanism characterized by the appearance of large membrane ruffles at the bacterial entry site. Bacterial effector proteins SipA, SipC, SopB, SopE, and SopE2, which are injected into host cells through T3SS1, induce this process. Actin remodeling, mediated by host factors represented in yellow, and membrane fusion, mediated by host factors represented in brown, are involved in the mechanism of internalization. The process is reverted by the effector SptP.

for the proper assembly of actin during invasion [30]. The relationship of these kinases with Cdc42 and Racl is not clear, but the activation of these GTPases is not impaired in the absence of FAK or Abl, suggesting that they are regulating other components that function either downstream or in parallel with Rac1 and Cdc42. A potential target of Cdc42 is the tyrosine kinase Ack. This kinase is activated upon infection with Salmonella in a T3SS1-dependent manner. However, although Ack is involved in Salmonella-induced cellular responses mediated by the MAPK ERK, it does not appear to be required for Salmonella internalization [31]. Other host factors that are recruited to the actin-rich ruffles (also known as phagocytic cups) induced by Salmonella are Shank3 and IQGAP1. Shank3 is a large cytoskeletal scaffold protein. IQGAP1 is another scaffold protein that interacts with actin, Racl, and $\mathrm{Cdc} 42$ and is necessary for efficient activation of Rac1 and Cdc42 by Salmonella. It has been suggested that interactions of IQGAP1 with Salmonella-activated Rac1 and Cdc42 maintain them in their active form [32, 33]. Another host factor that contributes to bacterial invasion by altering the dynamics of the actin cytoskeleton is the ubiquitin C-terminal hydrolase $\mathrm{UCH}$ L1 [34]. Since SopA, SopB, and SopE are substrates of the ubiquitin proteasome system, it has been suggested that UCH-L1, acting as a deubiquitinating enzyme, could play a role in controlling the half-life of these effectors and/or the activity of small GTPases of the Rho subfamily.

Concomitant with the actin remodeling process, three of these effectors also regulate fusion of membrane from different sources at the site of entry contributing to the expansion of ruffles. SipC interacts with Exo70, a component of the exocyst complex, which mediates docking and fusion of exocytic vesicles with the plasma membrane [35]. SopE can also activate RalA, a GTPase required for assembly of the exocyst [35]. Finally, SopB stimulates membrane fusion at the site of entry by increasing local levels of PI3P resulting in the recruitment to membrane ruffles of VAMP8, a v-SNARE protein that mediates homotypic fusion of early and late endosomes and regulates exocytosis by forming a SNARE complex with syntaxin 4 and SNAP23 [36].

2.2. Tight Junction Alterations. The epithelial cells lining the small intestine form a barrier that keeps the gut contents in the gut cavity, the lumen. These epithelial cells are bound by tight junctions, specialized cell junctions that function as barriers to the diffusion of some membrane proteins and lipids between apical and basolateral domains of the plasma membrane, and seal neighboring cells together preventing even small molecules from passing into the lumen. Tight junctions are composed of two major transmembrane proteins, claudins and occludins, intracellular peripheral membrane proteins called ZO proteins and several other associated proteins. Salmonella is one of the pathogens that have developed specific strategies to alter these structures during infection, resulting in diarrhea and other pathogenic effects [37]. Salmonella modifies tight junctions through the action of four T3SS1 effectors (Figure 3): SipA, SopB, 


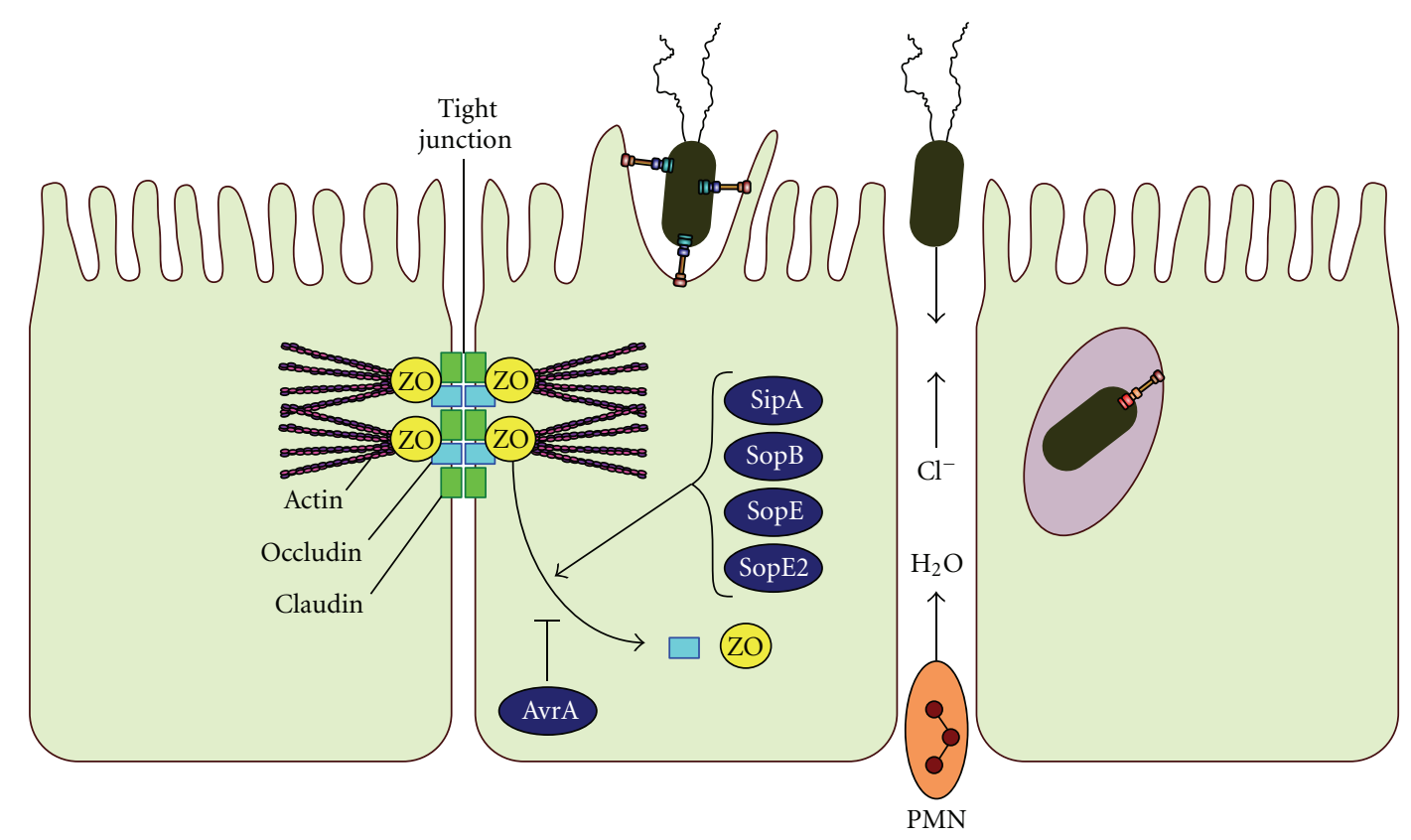

FIGURE 3: Effects of T3SS1 effectors on epithelial tight junctions. T3SS1 effectors SipA, SopB, SopE, and SopE2 contribute to disruption of tight junction by decreasing the amounts of ZO-1 ( $\mathrm{ZO})$ and phosphorylated occludin. In contrast, AvrA is a tight junction stabilizer.

SopE, and SopE2 [38]. All of them contribute to the effects of Salmonella infections in cell lines: decrease in transepithelial resistance, increase in permeability, decrease in ZO-1 expression, and decrease in the amount of phosphorylated occludin, which is the form that is present in tight junctions. Surprisingly, another T3SS1 effector, AvrA, has been described as a tight junction stabilizer [39].

2.3. Biogenesis of the Salmonella-Containing Vacuole. Following internalization, Salmonella establishes its intracellular niche in a modified phagosome termed the Salmonella containing vacuole $(\mathrm{SCV})$. This is a unique membrane-bound compartment where Salmonella, depending on the host cell type, can establish a replication niche [40]. Its biogenesis and maturation are characteristically accompanied by the formation of different types of tubules originating and connected to the SCV [41]. Additional hallmarks of the biogenesis of the SCV are the movement of the vacuole from the plasma membrane to a perinuclear position [42], the recruitment of several members of the Rab family of small GTPases [43], the interaction with endocytic and exocytic pathways, and the involvement of T3SS1 and T3SS2 effectors in the modulation of the process. The SCV biogenesis can be divided arbitrarily into three stages: early $(10 \mathrm{~min}-1 \mathrm{~h}$ postinfection), intermediate $(1 \mathrm{~h}-4 \mathrm{~h})$, and late $(>4 \mathrm{~h})[8,41]$ (Figure 4).

The early stage is governed by T3SS1 effectors SopB and SptP. The role of SopB is complex and involves direct, through its phosphoinositide phosphatase activity, as well as indirect manipulation of the host membrane phosphoinositide contents. (i) SopB activates Akt via $\mathrm{PI}(3,4) \mathrm{P}_{2}$ and $\mathrm{PI}(3,4,5) \mathrm{P}_{3}[44]$. (ii) Its activity is necessary for reducing the levels of $\mathrm{PI}(4,5) \mathrm{P}_{2}$, necessary for efficient formation of the vacuole [45], and phosphatidylserine. Reducing the levels of these negatively charged lipids results in the exclusion of several Rab from the SCV and may serve to delay the fusion with the lysosome [46]. (iii) SopB recruits the GTPase Rab5 to the SCV membrane, that in turn attracts the Rab5-interacting protein Vps34, a PI3K that generates PI3P in the SCV membrane [47]. The accumulation of this phosphoinositide is necessary for the recruitment of the sorting nexins SNX1 and SNX3, which are important regulators of membrane trafficking $[48,49]$. SNX1 shifts from its endosomal localization to the site of bacterial entry within the first minutes of Salmonella infection. Then, it forms highly dynamics tubules named spacious vacuoleassociated tubules (SVATs) that are accompanied by a reduction in vacuole size and removal of cation-independent mannose-6-phosphate receptor from the nascent SCV. This receptor is a late endosome marker involved in delivering soluble lysosomal enzymes to lysosomes. Its absence from the SCV was originally seen as an evidence of lack of SCVlysosome fusion [50], but there are reports that support a model in which SCVs can fuse to lysosomes, and then cationindependent mannose-6-phosphate receptor is removed in an SNX1-dependent manner $[49,51,52]$. SNX3 associates to specific tubular structures (SNX3 tubules) that last from $30 \mathrm{~min}$ to $2 \mathrm{~h}$ after invasion and contribute to the recruitment of Rab7 and LAMP1 to the SCV and to the movement of the vacuole [48]. The function of the effector SptP in the biogenesis of the SCV involves its GAP activity, that downregulates Cdc42 and Racl and reverts membrane ruffling [28], and its phosphatase activity, which dephosphorylates VCP [53], although this activity could be related to later events (see what follows). 


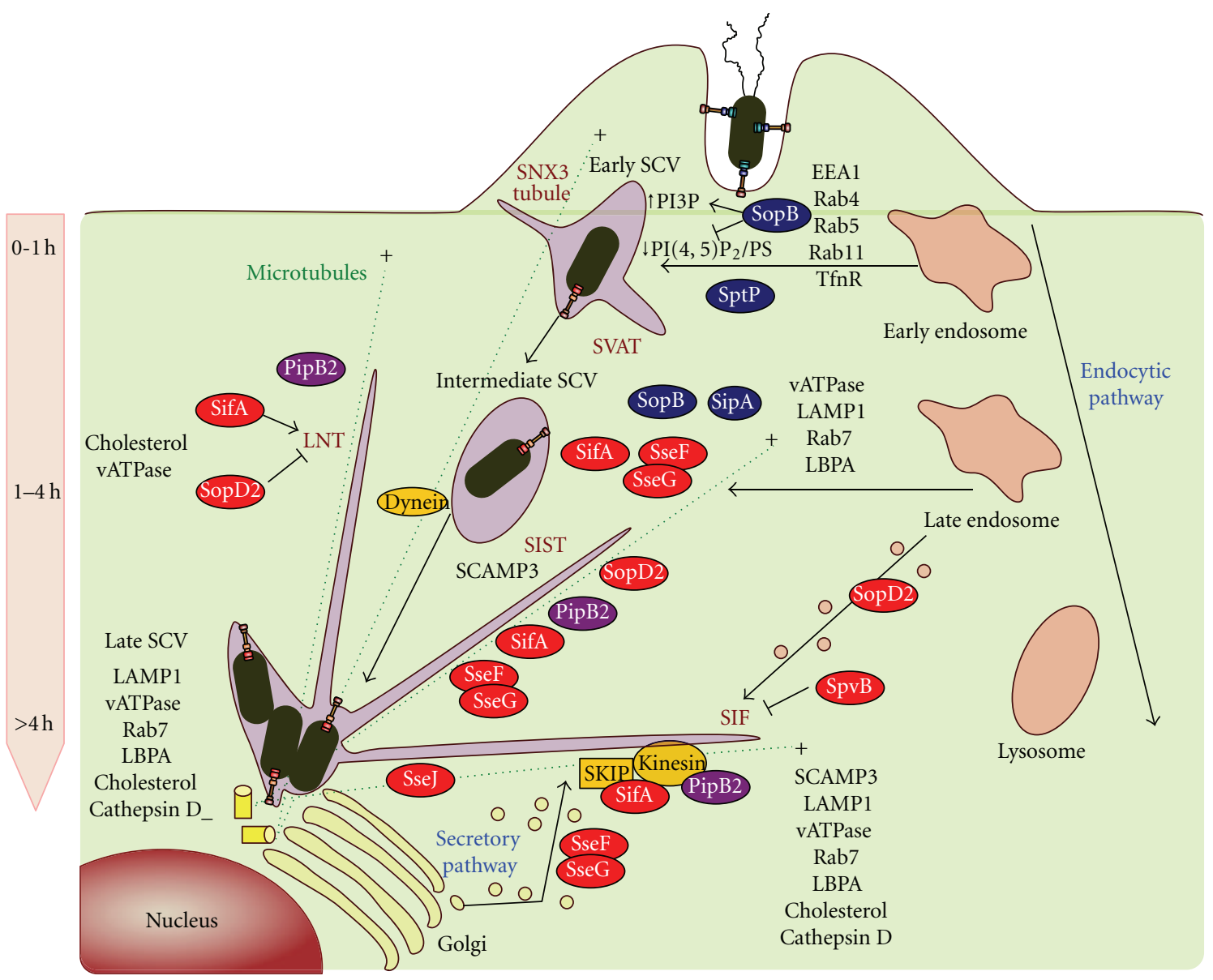

FIgURE 4: Biogenesis of the Salmonella-containing vacuole. After internalization, Salmonella establishes an intracellular niche inside a modified phagosome known as Salmonella-containing vacuole (SCV). The initial step in SCV biogenesis $(0-1 \mathrm{~h})$ is governed by T3SS1 effectors (in blue) SopB and SptP and is characterized by the formation of SVATs and SNX3 tubules. The movement of the SCV to a juxtanuclear position during the intermediate stage of development (1-4 h) requires the participation of the T3SS1 effectors SipA and SopB and the T3SS2 effectors (in red) SifA, SseF, and SseG. Many effectors are involved in the final stage of maturation and in the maintenance of the SCV. Replication is initiated $4-6 \mathrm{~h}$ postinvasion and is accompanied by the formation of different kinds of tubules known as SIFs, SISTs, and LNTs. Effectors involved in the formation of these tubules are depicted in red (T3SS2 effectors) and in purple (effectors of both systems). The maturation process is also characterized by the interaction with the host endocytic and secretory pathways.

The intermediate stage in the SCV development is characterized by dynein-mediated movement of the vacuole along microtubules to reach a juxtanuclear position adjacent to the microtubule-organizing center [42]. This process requires the participation of the T3SS1 effectors SipA and SopB, and the T3SS2 effectors SifA, SseF, and SseG (see below for details of the function of these effectors on SCV biogenesis). The actin-based motor nonmuscle myosin II appears to contribute to SCV positioning in a process involving the phosphatase activity of SopB [54].

During the late stage of SCV maturation, a set of T3SS effectors, exhibiting both cooperative and antagonistic activities, are involved in the maintenance of the vacuole at its perinuclear position, as well as in the generation of different types of tubular networks, namely, Salmonella-induced filaments (SIFs), Salmonella-induced secretory carrier membrane protein 3 (SCAMP3) tubules (SISTs), and LAMP1negative tubules (LNTs), that are more easily observed in cultured epithelial cells. SIFs are tubules extending from the SCV that form along a scaffold of microtubules and derive from late endocytic compartments. They have the same composition as that of SCV membranes and contain LAMPs, Rab7, cholesterol, lysobisphosphatidic acid, vATPase, and cathepsin D [55-57]. But, they are also positive for SCAMP3 [58], indicating that these tubules can incorporate membrane from the secretory pathway. Formation of SIFs involves effectors PipB2, SifA, SopD2, SseF, SseG, and SseJ, whereas SpvB appears to have a negative effect on SIF formation (see the last section of this paper for a detailed explanation of the function of these effectors). A model of SIF formation [41] suggests that a putative GEF activity of SifA activates the small GTPase RhoA, which then binds and activates SseJ. As a consequence, the lipid composition of the SCV membrane is changed, promoting the formation of tubules. Both PipB2 and the complex SifA-SKIP bind to kinesin-1, link the SCV and nascent tubules to microtubules, 


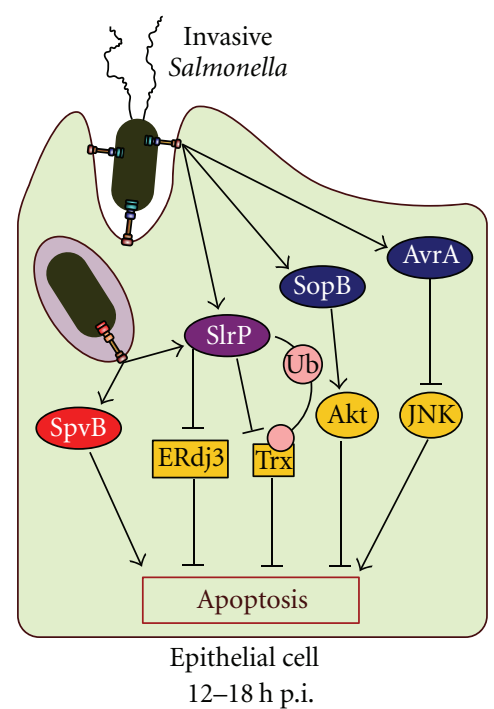

(a)

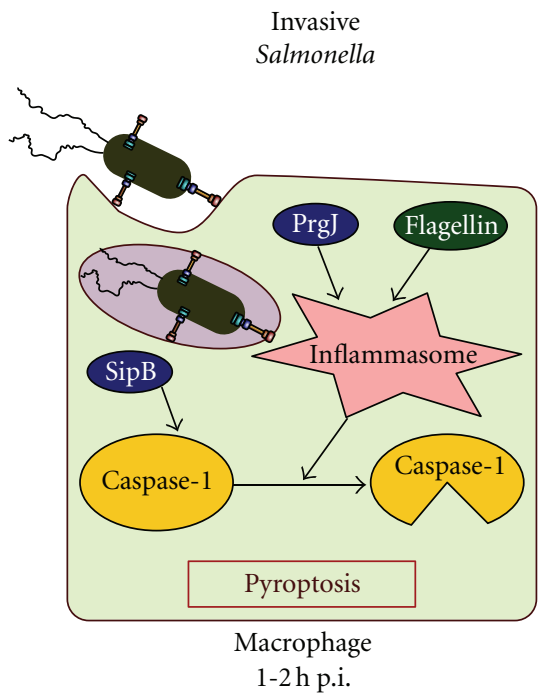

(b)

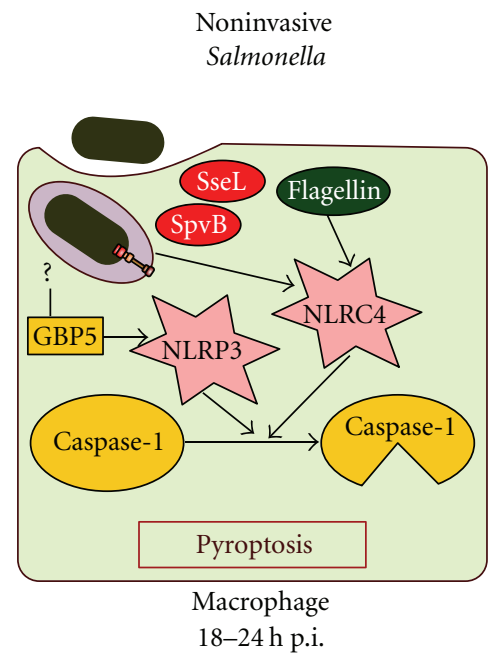

(c)

Figure 5: Salmonella-induced host cell death. (a) Salmonella induces apoptosis in epithelial cells 12-18 h postinfection (p.i.). Effectors AvrA and SopB (secreted through T3SS1), SpvB (secreted through T3SS2), and SlrP (secreted through T3SS1 and T3SS2) have been suggested to be involved in this process through different mechanisms. Ub: ubiquitin. (b) Salmonella expressing T3SS1 induces rapid pyroptosis in macrophages. Pyroptosis is a proinflammatory form of programmed cell death that depends on caspase-1 activation. The T3SS1 effector SopB, the T3SS1 rod protein PrgJ, and flagellin secreted through T3SS1 are involved in the induction of rapid pyroptosis. (c) Noninvasive Salmonella induces delayed pyroptosis in infected macrophages. T3SS2 effectors, SpvB and SseL, and flagellin are involved in this form of cell death.

and promote the elongation of tubules along microtubules. SopD2 associates to late endosome and can contribute to SIF formation by targeting endocytic vesicles to the SCV and nascent tubules [59]. Finally, SseF and SseG mediate bundling of microtubules near the SCV that can promote fusion of aggregated vesicles into tubules [60]. SISTs also contain SCAMP3 and T3SS2 effectors but lack LAMP1 and other late endocytic markers [58]. The formation of SISTs requires effectors PipB2, SifA, SopD2, SseF, and SseG. The mechanisms to segregate SISTs from SIFs remain unknown. Other tubules that arise at the late stage of SCV maturation are LNTs. These tubules are enriched in bacterial T3SS2 effectors but lack host LAMP1 and SCAMP3. Similarly to SIFs and SISTs, they form along microtubules in a kinesin1-dependent manner, but they lack all the markers of SIFs and SISTs except vATPase. A report suggests that SifA and SopD2 exert positive and negative roles, respectively, in the formation of LNTs and that PipB2 is involved in their centrifugal extension [59]. The role of the Salmonellainduced tubular networks is unclear, although it could be related to the interception of nutrients or membranes from host cell trafficking [58].

During its maturation, the SCV becomes a replicative niche for Salmonella in many tissue culture models. However, this is not the case in fibroblasts or dendritic cells. This is consistent with the low replication rate observed in vivo in acute or chronic infections and suggests the existence of mechanisms that restrict replication, but not survival, of bacteria inside the SCV [40]. Interestingly, replication in epithelial cells can also occur in the cytosol, and although it occurs only in less than $20 \%$ of infected cells, it accounts for the majority of the net replication [61]. In addition, in epithelial cells, a subset of SCVs is not maintained at a juxtanuclear position but moves towards the cell host periphery [62]. This centrifugal movement depends upon host microtubules and kinesin and the T3SS2 PipB2 and is associated with a decrease in the T3SS1 effectors SipA and SopB [62]. Both escape from the vacuole and centrifugal displacement of the SCV have been associated with the ability of Salmonella to achieve cell-to-cell transfer in order to repeat the intracellular cycle $[62,63]$.

2.4. Cell Death. Salmonella induces cell death in host cells using T3SS-dependent and -independent mechanisms [64]. Three processes of T3SS-dependent cell death will be discussed here (Figure 5): epithelial cell apoptosis, rapid T3SS1dependent macrophage pyroptosis, and delayed T3SS2dependent macrophage pyroptosis [65].

Salmonella invades intestinal epithelial cells during the enteric phase of infection and triggers death of cultured epithelial cell lines in vitro by apoptosis. This process requires bacterial entry and replication, and the phenotypic expression of apoptosis is delayed for $12-18 \mathrm{~h}$ after bacterial entry [66]. Apoptosis is a form of programmed cell death that can be initiated by external or internal stimuli. It involves the activation of a distinct subset of initiator caspases that activate executioner caspases, like caspase-3, which cleave cellular substrates to produce the features associated with apoptosis: reduced mitochondrial membrane potential, cell 
surface exposure of phosphatidylserine, cytokeratin cleavage, nuclear condensation, DNA fragmentation, and maintenance of an intact plasma membrane. Phagocytic cells ingest the apoptotic bodies that result, without accompanying inflammatory response [65]. Both T3SS1 and T3SS2 are required for triggering apoptosis in epithelial cells. Although it has been difficult to assess the role of T3SS1 independent from its function in cell invasion, there are at least some effectors translocated through this system that contribute to modulate the apoptotic process. Also, the T3SS2 effector SpvB is clearly required for apoptosis [67]. SlrP, which can be translocated by T3SS1 and T3SS2, has been recently suggested to contribute to epithelial cell death, likely through its interaction with thioredoxin-1 and with ERdj3 [68, 69]. At least two effectors, AvrA and SopB, can have antiapoptotic roles: AvrA suppresses the JNK MAPK apoptotic pathway [70], whereas SopB activates Akt, a kinase that can exert prosurvival effects [71]. Together, these effectors could be responsible for the delay in apoptosis seen in epithelial cells. This delay could be beneficial for the pathogen in order to establish a stable intracellular niche and avoid adaptive immunity [70]. Apoptosis at the later stages of the intestinal phase of the disease generates apoptotic bodies that are phagocytosed, together with Salmonella, by the incoming macrophages. Some of these macrophages could serve as sites for Salmonella proliferation in the mucosa and submucosa, whereas others carry bacteria to other tissues, allowing the progress of the systemic disease [64].

In macrophages, Salmonella expressing T3SS1 rapidly trigger another form of programmed cell death, called pyroptosis, which is dependent on caspase-1 [72, 73], a central mediator of innate immunity that is not activated in apoptosis. Caspase- 1 activation results in production of active IL-1 $\beta$ and IL-18, rapid cell lysis, and release of proinflammatory intracellular contents [74]. This phenomenon has been observed in macrophages and dendritic cells infected with Salmonella grown under conditions that favor expression of T3SS1, and the cytotoxic effect is detected within 1-2 $\mathrm{h}[75,76]$. Initial studies suggested that the T3SS1 translocase SipB was involved in this process through a direct interaction with caspase-1 [77]. Later studies revealed that caspase- 1 activation requires the host inflammasome components ASC and NLRC4 (also known as Ipaf). The inflammasome is a multiprotein signaling platform that can be activated by flagellin and by the T3SS1 rod protein PrgJ [78-80]. Both proteins share a common sequence motif that triggers NLRC4 activation and are injected into the host cell cytosol through T3SS1. Murine NLR proteins NAIP5 and NAIP2 directly recognize flagellin and PrgJ, respectively. The NAIP proteins then physically interact with NLRC4, resulting in activation of the NLRC4 inflammasome and macrophage innate immunity [81]. It has been recently shown that Salmonella infection also triggers PKC $\delta$-dependent phosphorylation of NLRC4 at serine-533 and that this is another important step in formation of a fully functional inflammasome [82].

Caspase-1 activation appears to play a protective role in host defense against bacterial infections. Consistent with this, expression of T3SS1 and bacterial flagellin are repressed during systemic bacterial infection $[83,84]$. In fact, when macrophages are infected with Salmonella grown under conditions that repress expression of T3SS1, rapid killing does not take place. However, delayed macrophage death becomes apparent 18-24h postinfection. This form of cell death (i) requires T3SS2 and the effectors SpvB and SseL, (ii) is mediated by caspase-1, and (iii) results in production of IL-1 $\beta$, DNA cleavage, cell lysis, and inflammation [85-88]. Interestingly, during this form of delayed macrophage death, Salmonella activates two inflammasome receptors, NLRP3 and NLRC4 [89]. Activation of NLRC4 is dependent on T3SS2 and flagellin, but the T3SS2 rod protein SsaI does not contribute to caspase-1 activation. The signal that activates NLRP3 is unknown, but a relevant intermediary host factor is GBP5 (guanylate binding protein 5) [90]. This form of cell death has features of pyroptosis. However, other authors have observed a delayed form of macrophage death similar to the apoptotic process described perviously for epithelial cells [91].

2.5. Exploitation of the Ubiquitin System. Ubiquitination is a reversible posttranslational modification that consists of the covalent attachment of ubiquitin onto a target protein. The process consists of a three-step enzymatic cascade involving the activity of an ubiquitin-activating enzyme (E1), an ubiquitin-conjugating enzyme (E2), and an ubiquitin ligase (E3), which controls the specificity of the reaction by recruiting the target protein [92]. Ubiquitination is found in all eukaryotic cells and plays important roles in protein degradation, signal transduction, transport of membrane proteins, and host defense. E3 enzymes belong to different families that are mechanistically distinct: the homologous to E6-AP C-terminus (HECT) domain family, the really interesting new gene (RING) domain family, or the U-box domain family. HECT E3s form a thioester intermediate with the ubiquitin before transferring it to the substrate. RING and U-box E3s function as scaffolds to bring E2 and substrate into proximity $[93,94]$. Ubiquitination can be reverted by a family of isopeptidases called deubiquitinases that catalyzes the removal of ubiquitin from ubiquitinated proteins [95]. Salmonella interacts with the host ubiquitin pathway in several ways: some T3SS effectors are ubiquitination substrates, and several effectors act as E3 ubiquitin ligases, while others mimic deubiquitinases [96, 97] (Figure 6).

Ubiquitination has been shown for the T3SS1 effectors SopA, SopB, SopE, and SptP. Interestingly, SopE and SptP are both polyubiquitinated and marked for proteasomedependent degradation; however, SopE is more quickly degraded, ensuring the sequential activity of these effectors [98]: first, SopE, acting as a GEF for Cdc42 and Rac1, contributes to Salmonella-invasion mediating actin binding polymerization and ruffle formation; then SptP, acting as a GAP on the same small GTPases, switches off actin polymerization. Ubiquitination also regulates the intracellular localization of SopB: it is transported from its initial localization at the plasma membrane to the SCV after monoubiquitination at several lysine residues [99]. Finally, SopA is ubiquitinated by the host E3 ubiquitin ligase 


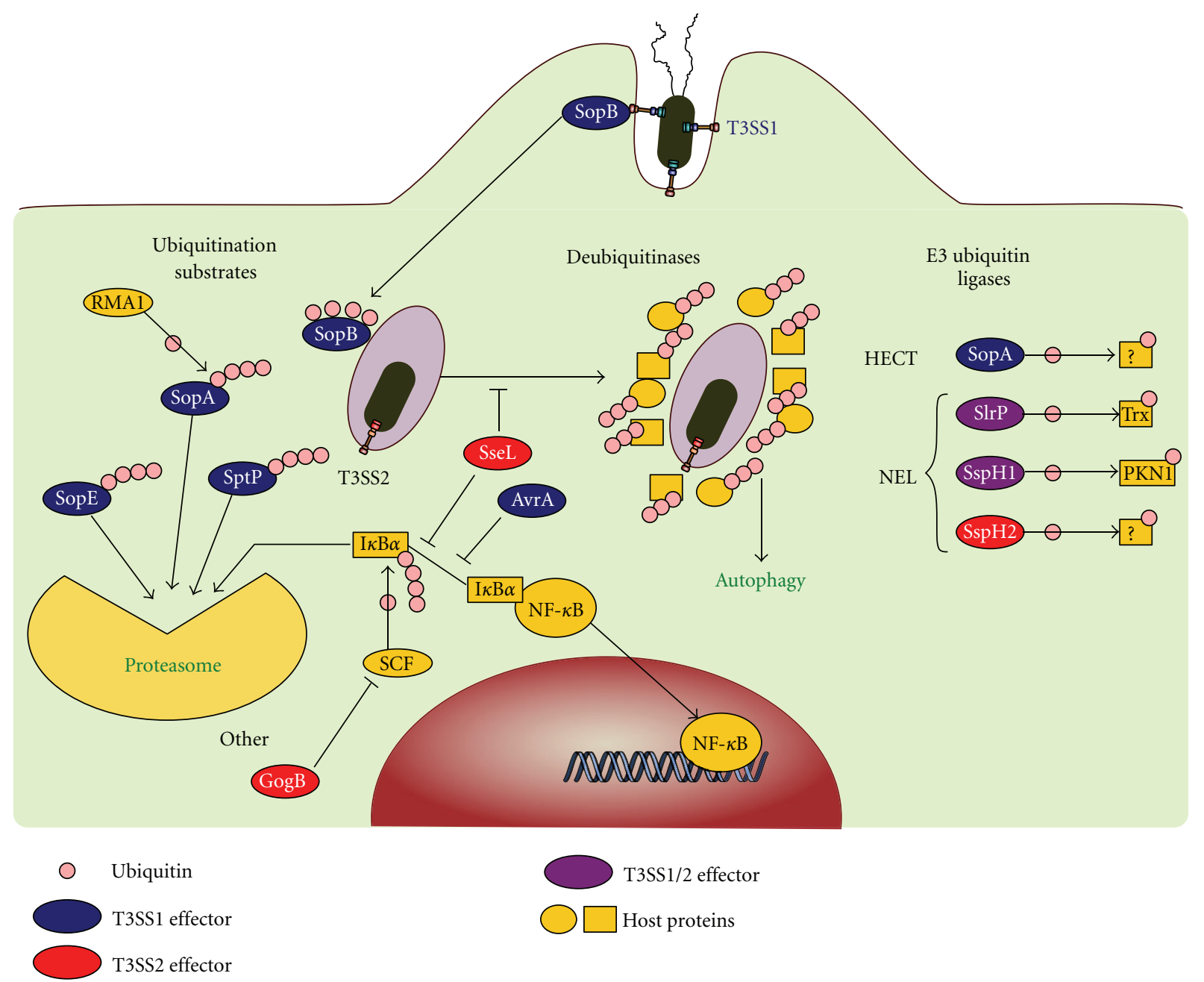

Figure 6: Exploitation of the ubiquitin system by Salmonella-secreted effectors. SopA, SopB, SopE, and SptP are substrates of the host ubiquitination system. AvrA and SseL possess deubiquitinase activity. SopA, SlrP, SspH1, and SspH2 are E3 ubiquitin ligases. GogB interferes with the E3 ubiquitin ligase activity of the host SCF complex.

HsRMA1. It has been proposed that monoubiquitinated SopA could contribute to Salmonella escape from the SCV into the cytosol of epithelial HeLa cells, whereas polyubiquitination of SopA leads to its degradation by the host proteasome pathway [100].

In addition to being a substrate for ubiquitination, SopA is itself an E3 ubiquitin ligase. Although it has little sequence identity to eukaryotic E3s, it is considered as a HECT-like E3 ligase because of its structure and proposed mechanism of action [101]. The substrates for the E3 activity of SopA are unknown, but this activity appears to be involved in Salmonella-induced PMN transepithelial migration [102]. Three additional Salmonella T3SS effectors, SlrP, SspH1, and $\mathrm{SspH} 2$, possess E3 ubiquitin ligase activity, but because they differ from all known E3 ligases in structure and mechanism, they can be considered as a new class of cysteinedependent E3 ubiquitin ligase, the novel E3 ligase (NEL) family. However, they share some generalized characteristics with the HECT family of ubiquitin ligases, including the presence of a conserved cysteine residue on a loop that is critical to the ubiquitination reaction, the formation of a stable covalent link with ubiquitin, and the requirement of conformational changes for biochemical activity [103]. Proposed substrates for the activities of SlrP and SspH1 are mammalian thioredoxin and the serine/threonine protein kinase PKN1, respectively $[69,104]$.

Salmonella has a T3SS1 effector, AvrA, and a T3SS2 effector, SseL, with deubiquitinase activity. Both effectors interfere with nuclear factor $\kappa \mathrm{B}(\mathrm{NF}-\kappa \mathrm{B})$ signaling through their suggested substrates: NF- $\kappa \mathrm{B}, \mathrm{I} \kappa \mathrm{B} \alpha$, and $\beta$-catenin, for AvrA, I $\kappa \mathrm{B} \alpha$ for SseL $[88,105-107]$. SseL has been shown to be involved in the regulation of autophagy. This is a process that involves degradation of intracellular components via the lysosome and that can be used by eukaryotic cells to control and degrade intracellular bacteria (xenophagy). Some examples of autophagy where Salmonella T3SS could have a role have been described. (i) SCV membranes damaged by bacteria entering the cytosol attract galectin-8 [108], and polyubiquitinated proteins accumulate on the bacterial surface [109]. Galectin-8 and ubiquitin are then detected 


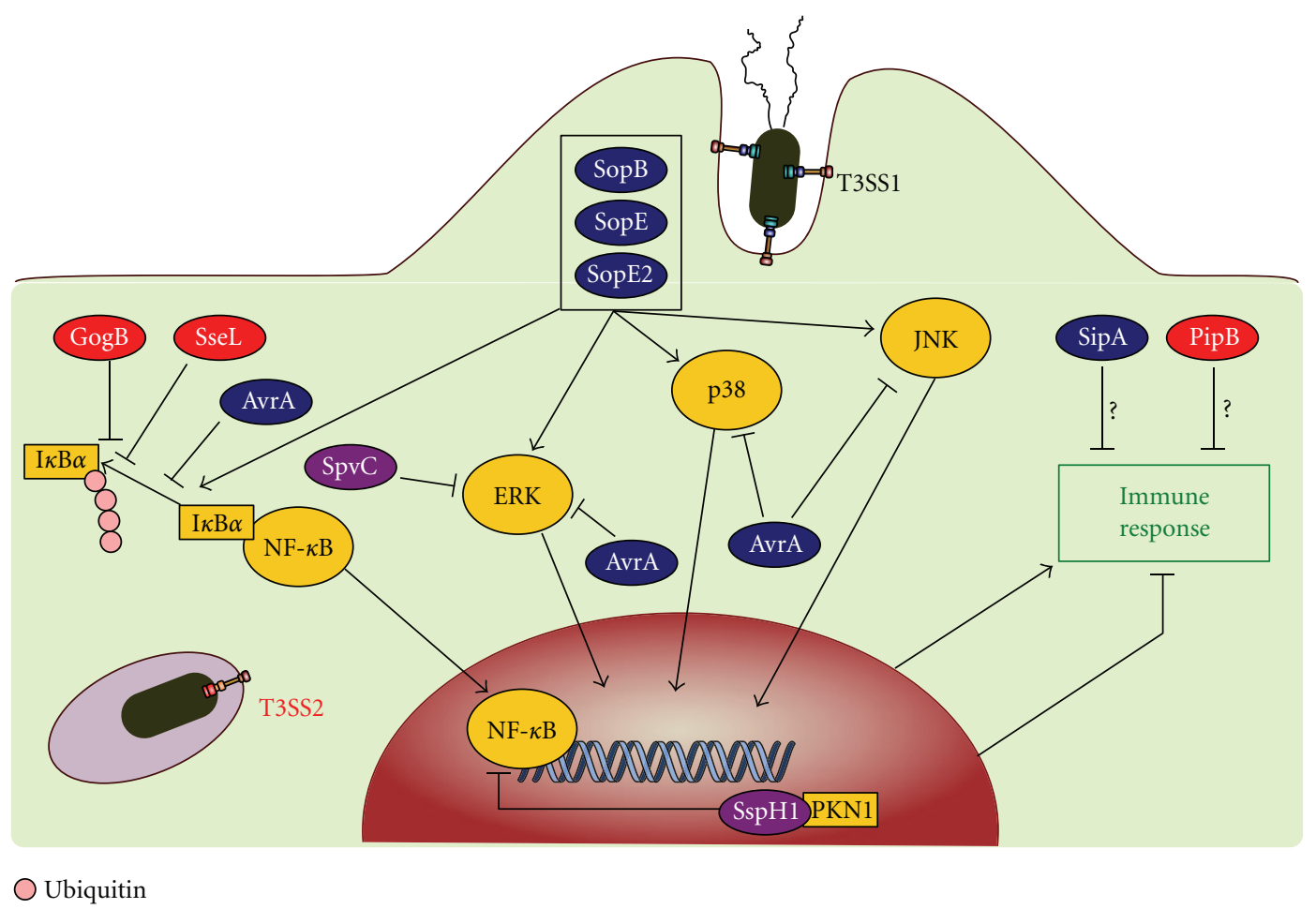

Figure 7: Nuclear responses induced by Salmonella effectors. Some of the effects of Salmonella T3SS effectors on host signal transduction pathways, leading to induction or inhibition of host immune responses, are depicted.

by autophagy receptors [110-112]. T3SS1 is involved in this process maybe by damaging the SCV membrane with its pore-forming activity. Also, the T3SS1 translocase SipB has been suggested to induce autophagy and cell death in macrophages $[113,114]$. (ii) Salmonella within vacuoles can induce a cellular response leading to the formation of T3SS2dependent ubiquitinated aggregates that attract autophagy markers. This process is opposed by the SseL deubiquitinase activity [115].

2.6. Nuclear Responses. T3SS effectors contribute to the transcriptional changes that are observed in Salmonellainfected cells (Figure 7). The effects of individual effectors on some signal transduction pathways are mentioned in other sections of this paper. This section will focus on transcriptomic studies.

Microarray analyses performed on host RNA responses have exploited a variety of in vivo and in vitro models and have allowed the study of the impact of pathogens on host cells on a global scale [116]. In one of the first studies of this type, differential host cell gene expression was examined in an in vitro model of $S$. enterica serovar Typhimurium infection using the RAW264.7 murine macrophage cell line [117]. This study detected significant changes in the expression of numerous genes encoding chemokines, cell surface receptors, signaling molecules, and transcriptional activators at $4 \mathrm{~h}$ postinfection. Genes encoding inducible nitric oxide synthase (iNOS), MIP- $1 \alpha$, MIP-1 $\beta$, MIP- $2 \alpha$, IL- $1 \beta, \operatorname{TNF} \alpha$ receptor, $\mathrm{CD} 40, \mathrm{I} \kappa \mathrm{B} \alpha, \operatorname{I} \kappa \mathrm{B} \beta, \operatorname{TGF} \beta 1, \operatorname{TGF} \beta 2$, caspase-1, Fas, TDAG51, TRAIL, LIF, Egr-1, NF-E2, IRF1 , and c-rel were among the upregulated genes, whereas expression of Ski, B-myb, Fli-1, c-Fes, cyclin D1, and cdk4 was downregulated. Another study that investigated the response of U-937 human monocytes to S. enterica serovar Typhimurium infection and the role of $\mathrm{PhoP}$ in this response detected upregulation of IL- 8, MIP- $1 \alpha$, MIP- $1 \beta$, IL$23 \mathrm{p} 19$, and $\mathrm{I} \kappa \mathrm{B} \alpha$ [118]. Genes upregulated in the human intestinal epithelial cell line HT-29 infected with $S$. enterica serovar Dublin for 3, 8, or $20 \mathrm{~h}$, included several cytokines (G-CSF, Inhibin $\beta$ A, EBI3, MIP- $\alpha$, IL-8), kinases (TKT, Eck, HEK), transcription factors (IRF-1), and HLA class I [119]. Other interesting examples of global in vitro and in vivo studies are the gene expression profiling in chicken heterophils infected with S. enterica serovar Enteritidis [120], the analysis of transcriptional responses to $S$. enterica serovar Choleraesuis infections in pig mesenteric lymph nodes [121], the analysis of the gene expression response of the rat small intestine following oral infection with S. enterica serovar Enteritidis [122], and the transcriptional profiles from $S$. enterica serovar Typhi-infected children [123]. However, the role of the T3SSs on host transcriptional responses was not investigated in these studies.

Recently, the impact of T3SS1 and particular effectors on the global transcriptional response of cultured human Henle-407 epithelial cells infected with S. enterica serovar Typhimurium was analyzed [124]. The genes up-regulated by wild-type Salmonella infection included genes whose products are proinflammatory such as several chemokines and cytokines and their receptors (MIP- $2 \alpha$, MIP- $2 \beta$, IL- 8, IL- $1 \alpha$, 
IL-11, IL-1R1, COX-2, TNFRSF10D, IL-4R, TNFRSF12A) and genes encoding transcription factors that amplify the immune response (Fos, FosB, FosL1, Jun, JunB, EGR1, EGR3, ATF3, STAT3). Salmonella infection also stimulated the expression of genes whose products limit the immune response (tristetraprolin, suppressors of cytokine signaling SOCS2 and SOCS3, I $\kappa$ B $\zeta$ and several members of the DUSP family of tyrosine phosphatases). The transcriptional profiles of epithelial cells infected with an invA mutant strain, that lacks a functional T3SS1, or with a "effectorless" mutant strain, lacking genes encoding T3SS1 effectors AvrA, SlrP, SopA, SopB, SopD, SopE, SopE2, SptP, and SspH1, were similar to that of uninfected cells, demonstrating that the transcriptional reprogramming triggered by the wild-type strain depended on one or more T3SS1 effectors. Additional experiments showed that SopB, SopE, and SopE2 were responsible for the stimulation of innate immune responses in epithelial cells in a manner that is independent of the canonical innate immune receptors and conserved bacterial products or pathogen-associated molecular patterns. These effectors redundantly mediate the stimulation of Rho-family GTPases leading to the activation of MAPK (ERK, p38, and JNK) and NF- $\kappa$ B signaling pathways [124]. In a recent in vivo study using a bovine-ligated ileal loop model, the transcriptional profiles of bovine host Peyer's patches inoculated with wild-type or a $\operatorname{sip} A \operatorname{sop} A \operatorname{sop} B \operatorname{sopD} \operatorname{sop} E$ sopE2 mutant of $S$. enterica serovar Typhimurium were compared at seven time points, from $15 \mathrm{~min}$ to $12 \mathrm{~h}$ [125]. The main difference was that the wild-type infection induced a biphasic host response with increased gene expression activity at $1 \mathrm{~h}$ and $12 \mathrm{~h}$ postinfection, whereas infection with the mutant strain induced a progressive increase in gene expression over time. In addition, both strains showed significantly different patterns of host response at early time points of infection within phosphatidylinositol, CCR3, Wnt, and TGF- $\beta$ signaling pathways and in the regulation of actin cytoskeleton.

Microarrays have also been used to analyze the role of AvrA in host transcriptional responses in vitro and in vivo [126-128]. Comparison of the effects of wild-type and avrA strains of S. enterica serovar Typhimurium on cultured intestinal epithelial cells suggested a specific role of this effector in inhibiting the Salmonella-induced activation of the JNK pathway, whereas no interference with NF- $\kappa$ B activation was observed [126]. In contrast, in vivo experiments carried out with RNA from mouse colon mucosa showed that NF$\kappa \mathrm{B}$ was one of the top-10 signaling pathways targeted by AvrA, although the effects were different at $8 \mathrm{~h}$ and 4 days postinfection [127]. Another in vitro study suggested a role of AvrA in Salmonella-induced p53 acetylation in epithelial cells [128].

The role of T3SS1 and T3SS2 in the transcriptional response of chicken macrophages to $S$. enterica serovar Enteritidis infection have also been investigated using cDNA microarrays [129]. This work suggested a role for the T3SS1 effector SipA and for the T3SS2 effector PipB in suppressing host innate response, since individual mutants lacking one of these effectors elicited higher transcription levels of certain chemokines and RhoA than the wild-type strain.
2.7. Inhibition of Antigen Presentation in Dendritic Cells. Dendritic cells are phagocytic cells with a pivotal role in the immune response [130]. In addition to playing a critical role in innate immunity, they are probably the most efficient and critical of all antigen-presenting cells [131]. They can sample a diverse array of antigens in peripheral tissues, transport the antigens to local lymph nodes, and present them to $\mathrm{T}$ cells as peptides bound to both MHC class I and II products. S. enterica serovar Typhimurium is efficiently taken up by dendritic cells, and these cells can serve as an alternative invasion pathway to M cells [132]. Initial studies carried out with an immortalized cell line suggested that Salmonella in these cells resides in a compartment that is different from that described for Salmonella inside macrophages because it lacks the late endosomal/lysosomal membrane marker LAMP1 [133]. However, in murine bone marrow-derived dendritic cells, S. enterica serovar Typhimurium resides in a membrane-bound compartment that has acquired late endosomal markers [134]. In these cells, Salmonella represents a static, nondividing population that is able to mount a functional T3SS2. The activity of this system is not required for intracellular survival [135] but is necessary for the correct maturation of the SCV in dendritic cells [134]. Salmonella inhibits the capacity of dendritic cells to process and present antigens by the MHC class II pathway and their ability to stimulate $\mathrm{T}$ cell proliferation in a T3SS2-dependent manner [136, 137]. T3SS2 effectors PipB2, SifA, SlrP, SopD2, and $\mathrm{SspH} 2$ are equally important for the interference with antigen presentation, whereas SseF and SseG contribute to a lesser extent. In contrast, effectors GogB, PipB, SifB, SseI, SseJ, SseK1, SseK2, and SspH1 have no contribution to this phenotype [138]. Salmonella interferes with MHC class II antigen presentation by specifically reducing cell surface HLA-DR expression in a process that requires SifA [139] and is mediated by T3SS2-dependent polyubiquitination, leading to removal of mature, peptide loaded, $\alpha \beta$ dimers from the cell surface [140]. The specific effector involved in this posttranslational modification is unknown, since, surprisingly, effectors that are known to interfere in the ubiquitination pathway (SlrP, SopA, SseL, SspH1, or $\mathrm{SspH} 2$ ) were not required for class II downregulation [140].

\section{Future Directions}

The study of Salmonella T3SS effectors has provided significant progress in our understanding of host-pathogen interactions in the last two decades. More than 40 effectors have been identified, and the characterization of the biochemical activities and host targets of some of them have been successfully addressed in the last years. The mechanisms for the establishment of an intracellular niche have been described in detail for some serovars, especially in certain cultured cell models, and Salmonella effectors have become an invaluable tool for the study of the cell biology of the host. However, many aspects of the contribution of these proteins to the relationship between Salmonella and its hosts at the cellular level and at the organism level remain unknown. 
Some of the topics in this field that are likely to be the subject of intense research in the next years are discussed in this section.

3.1. The Effector Repertoire. In spite of the recent availability of fully sequenced genomes, identifying T3SS effectors has not always been an easy task, since they do not share universally conserved features. A variety of different approaches have been used to identify some genes as good candidates to encode effectors. T3SS-dependent translocation has been then tested using different methodologies. Genes in SPI1 or SPI2, where the structural components of T3SSs are encoded, were obvious candidates, but most effectors are encoded outside these islands. Coregulation with SPI1 or SPI2 genes has been a guide in some cases [141]. Sequence similarity was useful for only a few effectors, like the effectors belonging to the Salmonella translocated effector (STE) family, which share an N-terminal secretion signal [142]. Because of the lack of conserved sequences, computational prediction of T3SS effectors has been a difficult challenge. Functional redundancy is another hurdle, since mutants lacking only one effector are usually as virulent as the wild type. An interesting functional approach to find new effectors was based on the generation of fusions with the catalytic domain of CyaA from Bordetella pertussis [143]. This is a calmodulindependent adenylate cyclase, and, since calmodulin is present in the eukaryotic cytosol but not in bacteria, translocation of a CyaA fusion into the host is detected as an increase in cAMP concentrations in Salmonella-infected cell cultures [144]. Although useful, this approach is time consuming and has limitations. More recently, the proteomic analysis of culture supernatants has been an efficient way to identify T3SS effectors [145]. Although the combinations of these and other approaches have probably been successful in finding the majority of Salmonella effectors, it is likely that other effectors exist, and finding them is an important task in this field. To do that, besides finding new screen methods, it could be useful trying the same screens under different conditions affecting: culture conditions, host cell types, or postinfection times. Also testing different serovars and a variety of strains is important since certain effectors are strain-specific.

An important, related topic is the study of the specificity of an effector for a particular T3SS and of the degree of cross-talk between systems. This is especially relevant in S. enterica since these bacteria possess three T3SS: the virulence-related T3SS1 and T3SS2 and the flagellar system. In fact, as mentioned above, flagellin can be secreted through T3SS1 or T3SS2 in the context of macrophage infections and induction of pyroptosis. Conversely, escape of effectors through the flagellar system has also been observed under certain circumstances [146]. Examples of effectors that have been shown to be secreted by T3SS1 and T3SS2 have been given above. They were initially seen as exceptions but the number is increasing. This is not surprising, since effectors from different bacterial species are efficiently secreted ectopically. In principle, translocation in vivo could be more restricted depending on the expression patterns of effectors and their cognate T3SSs. There are, however, evidences of overlapping in the expression of Salmonella T3SSs [147] and, therefore, this question should be studied in detail, since translocation through different systems open the possibility of different functions for the same effector. Specificity could also be connected with the presence of chaperones [148] that, in many cases, have not been identified yet. Related to this question is the kinetics of translocation and persistence in the host of each effector. There seems to be a hierarchy of translocation [149]. How is this imposed? How relevant is this for the infection process?

3.2. Biochemical Activities and Host Targets. Defining the biochemical activities and cellular targets [150] of T3SS effectors are the initial steps to understand their function. As seen in Table 1, this information is missing for a significant number of known Salmonella effectors. Similarity to proteins with known activities has been useful in some cases, but in many other cases, effectors mimic the activity of eukaryotic proteins without sharing significant sequence similarity [151]. Studying the effects of the expression of individual effectors in host cells, although nonphysiological, is a powerful tool that can help in the discovery of their activities. This can be carried out not only in mammalian cells but also in more simple models, like the yeast, that are more amenable to genetic analysis [152, 153]. Defining host substrates for the catalytic activities of effectors is another relevant subject of research. For instance, there are three known E3 ubiquitin ligases of the NEL family: SlrP, SspH1, and SspH2. SlrP and SspH1 have been shown to ubiquitinate Trx and PKN1, respectively, in vitro, but this has not been confirmed in vivo, and there are no putative substrates for $\mathrm{SspH}$. Finding the host binding partners for every effector (wild-type or catalytically dead to stabilize transient interactions) will provide putative substrates. The classical yeast two-hybrid screen [69] or the quantitative proteomics technique based on stable isotope labeling of amino acids in cell culture (SILAC) are examples of efficient methods that are being used to identify interaction partners [154]. Computational methods are also useful to predict host-pathogen protein-protein interactions [155]. Structural studies of effectors, especially in complex with their cognate host partners, are also instrumental in understanding their function and their mechanisms of action [156].

3.3. Global Responses. Details have been given in a previous section about the analysis of global transcriptional responses of the host to Salmonella infections and the role of T3SS in these responses. The analysis is far from complete because the role of individual effectors has been studied only in a few cases. DNA microarrays or deep sequencing [157] are being used to compare the effect of wild-type and specific mutant strains of Salmonella. These methods could also be used to analyze the transcriptional profiles of cultured cells expressing or not a particular effector. In addition, proteomics will provide the pattern of global responses at the protein level, which should be useful, for instance, to define the substrates for the effectors that interfere with the host ubiquitination pathway. 
3.4. Different Lifestyles. The SCV has been historically seen as the primary survival and replication niche for intracellular Salmonella. However, the behavior of a strain of S. enterica is different depending on the host cell type, and, although the SCV is a replicative niche in cultured epithelial cells and macrophages, this is not the case in fibroblasts or dendritic cells [40]. In addition, Salmonella can have a bimodal lifestyle in epithelial cells and replicate in the SCV and in the cytosol, as has been beautifully analyzed recently in human HeLa cells [61]. This issue is still more complex if we take into account the heterogeneity that is observed in tissue culture infection models, where neither all cultured host cells are infected nor all pathogen cells inflict alterations in host physiology [158]. Defining the specific cell types, where Salmonella survive and replicate in vivo, and understanding the role of T3SS effectors in establishing different intracellular lifestyles and different host responses will be an interesting subject of research in the next years. This effort should be assisted by new technologies that allow real-time and single-cell analysis.

A related topic is the study of the relationships between different serovars of $S$. enterica and their hosts and the different outcomes that can result in terms of pathological manifestations. T3SS effectors play a central role in this context; therefore, defining the effector repertoire for every serovar and every strain and comparing the effects of different serovars on the same host cells are other relevant subjects of research. In contrast with the impressive amount of data accumulated about the role of T3SSs in the pathogenesis of S. enterica serovar Typhimurium, limited data is available concerning the role of these systems in S. enterica serovars Typhi or Paratyphi, which are responsible for systemic diseases in humans. The in vivo study of these serovars has been hampered by their strict adaptation to a particular host, but the development of new models is in progress [159].

3.5. Extracellular Roles and Applications of Effectors. T3SS1 effectors are easily detected in the culture media of Salmonella growing under standard laboratory conditions. The physiological relevance of this host-independent secretion remains to be explored. Interestingly, it has been recently shown that $S$. enterica serovar Typhimurium overexpressing SPI1 displays an adherent biofilm that is able to massively recruit heterologous nonbiofilm forming bacteria [160]. Although this phenotype is not observed when SPI1 is expressed from its original genomic location, the authors suggest a number of potential uses for engineered biofilm formation including bioremediation, biofuel cell design, and engineered infections for beneficial purposes. Because of its ability to export protein to the extracellular environment, T3SS1 is, in fact, a potential useful tool when proteins need to be exported for their function or to ease purification. T3SSs from several bacteria have already been used to export recombinant proteins including enzymes, peptides to induce an immune response, and spider silk proteins, but the range of foreign proteins that can be secreted and their limits are currently under study [161]. Effectors are also promising candidates to be carriers for delivery of heterologous vaccine antigens, especially T3SS2 effectors that are synthesized only when Salmonella is inside host cells [162].

3.6. Salmonella in Plants. Many reports have linked food poisoning with the consumption of raw vegetables and fruits contaminated with Salmonella and other enteric bacteria [163]. Therefore, there is a great interest in understanding the interaction between Salmonella and plants. The role of plants in the life cycle of Salmonella and the ability of these bacteria to use plants as alternative hosts to human and other animals have been recently reviewed $[164,165]$. Salmonella usually enters agricultural environments via animal feces. Animals can directly excrete waste onto plants or can contaminate surface water used for irrigation and pesticide or fertilizer diluent. Once it has found its way to plants, Salmonella actively attaches to plant tissues, colonizes plant organs, and uses them as viable hosts. In addition, plants inoculated with Salmonella have been reported to show reduced vigor [166], or chlorosis and wilting of leaves [167]. However, Salmonella is not considered a phytopathogen because Koch's postulates were not completed on any plant.

It is well established that T3SS effectors secreted by plant pathogens like Pseudomonas syringae are recognized by host plant cells and induce an immune response that usually result in a hypersensitive cell death response at the infection site [168]. Interestingly, components of Salmonella T3SS1 also appear to be recognized by plants, since mutants lacking this system (spaS or sipB mutants) exhibit increased colonization of alfalfa roots and wheat seedlings [169]. These results contrast with the reduced proliferation observed for mutants $\operatorname{prgH}$ and ssaV, lacking T3SS1 and T3SS2, respectively, in Arabidopsis thaliana [170]. These mutants also induced more apparent symptoms in Arabidopsis plants, suggesting that, in this case, T3SSs are necessary to prevent the hypersensitive response. In fact, transcriptomic analysis indicated that 649 host genes are induced specifically by the T3SS1 mutant, and many of these genes encode proteins related to responses against pathogens [170]. Consistent with this idea, wild-type bacteria, but not a T3SS1 mutant, were able to suppress the oxidative burst and the increase in extracellular $\mathrm{pH}$ after inoculation of a tobacco cell culture [171]. Clearly, the role of Salmonella T3SSs and the outcome of the interactions are different depending on plant species and cultivars and on Salmonella serovars [166, 172]. It has been recently shown that Salmonella effector SseF, but not AvrA, PipB2, SseG, SseJ, SseL, SopB, or SopD2, triggers a hypersensitive-like response in Nicotiana benthamiana when expressed in leaves by Agrobacterium tumefaciensmediated infiltration or when translocated into leaves by the T3SS of Xanthomonas campestris [173]. However, Salmonella was unable to elicit this response in $N$. benthamiana, and more studies are needed to understand the extent of the contribution of individual effectors during endophytic growth.

Many questions remain unresolved about the role of T3SSs in Salmonella-plant interactions: what are the signals that induce expression of T3SS1 and T3SS2 in plants? How does Salmonella achieve the delivery of effectors across plant 
cell walls and plasma membranes? What is the role of individual effectors?

3.7. Final Remarks. The topics discussed in this section are just a few examples of the issues that are likely to be the subject of investigation in the near future in this fertile research field. No doubt, Salmonella, and particularly its T3SS effectors, will continue to be an outstanding tool in basic cell biology studies. Examples of advances in the understanding of host cells processes, like innate immunity, programmed cell death, cytoskeleton organization, or membrane trafficking, have been presented in this paper. Many more are expected to arise, as the details of the effector functions are unveiled.

\section{An Alphabetical Guide to Salmonella T3SS Effectors}

4.1. AvrA. AvrA is a T3SS1 effector that shares sequence similarity with YopJ of the animal pathogen Yersinia pseudotuberculosis and AvrRxv of the plant pathogen Xanthomonas campestris pv. vesicatoria [174]. Several signaling pathways have been proposed as targets of AvrA. Initial studies used transient expression of avrA in human epithelial HeLa cells and infections with $S$. enterica serovar Typhimurium pho-24 (or its $A v r A^{-}$variant). The pho-24 mutation induces constitutive activation of the PhoQ/PhoP two-component system, and this activation increases expression of avrA. These studies suggested that AvrA inhibits the NF- $\kappa \mathrm{B}$ pathway [175]. Inhibition of c-Jun N-terminal kinase (JNK) and NF- $\kappa \mathrm{B}$ signaling pathways were observed in transgenic Drosophila and murine models leading to suppression of innate immunity, inflammation, and apoptosis during natural infection [176]. Recently, DNA microarray analysis of mouse colon mucosa infected with wild-type or AvrA- Salmonella suggested that several pathways, including mTOR, NF- $\kappa$ B, platelet-derived growth factors, vascular endothelial growth factor, oxidative phosphorylation, and MAPK signaling, are specifically regulated by AvrA in vivo [127]. Using the streptomycin pretreatment mouse model of enteric salmonellosis, it was shown that AvrA modulates survival of infected macrophages likely via JNK suppression and prevents macrophage death and rapid bacterial dissemination. AvrA suppression of cell death in infected macrophages may allow for establishment of a stable intracellular niche typical of intracellular pathogens [70]. In addition, bacteria expressing avrA decrease the intestinal permeability in comparison with AvrA-deficient bacteria through an increase in the tight junction proteins ZO-1 (Zonula occludens-1), occludin, and claudin-1. It is suggested that this effect of AvrA is mediated by a decrease in the expression of inflammatory cytokine interleukin-6 (IL-6) [39].

Two biochemical activities have been proposed for AvrA that can explain some of its effects in the host: deubiquitinase activity and acetyltransferase activity. Suggested targets for the deubiquitinase activity of AvrA are two inhibitors of NF- $\kappa \mathrm{B}, \mathrm{I} \kappa \mathrm{B} \alpha$, and $\beta$-catenin $[106,107]$. In addition, several members of the Wnt family have been shown to be upregulated by AvrA [177], and since Wnt2 is regulated by ubiquitination, AvrA may stabilize Wnt2 by removing the ubiquitin from Wnt2 [178]. This, in turn, stabilizes $\beta$ catenin, a downstream target of Wnt. Proposed targets for the acetyltransferase activity of AvrA are MAPK kinase 4 (MKK4) in a Drosophila model, leading to inhibition of JNK [176] and p53. p53 acetylation is increased by AvrA in vitro and in an in vivo mouse model. Activation of the p53 pathway through acetylation would lead to cell cycle arrest and would block apoptosis and inflammation [128]. Both YopJ and AvrA require the eukaryotic host cell factor inositol hexakisphosphate for activation of their acetyltransferase activity [179].

In a recent study, pho-24 strains with wild-type or mutated avrA were used in a model of chronic Salmonella infection in mice. In this model, Salmonella persistently promotes small intestinal and colonic epithelial proliferation in vivo over 10-27 weeks [180]. This study also showed that, under these conditions, Salmonella strains expressing AvrA enhance expression of Akt, potentiate phosphorylation and acetylation of $\beta$-catenin, induce $\beta$-catenin nuclear translocation, and increase transcription of target genes, which could be the explanation for increased proliferation. In addition, AvrA inhibits the Salmonella-induced activation of the JNK pathway through its physical interaction with MKK7: the catalytic mutant of AvrA (C172S) interacted with MKK7 (but not with MKK3, MKK4, or MKK6) in the yeast two-hybrid system. Interestingly, AvrA is phosphorylated at conserved residues by a T3SS-effector-activated ERK pathway. This phosphorylation could have a negative effect on AvrA activity [126].

4.2. $\operatorname{Gog} B$. GogB is encoded within the bacteriophage Gifsy1 , which is present in most $S$. enterica serovar Typhimurium strains [181]. GogB is a secreted substrate of T3SS1 and T3SS2, but it is translocated specifically through T3SS2 to the host cytoplasm during infection [182]. Very recently, Fbox only protein 22 (FBXO22) was identified as the host cell target of GogB. This interaction targets GogB to the Skp, Cullin, F-box containing (SCF) ubiquitin ligase complex to dampen the host inflammatory response by inhibiting $\mathrm{I} \kappa \mathrm{B} \alpha$ degradation and NF $\kappa B$ activation. Therefore, GogB can be seen as an anti-inflammatory effector that manipulates the host ubiquitination system to prevent host inflammatory responses following colonization in order to limit tissue damage and bacterial burden during chronic infection [183].

4.3. $P i p B$. The gene encoding this effector, $p i p B$ (for pathogenicity island-encoded protein B), is located in SPI5 and contributes to enteropathogenesis in a calf model of infection [184]. This gene is highly induced inside macrophages and epithelial cells [185]. PipB is expressed under SPI2-inducing conditions and is translocated through T3SS2 to the SCV and SIFs [186]. These are stable filamentous lysosomal glycoprotein-containing structures connected to the SCV that are formed in epithelial cells four to six hours after invasion with Salmonella [187]. PipB associates with host membranes and is enriched in detergent-resistant 
microdomains, also known as lipid rafts [188]. Interestingly, PipB is implicated in intestinal tract colonization of chicks by S. enterica serovar Typhimurium [189] and contributes to invasion and survival of $S$. enterica serovar Enteritidis in chicken oviduct epithelial cells [190]. In addition, PipB plays a role in repressing avian $\beta$-defensins genes [191] and in stimulating inducible nitric oxide synthase in these cells [192].

4.4. PipB2. PipB2 was described as a Salmonella T3SS2 effector [193] with sequence similarity to PipB [186]. PipB2 is synthesized under SPI2-inducing growth conditions and upon infection of macrophages [194], where it localizes to the SCV and to SIFs $12 \mathrm{~h}$ postinfection. PipB2 reorganizes late endosome/lysosome compartments in mammalian cells resulting in the centrifugal extension of SIFs away from the SCV along microtubules. This activity is a consequence of its kinesin-1 binding activity [195]. Since SifA, another T3SS2 effector, downregulates kinesin-1 recruitment, PipB2 and SifA demonstrate antagonistic activities [195]. PipB2 promotes outward movement of the SCV when myosin II activity is inhibited [54]. The characteristic positioning of SCV to juxtanuclear regions suggests that the kinesininhibitory action of SifA may be dominant over the effects of PipB2 at 8 to $14 \mathrm{~h}$ postinfection. However, at later stages of epithelial cell infection, there is an outward displacement of a significant proportion of SCV s that is dependent upon host microtubules, kinesin and PipB2, and that is involved in cellto-cell spread of Salmonella during infection [62]. Recently, it has been shown that the level of PipB2 is similar under SPI1- and SPI2-inducing conditions and that, in addition to T3SS2, this effector can use T3SS1 to be translocated into several mammalian cell types [196].

4.5. SifA. Salmonella-induced filament gene A (SifA) was described as a gene necessary for the formation of SIFs [197]. SifA was initially associated with T3SS on the basis of similarity to the N-termini of effectors SspH1, SspH2, and SlrP and of its specific synthesis under SPI2-inducing conditions in an SsrB-dependent manner. Although several lines of evidence indicated that it was a T3SS2 effector, its translocation could not be demonstrated using the CyaA fusion protocol $[142,198,199]$. However, secretion through T3SS2 of a SifA-M45 fusion was demonstrated in vitro [200].

In addition to its role in SIF formation, SifA is required for the development of SISTs. Both SIFs and SISTs are SCAMP3-positive tubules, but while SISTs are devoid of late endocytic markers, SIFs are positive for both late endocytic markers and SCAMP3. Salmonella recruits membrane from a trans-Golgi network-derived SCAMP3-containing pathway to induce the formation of both types of tubules [58].SifA is also necessary for the maintenance of the SCV [198]. Because of their inability to maintain the SCV, sifA mutants have a defect in replication in macrophages and fibroblasts [198, 199, 201], but they replicate more efficiently in epithelial cells, and this enhanced replication occurs in the host cytosol [202]. Formation of SCVs and SIFs requires the host factor
Rab7 [203], but, unlike SCVs, SIFs are devoid of Rab7interacting lysosomal protein (RILP) and dynein, and in vitro experiments suggested that SifA contributes to uncoupling Rab7 from RILP by interacting with Rab7 [204]. Transfection experiments suggested that SifA directs membrane fusion events involving late endosomes [205]. Data obtained in eukaryotic cell cultures infected with Salmonella established that SifA is required for the recruitment of lysosomal glycoproteins LAMP1 and LAMP2 to the SCV [206, 207]. An additional role for SifA in interfering with MHC class II antigen presentation has also been suggested [139].

Targeting of SifA to membranes requires a C-terminal, CAAX motif (where AA represents two aliphatic residues) that is commonly found in small GTPases [208]. The cysteine residue within this motif is modified by host prenylation machinery [209]. SifA interacts with the host protein SKIP (SifA and kinesin-interacting protein) forming a functional complex that mediates the role of SifA in virulence [210, 211]. SKIP interacts both with kinesin-1 and SifA via its $\mathrm{N}$-terminal RUN and C-terminal PH domains, respectively. Mammalian proteins SKIP and RhoA form a protein complex with Salmonella effectors SifA and SseJ that promotes host membrane tubulation [212]. In addition, the SifA-SKIP complex plays an essential role in the formation and/or the anterograde movement of PipB2/kinesin-1-positive vesicles that are likely to derive from SCV [213].

The biochemical activity of SifA is not completely understood. SifA was identified as a member of the WxxxE family of bacterial T3SS effectors that stimulate small G protein signaling events. Members of this family were initially suggested to act in some cases by mimicking activated small GTPases [214], but more recent data suggest that they function as GEFs [215]. In fact, the structure of SifA in complex with the PH domain of SKIP revealed that SifA has two distinct domains: the N-terminus binds to SKIP, and the C-terminus has a fold similar to SopE, a Salmonella effector with GEF activity toward Rho GTPases [212]. In addition, SifA can bind to RhoA in human HeLa cells [212], and an interaction of SifA with a Rho GTPase has also been found using the model organism Saccharomyces cerevisiae [216]. However, the ability of SifA to catalyze nucleotide exchange on RhoA has not been demonstrated [217]. Interestingly, SKIP also interacts, through its $\mathrm{PH}$ domain, with the late endosome GTPase Rab9. This interaction is important to maintain peripheral LAMP1 distribution in cells and is inhibited by SifA, suggesting that bacterial G protein mimicry may result in G protein antagonism [218].

4.6. SifB. This effector was identified through the similarity of its $\mathrm{N}$-terminal amino acid sequence with the translocation signal present in other effectors [142]. Similarly to SifA, SifB is a member of the WxxxE family [214], which after translocation through T3SS2 is targeted to the SCV and SIFs in association with LAMP1 [219].

4.7. SipA. Salmonella invasion protein A (SipA) is a protein encoded on SPI1 [220] that is delivered into the host cell through T3SS1 [21]. This effector has a role in invasion of 
epithelial cells by modulating actin assembly through its Cterminal actin-binding domain, stabilizing F-actin filaments, and increasing the bundling activity of the host protein $\mathrm{T}$ plastin [21, 221-223]. SipA contributes, together with other T3SS1 effectors, to the disruption of tight junctions, protein complexes intimately linked to the actin cytoskeleton that are located at the interface between epithelial cells [38]. The Nterminal 425 amino acids of SipA trigger PMN transepithelial migration in vitro [224-226]. This effect is mediated by the activation of ezrin, via a PKC- $\alpha$-dependent pathway, that leads to the apical surface expression of multidrug resistanceassociated protein 2 (MRP2), which in turn facilitates the

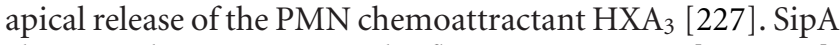
also contributes to intestinal inflammation in vivo [228, 229]. The proinflammatory effects of SipA require the activity of host pattern recognition receptors NOD1 and NOD2 that leads to $\mathrm{NF}-\kappa \mathrm{B}$ activation in a process that does not require its actin-binding domain [230]. A role for SipA in promoting the phosphorylation of Jun and p38 MAPKs coupled to activation of IL-8 expression has also been suggested [231].

Interestingly, in addition to its role during invasion, SipA continues to act long after invasion [232, 233]. From the cytosolic face of the SCV, SipA, through its N-terminal domain, promotes intracellular replication and redistribution of late endosomes and cooperates with SifA in the modulation of SCV morphology and perinuclear positioning. These results emphasize the complex relationships that exist between effectors of different T3SS and provide evidence of secretion through T3SS1 from inside the SCV [232].

4.8. SipB, SipC, and SipD Translocases. SipB, SipC, and SipD $[220,234,235]$ are a group of proteins known as translocases that are themselves secreted through T3SS1 and mediate the passage of effectors through the target host cell membrane [236]. SipD is present in the bacterial cell surface, probably localized at the tip of the needle complex, prior to the contact with the host cell. SipB and SipC become surface exposed upon contact of S. enterica serovar Typhimurium with epithelial cells [237]. Presumably, these translocases form a pore structure called the translocon through which the effectors are translocated and that mediates intimate association of Salmonella with mammalian cells [237].

Because SipD is present in the bacterial surface before invasion, it can act as a sensor for environmental molecules. In fact, SipD interacts with bile salts [238-240], which are present in the intestines and decrease Salmonella invasiveness [241].

SipB is involved in the induction of a form of macrophage cell death that is caspase-1 dependent [77] and is known as pyroptosis [72]. This translocase was shown to directly interact and activate caspase-1 [77], which in turn mediates activation of IL1- $\beta$ in murine macrophages [77] and IL-18 in human dendritic cells and human alveolar macrophages [242, 243].

In addition to its general role in the translocation of T3SS1 effectors, SipC possesses an actin nucleation activity and cooperates with SipA in the production of F-actin foci at sites of bacteria-host cells contact $[20,83,244]$. Topological analysis suggests that SipC is inserted in the host cell membranes with its N-terminal domain (amino acids 1-120) and its C-terminal domain (amino acids 200-409) in the host cytosol [244]. Residues 201-220 of SipC are necessary for its actin nucleation activity, whereas the C-terminal 88 amino acids are important for its translocase function [23]. Initial studies ascribed the F-actin bundling activity of SipC to its $\mathrm{N}$-terminal domain [244], but a more recent report suggests that this activity is directed by residues $221-260$ and 381409 in the C-terminal region [24]. The C-terminal region is also involved in the interaction with cytokeratin $8[245,246]$. Besides its role in invasion of epithelial cells, a recent work suggests that in macrophages SipC is localized in the surface of the phagosome, and through its C-terminal domain, it interacts with the SNARE motif of syntaxin 6 and thereby recruits LAMP1 from Golgi-derived vesicles [247]. Other translocases or T3SS1 effectors have no role in this process. These findings correlate with a previous report suggesting that SipC is involved in docking and fusion of exocytic vesicles by directly interacting with Exo70, a component of the exocyst complex [35].

4.9. SlrP. Salmonella leucine-rich repeat protein (SlrP) was identified by signature-tagged mutagenesis as $S$. enterica serovar Typhimurium host range factor [248]: an slrP-null mutant is as virulent as the wild-type in calves, but it is 6-fold attenuated for mouse virulence after oral infection. The predicted protein has a complete sequence of 765 amino acid residues that can be divided in three domains [249]. The N-terminal domain is necessary for secretion through both T3SS1 and T3SS2 and is similar to the N-termini of other effectors [142]. The central domain contains several copies of a leucine-rich repeat signature, a protein motif frequently involved in protein-protein interactions [250]. Finally, the C-terminal domain is conserved in the effectors SspH1, and SspH2, from S. enterica, and the IpaH family of Shigella flexneri effectors. IpaH9.8, SspH1, and SspH2 possess E3 ubiquitin ligase activities and define a new class of ubiquitin ligases [103, 251-253]. SlrP is also an E3 ubiquitin ligase that interacts with mammalian thioredoxin-1 (Trx) and, at least in vitro, can use this host protein as a substrate [69]. Transient transfections of epithelial cells showed that although the localization of SlrP is mainly cytosolic, a part of this protein is translocated into the endoplasmic reticulum where it can interact with the chaperone ERdj3 [68]. HeLa cells stably transfected with $\operatorname{sr} P$ are more prone to cell death, and the current working model suggests that SlrP promotes apoptosis in host cells by interfering with the functions of its targets Trx and ERdj3 [68, 69].

4.10. SopA. Salmonella outer protein A (SopA) is a T3SS1 effector that contributes to enteric disease [254]. HA-tagged SopA is targeted to the mitochondria of host cells [255]. A role of SopA in invasion of polarized T84 cells [256] and in escape to the cytosol [100] has been described. SopA is a HECT-like E3 ubiquitin ligase whose activity is involved in Salmonella-induced PMN transepithelial migration but not in invasion in cultured HeLa cells or in escape of 
the SCV [102]. It preferentially uses E2s UbcH5a, UbcH5c, and $\mathrm{UbcH} 7$ for its ubiquitination reaction. Although the E2interacting surface of SopA has little similarity to those of eukaryotic E3s, structural analysis reveals that SopA binds to human $\mathrm{UbcH} 7$ on the same region as eukaryotic HECT E3s [101, 257]. Thus, Salmonella SopA illustrates a functional mimicry of the mammalian HECT E3 ubiquitin ligase by a Gram-negative bacterial pathogen. Interestingly, it was previously shown that SopA interacts with the host E3 ubiquitin ligase HsRMAl and is ubiquitinated and degraded by the HsRMA1-mediated ubiquitination pathway [100].

4.11. SopB. SopB (also known as $\operatorname{SigD}$ [258]) is a T3SS1 secreted Salmonella effector protein [259] that is encoded within SPI5 [184]. SopB is a phosphoinositide phosphatase [260] bearing, in its C-terminal region, motifs of mammalian inositol 4-phosphatases and a putative synaptojanin (inositol 5-phosphatase-) like domain [260, 261]. This activity mediates most of the multiple roles that this effector plays at different levels. (i) Invasion: SopB mediates actin cytoskeleton rearrangements to promote bacterial invasion [262] through activation of RhoG. It activates RhoG by indirectly stimulating SGEF (SH3-containing guanine nucleotide exchange factor) [27]. SopB also hydrolyzes $\mathrm{PI}(4,5) \mathrm{P}_{2}$ at the plasma membrane. Hydrolysis of this phospholipid promotes host membrane fission, a process that facilitates bacterial entry $[45,263]$. (ii) Nuclear responses: by controlling phosphoinositide signaling during invasion, it can activate the prosurvival serine-threonine kinase Akt (protein kinase B) and protect epithelial cells from apoptosis [44, 264]. In addition, SopB can indirectly activate Rho-family GTPases (Cdc42 and RhoG) leading to activation of MAPK and NF- $\kappa B$ signaling [124]. It has been suggested that, through its action on Cdc42 and Akt, SopB is responsible for a large fraction of host signaling and phosphorylation events that are induced by Salmonella infection [265]. (iii) SCV maturation: SopB recruits Rab5 to the SCV, which in turn recruits Vps34, a PI3-kinase, leading to PI3P accumulation on the SCV [47]. Rab5 is required for the formation of sorting nexin 3 (SNX3) tubules, and depletion of SNX3 partially inhibits Rab7 and LAMP1 recruitment to the SCV and decreases SIF formation. These results suggest that through the modulation of phosphoinositides by SopB at the membrane of the vacuole, Salmonella is able to modify the localization of the host protein SNX3 and induce a network of tubules to promote SCV maturation [48]. SopB, by reducing the levels of $\mathrm{PI}(4,5) \mathrm{P}_{2}$ and phosphatidylserine in the nascent $\mathrm{SCV}$, reduces the negative membrane surface charge in this compartment. This affects SCV targeting of host cell proteins involved in membrane trafficking and inhibits SCV-lysosome fusion [46]. (iv) Diarrhea: the activity of SopB is required to induce fluid secretion in infected calf intestine loops [260]. This can occur by attenuation of signaling pathways that normally limit chloride secretion [266].

Interestingly, the $\mathrm{N}$-terminal region of SopB may exert a function on the actin cytoskeleton independent of the catalytic domain [267]. Both, a catalytically inactive SopB and a truncated SopB devoid of the phosphatase domain are able to complex with yeast $\mathrm{Cdc} 42$ and to inhibit Cdc42dependent pathways when expressed in the eukaryotic cell model S. cerevisiae [153]. SopB also interacts with mammalian Cdc42 [268] through its $\mathrm{N}$-terminal region independently of its catalytic activity and regardless of the activation state of the GTPase [269]. Structural and biochemical analyses have recently shown that SopB structurally and functionally mimics a host guanine nucleotide dissociation inhibitor (GDI) by contacting key residues in the regulatory switch regions of $\mathrm{Cdc} 42$ and slowing $\mathrm{Cdc} 42$ nucleotide exchange [156]. The interaction with Cdc42 is important for retention of SopB on the SCV and for bacterial growth [269]. Another independent factor involved in shifting the localization of SopB from the ruffling plasma membrane to endosomal compartments that will mature into SCV is ubiquitination on lysine residues that are present in the Nterminal region of SopB $[99,268,270,271]$.

4.12. SopD and SopD2. SopD and SopD2 are related proteins belonging, like SifA or SlrP, to the STE family, which shares a conserved $\mathrm{N}$-terminal sequence that serves as a secretion signal for both T3SS1 and T3SS2 [142]. The similarity between SopD and SopD2 spans the entire length of both proteins and includes a putative coiled-coil domain in the C-terminal region [272]. SopD2 is a T3SS2 effector, and, although SopD was initially described as a T3SS1 effector [273], its pattern of expression suggests that it may also be translocated into host cells by the T3SS2 [272]. SopD contributes to promote the inflammatory responses and fluid secretion in Salmonella-infected intestines [273]. Together with SipA, SopA, SopB, and SopE2 is a major virulence factor responsible for diarrhea during $S$. enterica serovar Typhimurium infection of calves [229] that contributes to invasion of epithelial cells [256]. SopD acts cooperatively with $\mathrm{SopB}$ in the induction of membrane fission and macropinosome formation during Salmonella invasion [274]. It also contributes to virulence during systemic infection of mice and to optimal replication in macrophages, suggesting that SopD contributes not only to early but also to late stages of disease [275]. Both SopD and SopD2 bind with membranes but using different mechanisms. The binding of SopD is ATP-dependent, requires the full-length protein, has broad distribution on endosomes, and occurs at the invasion site of Salmonella. Conversely, SopD2 binding with membranes is ATP-independent, requires only the Nterminus of the protein, and occurs only in late endosomes $[272,274]$. As mentioned previously, SifA is necessary for the stability of the SCV and for intracellular replication in macrophages and fibroblasts. Interestingly, deletion of sopD2 in a sifA mutant stabilizes the SCV and restores intramacrophage replication and virulence. This deletion also induces the formation of tubules different from SIFs and SISTs that are called LNTs, indicating that SopD2 inhibits the formation of LNTs. SopD2 also acts as an inhibitor of vesicle transport from the vacuole [59]. These results suggest a role for SopD2 as an antagonist of SifA in terms of vacuolar membrane dynamics. 
4.13. SopE and SopE2. Salmonella outer protein E (SopE) was initially characterized as a T3SS1 effector involved in invasion of epithelial cells [276]. This effector localizes to the host plasma membrane [277] and contributes to invasion by stimulating membrane ruffling acting as GEF on Rho GTPases Cdc42 and Rac1 [25, 278]. Both Rho GTPases initiate actin polymerization via nucleation promoting factors that activate the Arp2/3 complex. The best characterized nucleation promoting factors are N-WASP (neural WiskottAldrich syndrome protein) and WAVE (WASP family verprolin homolog). Recruitment and activation of Cdc42 and Rac1 at the membrane by SopE lead to recruitment of N-WASP and the WAVE regulatory complex (WRC). SopE triggers activation of N-WASP and cooperates with Arf1 (recruited and activated by the host GEF ARNO) in the activation of WRC [279].

SopE activates several innate immune signaling pathways [124] and is of major importance for eliciting intestinal inflammation [229] through activation of caspase-1 in enterocytes [280]. Caspase-1 activation results in cleavage and secretion of IL- $1 \beta$ and IL-18, which are important for the inflammatory response. The sopE gene is encoded within a prophage, SopE $\phi$, which is not present in all strains of Salmonella [281, 282]. Based on the association of SopE $\phi$ with an epidemic $S$. enterica serovar Typhimurium clone, it was speculated that acquisition of the SopE protein by phagemediated horizontal gene transfer might have increased the fitness of the resulting strain in the host population [283]. Recently, it was shown that SopE enhances the production of host-derived nitrate, an energetically highly valuable electron acceptor, in a mouse colitis model. Nitrate enhances the growth of Salmonella in the gut lumen through anaerobic nitrate respiration [284].

In contrast to sopE, sopE2 appears to be broadly distributed in Salmonella. This gene encodes a protein, SopE2, that is $69 \%$ identical to SopE and also acts as an efficient GEF for Cdc42 [26, 285] but in contrast with SopE, not for Rac1, suggesting that these two similar effectors can activate different sets of Rho GTPases signaling cascades [286]. Like SopE, SopE2 has been implicated in the pathogenesis of diarrhea and enteritis associated with Salmonella infection in calves [229] and in streptomycin-pretreated mice [228]. Consistent with a role in diarrhea and inflammation are the reports indicating that SopE2 is involved in upregulation of macrophage iNOS independently of effects on invasion [287]: that this effector cooperates with flagellin in triggering increased epithelial IL-8 production [288], and that SopE2, together with SopE, SipA, and SopB disrupt tight junction structure and function [38].

4.14. SpiC. SpiC (also known as SsaB [289]) is a SPI2encoded protein with effector and translocator functions. Initially, it was shown to be exported into host cells through T3SS2 and was proposed to interfere with intracellular trafficking to inhibit fusion of SCV with lysosomes [290]. Two host targets have been proposed for SpiC: TassC [291] and Hook3 [292]. TassC is also known as Nipsnap4 or Nps4. It was reported to be a protein that associates with membranes and partly localizes in lipid rafts [293], although more recently it was shown to be a mitochondrial protein [294]. Hook3 is a member of the microtubule binding Hook family of coiled-coil proteins that forms part of a protein complex that has been involved in vesicle trafficking and/or fusion [295] and in the traffic of pericentriolar satellites [296] and could be a mediator of the proposed role of SpiC as a T3SS2 effector. In addition to its role as an effector, SpiC was found to be necessary for the secretion of SseB, SseC, and SseD in vitro [297, 298]. These three proteins are components of the T3SS2 translocon. SpiC interacts with SsaM [299], and both proteins are part of the SsaM/SpiC/SsaL regulatory complex that functions within the bacterial cell to mediate the switch from translocon protein secretion to effector translocation [300]. The complex is dissociated and degraded in response to cytoplasmic $\mathrm{pH}$ sensed through the translocon pore, triggering effector delivery [300].

4.15. SptP. The T3SS1 effector Salmonella protein tyrosine phosphatase (SptP) [301, 302] is a modular protein consisting of two discrete domains. The N-terminal domain functionally mimics a GAP for Cdc42 and Rac1, mediating the reversion of the changes in the actin cytoskeleton that were triggered by effectors like SopE and SopE2 that act as GEF on the same Rho GTPases [28]. The Cterminal half of SptP shares sequence similarity with the prokaryotic tyrosine phosphatase $\mathrm{YopH}$ from Yersinia, as well as with eukaryotic tyrosine phosphatases, and possesses potent tyrosine phosphatase activity [301]. This activity is involved in reversing the activation of the MAPK ERK that results from Salmonella infection [31]. SptP inhibits activation of ERK by interfering with activation of Raf1 in a process that involves both SptP activities [303]. Probably as a consequence of downregulation of ERK, SptP contributes, together with $\mathrm{SspH}$, to downmodulate IL-8 production after invasion of intestinal epithelial cells [304]. The tyrosinephosphorylated form of the filament protein vimentin was proposed as a potential binding partner and substrate for SptP, but the significance of this interaction remains unclear. More recently, valosin-containing protein (VCP), a host $\mathrm{AAA}+\mathrm{ATPase}$ that performs motor-like function to facilitate protein complex disassembly in diverse cellular processes [305], has been identified as an interacting partner of SptP and a substrate for its phosphatase activity, both in vitro and during infection of HeLa cells [53]. Dephosphorylation of VCP leads to an increase in binding of this protein to syntaxin 5 , promoting fusion events within the cells that are likely important for the maturation and maintenance of the SCV. In summary, SptP has a role in downregulating membrane ruffling within $1 \mathrm{~h}$ of pathogen internalization, but it persists for at least $8 \mathrm{~h}$ to be also involved in later events related to SCV maintenance and intracellular bacterial proliferation [53].

4.16. SpvB and SpvC. Several Salmonella serovars belonging to subspecies I harbor plasmids essential for virulence [306]. Only a particular region of the virulence plasmid, Salmonella 
plasmid virulence $(s p v)$, is necessary for the virulent phenotype, and this locus is found in the chromosome in certain $S$. enterica lineages [307]. This region contains the operon spvABCD (spvABC in the chromosomal locus), which is positively regulated by the product of $s p v R$. Genes $s p v R, s p v B$, and $\operatorname{spvC}$ are required for virulence [91].

SpvB has two distinct domains separated by seven proline residues. The C-terminal domain possesses ADPribosyltransferase activity that covalently modifies G-actin monomers at arginine-177 and prevents their polymerization into F-actin filaments [308-311]. SpvB inhibits the formation of vacuole-associated actin polymerizations (VAPs) in HeLa cells [312] and negatively regulates the formation of SIFs [313]. The ADP-ribosylation activity of SpvB is also required for a delayed form of cell death that is observed in host cells $18-24 \mathrm{~h}$ after infection with noninvasive bacteria or T3SS1 mutants [67, 85, 314, 315]. One report showed that SpvB could be secreted into a culture medium mimicking the intracellular iron concentrations of eukaryotic cells in a T3SS-independent manner [316]. However, several components of the T3SS2, have been shown to be essential for SpvB-induced actin depolymerization and delayed cytotoxicity, strongly supporting the idea that $\mathrm{SpvB}$ is translocated into the host cell through T3SS2 [314, 317].

SpvC can be secreted to the culture medium by either T3SS1 or T3SS2, but its translocation into the cytosol of macrophages was shown to be dependent on T3SS2 [318]. Recently, it was demonstrated that SpvC is translocated into the host cell cytosol through T3SS1 when bacteria are grown under SPI1-inducing conditions [319]. This effector has phosphothreoninelyase activity $[318,320]$. This enzyme uses a novel catalytic mechanism, called eliminylation [321], that irreversibly removes the phosphate group from a phosphorylated threonine via $\beta$-elimination [322-325]. SpvC specifically removes phosphate from threonine in the conserved activation loop motif TXY of ERK and inactivates this MAPK, and it is also active towards $\mathrm{p} 38$ and JNK in vitro $[318,320]$. Inactivation of MAPK is the proposed reason for the effect of SpvC in modulating host immune response by reducing inflammatory cytokines during the early stages of infection [319].

4.17. SrfJ. The gene SsrB regulated factor J (SrfJ) was identified in a screen whose aim was finding genes regulated by SsrB, the main positive regulator of SPI2, located outside this island [141]. Because of its pattern of expression, Srf] was immediately suggested as a putative T3SS2 effector. However, secretion of SrfJ through this system was shown only very recently [326]. Interestingly, SrfJ is similar to human lysosomal glucosylceramidase, an enzyme involved in regulating metabolism of the sphingolipid ceramide [327]. Intriguingly, in addition to being positively regulated by SsrB, SrfJ is negatively regulated by IolR, the regulator of genes involved in myoinositol utilization in Salmonella [326, 328].

4.18. SseB, SseC, and SseD Translocases. Genes sseB, sseC, and $s s e D$ are located in SPI2 and their products display weak similarity to EspA, EspD, and EspB, which are secreted by the T3SS of the locus of enterocyte effacement of enteropathogenic E. coli [289]. SseB, SseC, and SseD are secreted to the bacterial surface through T3SS2 after exposition of bacteria to acidic $\mathrm{pH}$ and function as the translocon for T3SS2 effector proteins [329-331].

4.19. SseF and SseG. The genes encoding these effectors, sseF and sseG, are located in SPI2 [289]. SseF and SseG are secreted in vitro [200] and translocated into the host cell through T3SS2 [332]. Both effectors associate with SCV membranes and are necessary for the formation of SIFs [332-334]. SseF and SseG colocalize with microtubules in infected HeLa cells and are responsible for the induction of massive bundling of microtubules at late time points after infection. These bundles serve as a scaffold for SIF formation [335]. In addition to its role in SIF formation, SseG and SseF physically interact with each other and have a role in the targeting of the SCV to the vicinity of the Golgi network in infected epithelial cells [60, 336, 337]. SseG is targeted specifically to the trans-Golgi network through a predicted transmembrane domain located in the middle of the protein. An intact Golgi network is required for intracellular replication of Salmonella. These results suggest that, besides the selective interactions with the endocytic pathway that are necessary for the maturation of the SCV, interactions with the secretory pathway are also required for intracellular replication [337]. In fact, Salmonella can induce a general redistribution of compartments involved in exocytic transport in order to redirect exocytic cargo vesicles to the SCV, and this process is dependent on SifA, SseF, and SseG [338]. Two models have been suggested to explain the role of the SseF-SseG complex and SifA in the spatial distribution or the SCV [339]. The first model is based on the balance between the activity of the microtubule motors kinesin and dynein: as mentioned previously, SifA controls the positioning of the SCV by modulating kinesin activity through SKIP; SseF-SseG would control positioning of bacterial vacuoles by modulating activity of dynein on the SCV $[336,340]$. The second model suggests that tethering between SseF-SseG and Golgi-related molecules determines SCV positioning [42, 337], although no Golgi protein has been found to interact with SseF or SseG. It is also possible that both kinds of mechanisms, motor balance and tethering, contribute to SCV positioning [339]. Intriguingly, TIP60, an acetyltransferase that catalyzes histone acetylation, has been described as a host interacting partner of SseF using the yeast two-hybrid system [341]. TIP60 was upregulated upon Salmonella infection, its acetylation activity was increased in the presence of SseF, and, interestingly, experimental downregulation of TIP60 in macrophages led to decreased intracellular proliferation of Salmonella. However, the interaction has not been confirmed by other methods, and since TIP60 is not directly involved in vesicular trafficking, the functional significance of this interaction is not understood.

4.20. SseI/SrfH. Salmonella secreted effector I (SseI), also known as $\mathrm{SsrB}$ regulated factor $\mathrm{H}(\mathrm{SrfH})$ was identified as 
a member of the STE family on the basis of similarity to the SspH1/SspH2/SlrP N-termini [142] and as a gene located outside SPI2 that was regulated by SsrB, the main positive regulator of SPI2 and T3SS2 [141]. The gene sseI lies within the Gifsy-2 prophage. This gene is expressed under SPI2inducing conditions, and its product is translocated into macrophages in a T3SS2-dependent manner [142]. SseI has been shown to bind to the mammalian actin cross-linking protein filamin and to colocalize with the polymerizing actin cytoskeleton [312]. SseI could play at least two different roles. (i) It has been suggested that, through interaction with TRIP6, a member of the zyxin family of adaptor proteins that regulate motility and adherence, SseI can stimulate migration [342] or regulate cell adherence [343] of phagocytes in order to cause early escape of S. enterica out of the gastrointestinal tract and into the blood stream. (ii) SseI blocks migration of macrophages and dendritic cells by a mechanism that involves interaction of SseI with the host factor IQGAP1, a regulator of the cytoskeleton and cell migration [343]. This second role could be critical during later stages of infection and could explain the attenuation of the sseI mutant in long-term, but not short-term, systemic infections $[207,343]$. The discrepancy between these two roles (stimulation or inhibition of cell migration) has been recently resolved: a naturally occurring allele of sseI/srfH promotes the migration of infected phagocytes into the bloodstream, while another naturally occurring allele that differs by only a single nucleotide polymorphism does not [344]. Upon infection of polarized epithelial cells, SseI is targeted to the plasma membrane in a manner dependent on $S$-palmitoylation of a conserved cysteine residue within its $\mathrm{N}$-terminal domain. This posttranslational modification is necessary for its function in modulating host cell migration [345].

4.21. SseJ. SseJ possesses the N-terminal conserved domain typical of the STE family. It is expressed under SPI2-inducing conditions and translocated through T3SS2 [142]. The Cterminal domain has homology to members of the GDSL motif lipase family, and, in fact, SseJ exhibits phospholipase A1, deacylase, and glycerophospholipid:cholesterol acyltransferase activity. This activity results in the esterification of cholesterol [346-348]. Cholesterol is important in endocytic trafficking events and accumulates in the SCV. It has been suggested that, through cholesterol modification, SseJ is controlling the dynamics of the SCV in cooperation with SifA. SseJ is recruited to the cytosolic face of the SCV where it binds specifically to the GTP-bound form of the RhoA GTPase, and this interaction activates the lipase activity of this effector [349]. SseJ was also able to bind to GTP-bound RhoC (and maybe also to RhoB [350]), but not to other GTPases like Cdc42, H-Ras, or Rac1, and only RhoA acted as a potent activator of the lipase activity of SseJ [349]. Recent structural studies demonstrated that SseJ binds to RhoA through a large surface that includes residues of the switch region II. This is one of the regions in RhoA that undergoes conformational changes upon binding to either GTP or GDP. This region is involved in the interaction of
RhoA-GTP with eukaryotic proteins, like protein kinase N 1 (PKN1), Rock and Rhotekin, which mediate the regulatory effect of the GTPase in several cellular processes. Thus, SseJ competes with eukaryotic effectors for binding to the same surface on RhoA [350].

4.22. SseK1, SseK2, and SseK3. SseK1 and SseK2 were identified because of their similarity to NleB, a known type III secreted protein from Citrobacter rodentium [351]. Another effector of the same family, SseK3, is encoded on the ST64B prophage, which is present in a subset of strains and serovars of S. enterica [352]. Translocation of these effectors through T3SS2 was demonstrated using the CyaA method, and they have a minor role in virulence, since an sseK1 sseK2 double mutant and an sseK1 sseK2 sseK 3 triple mutant are slightly attenuated for virulence in mice $[351,352]$. Their specific functions in the host cells have not been elucidated yet.

4.23. SseL. sseL was described as a member of the SsrB regulon whose product is translocated through T3SS2 $[88,353]$ onto the vacuolar surface in infected host cells. SseL targets the host cell ubiquitin pathway acting as a deubiquitinase that is required for delayed cytotoxicity of macrophages and full virulence in the mouse model [88]. One of the targets of the deubiquitinase activity of SseL is $\mathrm{I} \kappa \mathrm{B} \alpha$ [105]. Suppression of $\mathrm{I} \kappa \mathrm{B} \alpha$ ubiquitination and degradation by SseL suppresses NF- $\kappa \mathrm{B}$ activation. This effect was detected by expressing SseL in HEK293T cells by transfection and also in RAW264.7 cells and primary cultured mouse macrophages by infection with wild-type and sseL mutant strains [105]. However, it was not detected in a previous report using J774 murine macrophages [88]. SseL binds to oxysterolbinding protein (OSBP) [154] via a region within OSBP that contains a predicted coiled-coil and an FFAT motif [354]. OSBP is a lipid-binding protein that has been implicated in the regulation of various cellular processes, including nonvesicular cholesterol transport, signaling, lipid metabolism, and vesicular trafficking. Although OSBP is not a substrate for the activity of SseL, this interaction could be connected to a proposed role of SseL in interfering with lipid metabolism: SseL prevents the accumulation of lipid droplets during infection of gallbladder epithelial cells. This phenotype depends on the deubiquitinase activity of this effector, suggesting a mechanism by which Salmonella can intercept host lipid homeostasis by the direct modification of cellular ubiquitination patterns [355]. In addition, SseL counteracts a cellular response to Salmonella infection that leads to the formation of T3SS2-dependent ubiquitinated aggregates and aggregosome-like induced structures. Accumulation of these aggregates is at least in part due to the combined actions of SifA and SseJ. SseL deubiquitinates these aggregates and prevents recruitment of the autophagy markers p62 and LC3, leading to a reduction in autophagic flux during infection [115]. Since lipid droplet metabolism has been associated with autophagy [356], a relationship between the interference with lipid droplet metabolism and inhibition of selective autophagy by SseL could exist. 
4.24. SspH1 and SspH2. SspH1 is encoded by the prophage Gifsy-3 [181], which is present in only a few S. enterica serovar Typhimurium strains. $\mathrm{SspH} 2$ is encoded in the vicinity of a phage remnant, suggesting that it was acquired also by lysogenic conversion [283], and is conserved among most Salmonella serovars [249]. SspH1 is translocated through T3SS1 and T3SS2, whereas SspH2 is specifically translocated via T3SS2 [249], but both share a similar Nterminal translocation signal that is also present in several other effectors [142]. These effectors also share with other effectors like SlrP a central region containing leucine-rich repeats [249]. These motifs are present in many proteins and can participate in protein-protein interactions [357]. In fact, the leucine-rich repeat domain of SspH1 has been shown to mediate interaction with a mammalian serine/threonine protein kinase called PKN1 [104], an interaction that could explain the nuclear localization of SspH1 and its role in the inhibition of NF- $\kappa \mathrm{B}$-dependent gene expression [304]. In contrast, SspH2 colocalizes with VAPs, and two host interacting partners identified for $\mathrm{SspH} 2$, filamin and profilin, related to the actin cytoskeleton, interact through the C-terminal and the N-terminal domains of the effector, respectively [312]. The $\mathrm{N}$-terminal domain of $\mathrm{SspH} 2$ is also important for targeting of the effector to the host plasma membrane, a process that requires $S$-palmitoylation [345]. Biochemically, SspH1 and SspH2 belong to a family of E3 ubiquitin ligases whose activity resides in their C-terminal domain $[103,251,358]$. Other members of this family are SlrP from Salmonella and IpaH9.8 from Shigella. SspH1 can ubiquitinate its host partner PKN1 in vitro, although the functional significance is unknown [251]. No putative substrates have been identified for $\mathrm{SspH} 2$.

4.25. SteA, SteB, and SteC. These proteins were identified in a screen, based on the generation of CyaA fusions, to find genes encoding effectors in S. enterica serovar Typhimurium [143]. SteA can be translocated into epithelial cells and macrophages through T3SS1 and T3SS2 [143, 359] and localizes to the trans-Golgi network in both transfected and infected human epithelial HeLa cells and to Salmonellainduced membrane tubules containing trans-Golgi markers $[143,360]$. No functional studies have been published about SteB. SteC is a kinase whose activity is necessary for actin meshwork formation in the vicinity of SCV. Overexpression of SteC in host cells causes extensive alterations to the actin cytoskeleton [361], also in a yeast model [152]. In the yeast model, SteC inhibits signaling at the level of the GTPase Cdc42 through binding to the exchange factor Cdc24. Interestingly, SteC is also able to bind to human Vav1, a member of the family of Rho GEFs involved in key biological functions, including actin cytoskeleton reorganization, activation of ERK and JNK, and development and activation of immune cells [362].

4.26. Other Effectors. Six new effectors were identified in a proteomic study of the secretome of an ssaL mutant strain [145]: CigR, GtgA, GtgE, SpvD, SteD, and SteE. All of them are translocated through T3SS2, and GtgE, SpvD, and SteE are also substrates of T3SS1, but, except for GtgE, very little is known about the functions of these effectors.

CigR is encoded in the SPI3 island [363] and induced $4 \mathrm{~h}$ after infection of macrophages [194]. GtgA and GtgE are Gifsy-2 prophage-encoded proteins [181, 364]. GtgE is a protease that cleaves Rab29. This is a Rab GTPase that is recruited to the S. enterica serovar Typhi-containing vacuole and is necessary for the export of typhoid toxin, which is exclusively encoded by the human-specific $S$. enterica serovars Typhi and Paratyphi. Interestingly, these serovars do not encode GtgE, since they are not Gifsy-2 lysogens. In contrast, S. enterica serovar Typhimurium and other broadrange serovars produce GtgE, and this effector, secreted through T3SS1, prevents the recruitment of Rab29 to the SCV [365]. SpvD is encoded within the Salmonella virulence plasmid and was previously predicted to be a T3SS effector using a computational approach [366]. Whereas steD is located outside a pathogenicity island, and steE is in the Gifsy-3 prophage [181], which is present specifically in strain 14028 but not strains LT2 or SL1344 from S. enterica serovar Typhimurium. Both genes significantly contribute to virulence in mice [145].

\section{Abbreviations}

CU: Chaperone-usher

GAP: GTPase-activating protein

GDI: Guanine nucleotide dissociation inhibitor

GEF: Guanine nucleotide exchange factor

IL: Interleukin

iNOS: Inducible nitric oxide synthase

LNT: LAMP1-negative tubule

MAPK: Mitogen-activated protein kinase

MKK: MAPK kinase

NF- $\kappa B:$ Nuclear factor $\kappa B$

PI: Phosphatidylinositol

PMN: Polymorphonuclear leukocytes

SCV: Salmonella-containing vacuole

SIF: Salmonella-induced filament

SIST: Salmonella-induced secretory carrier

SPI: $\quad$ Salmonella pathogenicity island

STE: Salmonella translocated effector

SVAT: Spacious vacuole-associated tubule

T1SS: Type I secretion system

T2SS: Type II secretion system

T3SS: Type III secretion system

T4SS: Type IV secretion system

T5SS: Type V secretion system

T6SS: Type VI secretion system

VAP: Vacuole-associated actin polymerization

WRC: WAVE regulatory complex.

\section{Acknowledgments}

The work in the laboratory of the author is supported by Grant SAF2010-15015 from the Spanish Ministry of Science and Innovation and the European Regional Development 
Fund and Grant P08-CVI-03487 from the Consejería de Economía, Innovación y Ciencia, Junta de Andalucía, Spain.

\section{References}

[1] R. E. Dalbey and A. Kuhn, "Protein Traffic in Gram-negative bacteria-how exported and secreted proteins find their way," FEMS Microbiology Reviews, vol. 36, no. 6, pp. 1023 1045, 2012.

[2] D. Buttner, "Protein export according to schedule: architecture, assembly, and regulation of type III secretion systems from plant- and animal-pathogenic bacteria," Microbiology and Molecular Biology Reviews, vol. 76, no. 2, pp. 262-310, 2012.

[3] P. Cossart, P. Boquet, S. Normark, and R. Rappuoli, “Cellular microbiology emerging," Science, vol. 271, no. 5247, pp. 315316, 1996.

[4] P. Garai, D. P. Gnanadhas, and D. Chakravortty, "Salmonella enterica serovars Typhimurium and Typhi as model organisms: revealing paradigm of host-pathogen interactions," Virulence, vol. 3, no. 4, pp. 377-388, 2012.

[5] J. E. Galan and R. Curtiss, "Cloning and molecular characterization of genes whose products allow Salmonella typhimurium to penetrate tissue culture cells," Proceedings of the National Academy of Sciences of the United States of America, vol. 86, no. 16, pp. 6383-6387, 1989.

[6] H. Ochman, F. C. Soncini, F. Solomon, and E. A. Groisman, "Identification of a pathogenicity island required for Salmonella survival in host cells," Proceedings of the National Academy of Sciences of the United States of America, vol. 93, no. 15 , pp. 7800-7804, 1996.

[7] J. E. Shea, M. Hensel, C. Gleeson, and D. W. Holden, "Identification of a virulence locus encoding a second type III secretion system in Salmonella typhimurium," Proceedings of the National Academy of Sciences of the United States of America, vol. 93, no. 6, pp. 2593-2597, 1996.

[8] P. Malik-Kale, C. E. Jolly, S. Lathrop, S. Winfree, C. Luterbach et al., "Salmonella - at home in the host cell," Frontiers in Microbiology, vol. 2, p. 125, 2011.

[9] S. M. Bueno, A. Wozniak, E. D. Leiva et al., "Salmonella pathogenicity island 1 differentially modulates bacterial entry to dendritic and non-phagocytic cells," Immunology, vol. 130, no. 2, pp. 273-287, 2010.

[10] M. A. Clark, M. A. Jepson, N. L. Simmons, and B. H. Hirst, "Preferential interaction of Salmonella typhimurium with mouse Peyer's patch M cells," Research in Microbiology, vol. 145, no. 7, pp. 543-552, 1994.

[11] B. B. Finlay, B. Gumbiner, and S. Falkow, "Penetration of Salmonella through a polarized Madin-Darby canine kidney epithelial cell monolayer," Journal of Cell Biology, vol. 107, no. 1, pp. 221-230, 1988.

[12] C. V. da Silva, L. Cruz, S. Araujo Nda, M. B. Angeloni, B. B. Fonseca et al., "A glance at Listeria and Salmonella cell invasion: different strategies to promote host actin polymerization," International Journal of Medical Microbiology, vol. 302, no. 1, pp. 19-32, 2011.

[13] M. Rosselin, I. Virlogeux-Payant, C. Roy et al., "Rck of Salmonella enterica, subspecies enterica serovar Enteritidis, mediates Zipper-like internalization," Cell Research, vol. 20, no. 6, pp. 647-664, 2010.

[14] J. A. Fuentes, N. Villagra, M. Castillo-Ruiz, and G. C. Mora, "The Salmonella Typhi hlyE gene plays a role in invasion of cultured epithelial cells and its functional transfer to
S. typhimurium promotes deep organ infection in mice," Research in Microbiology, vol. 159, no. 4, pp. 279-287, 2008.

[15] M. A. Lambert and S. G. J. Smith, "The PagN protein of Salmonella enterica serovar Typhimurium is an adhesin and invasin," BMC Microbiology, vol. 8, article 142, 2008.

[16] M. A. Lambert and S. G. J. Smith, "The PagN protein mediates invasion via interaction with proteoglycan," FEMS Microbiology Letters, vol. 297, no. 2, pp. 209-216, 2009.

[17] M. Rosselin, N. Abed, I. Virlogeux-Payant et al., "Heterogeneity of type III secretion system (T3SS)-1-independent entry mechanisms used by Salmonella Enteritidis to invade different cell types," Microbiology, vol. 157, no. 3, pp. 839847, 2011.

[18] P. Velge, A. Wiedemann, M. Rosselin, N. Abed, Z. Boumart et al., "Multiplicity of Salmonella entry mechanisms, a new paradigm for Salmonella pathogenesis," MicrobiologyOpen, vol. 1, no. 3, pp. 243-258, 2012.

[19] B. Misselwitz, N. Barrett, S. Kreibich, P. Vonaesch, D. Andritschke et al., "Near surface swimming of Salmonella typhimurium explains target-site selection and cooperative invasion," PLOS Pathogens, vol. 8, no. 7, Article ID 100281, 2012.

[20] E. J. McGhie, R. D. Hayward, and V. Koronakis, "Cooperation between actin-binding proteins of invasive Salmonella: SipA potentiates SipC nucleation and bundling of actin," The EMBO Journal, vol. 20, no. 9, pp. 2131-2139, 2001.

[21] D. Zhou, M. S. Mooseker, and J. E. Galán, "An invasionassociated Salmonella protein modulates the actin-bundling activity of plastin," Proceedings of the National Academy of Sciences of the United States of America, vol. 96, no. 18, pp. 10176-10181, 1999.

[22] E. J. McGhie, R. D. Hayward, and V. Koronakis, "Control of actin turnover by a Salmonella invasion protein," Molecular Cell, vol. 13, no. 4, pp. 497-510, 2004.

[23] J. Chang, J. Chen, and D. Zhou, "Delineation and characterization of the actin nucleation and effector translocation activities of Salmonella SipC," Molecular Microbiology, vol. 55, no. 5, pp. 1379-1389, 2005.

[24] S. K. Myeni and D. Zhou, "The C terminus of SipC binds and bundles F-actin to promote Salmonella invasion," The Journal of Biological Chemistry, vol. 285, no. 18, pp. 1335713363, 2010.

[25] W. D. Hardt, L. M. Chen, K. E. Schuebel, X. R. Bustelo, and J. E. Galán, "S. typhimurium Encodes an activator of Rho GTPases that induces membrane ruffling and nuclear responses in host cells," Cell, vol. 93, no. 5, pp. 815-826, 1998.

[26] S. Stender, A. Friebel, S. Linder, M. Rohde, S. Mirold, and W. D. Hardt, "Identification of SopE2 from Salmonella typhimurium, a conserved guanine nucleotide exchange factor for Cdc42 of the host cell," Molecular Microbiology, vol. 36, no. 6, pp. 1206-1221, 2000.

[27] J. C. Patel and J. E. Galán, "Differential activation and function of Rho GTPases during Salmonella-host cell interactions," Journal of Cell Biology, vol. 175, no. 3, pp. 453-463, 2006.

[28] Y. Fu and J. E. Galán, "A Salmonella protein antagonizes Rac1 and Cdc42 to mediate host-cell recovery after bacterial invasion," Nature, vol. 401, no. 6750, pp. 293-297, 1999.

[29] K. T. Ly and J. E. Casanova, "Abelson Tyrosine kinase facilitates Salmonella enterica serovar typhimurium entry into epithelial cells," Infection and Immunity, vol. 77, no. 1, pp. 60-69, 2009.

[30] J. Shi and J. E. Casanova, "Invasion of host cells by Salmonella typhimurium requires focal adhesion kinase and p130Cas," 
Molecular Biology of the Cell, vol. 17, no. 11, pp. 4698-4708, 2006.

[31] S. Murli, R. O. Watson, and J. E. Galán, "Role of tyrosine kinases and the tyrosine phosphatase SptP in the interaction of Salmonella with host cells," Cellular Microbiology, vol. 3, no. 12, pp. 795-810, 2001.

[32] M. D. Brown, L. Bry, Z. Li, and D. B. Sacks, "IQGAP1 regulates Salmonella invasion through interactions with actin, Rac1, and Cdc42," The Journal of Biological Chemistry, vol. 282, no. 41, pp. 30265-30272, 2007.

[33] H. Kim, C. D. White, Z. Li, and D. B. Sacks, "Salmonella enterica serotype Typhimurium usurps the scaffold protein IQGAP1 to manipulate Rac1 and MAPK signalling," The Biochemical Journal, vol. 440, no. 3, pp. 309-318, 2011.

[34] E. Bassères, G. Coppotelli, T. Pfirrmann, J. B. Andersen, M. Masucci, and T. Frisan, "The ubiquitin C-terminal hydrolase $\mathrm{UCH}-\mathrm{L} 1$ promotes bacterial invasion by altering the dynamics of the actin cytoskeleton," Cellular Microbiology, vol. 12, no. 11 , pp. 1622-1633, 2010.

[35] C. D. Nichols and J. E. Casanova, "Salmonella-directed recruitment of new membrane to invasion foci via the host exocyst complex," Current Biology, vol. 20, no. 14, pp. 13161320, 2010.

[36] S. Dai, Y. Zhang, T. Weimbs, M. B. Yaffe, and D. Zhou, "Bacteria-generated PtdIns(3) P recruits VAMP8 to facilitate phagocytosis," Traffic, vol. 8, no. 10, pp. 1365-1374, 2007.

[37] J. A. Guttman and B. B. Finlay, "Tight junctions as targets of infectious agents," Biochimica et Biophysica Acta, vol. 1788, no. 4, pp. 832-841, 2009.

[38] E. C. Boyle, N. F. Brown, and B. B. Finlay, "Salmonella enterica serovar Typhimurium effectors SopB, SopE, SopE2 and SipA disrupt tight junction structure and function," Cellular Microbiology, vol. 8, no. 12, pp. 1946-1957, 2006.

[39] A. P. Liao, E. O. Petrof, S. Kuppireddi et al., "Salmonella type III effector AvrA stabilizes cell tight junctions to inhibit inflammation in intestinal epithelial cells," PLOS ONE, vol. 3, no. 6, Article ID e2369, 2008.

[40] F. García-del Portillo, C. Núñez-Hernández, B. Eisman, and J. Ramos-Vivas, "Growth control in the Salmonella-containing vacuole," Current Opinion in Microbiology, vol. 11, no. 1, pp. 46-52, 2008.

[41] N. Schroeder, L. J. Mota, and S. Méresse, "Salmonellainduced tubular networks," Trends in Microbiology, vol. 19, no. 6, pp. 268-277, 2011.

[42] A. E. Ramsden, L. J. Mota, S. Münter, S. L. Shorte, and D. W. Holden, "The SPI-2 type III secretion system restricts motility of Salmonella-containing vacuoles," Cellular Microbiology, vol. 9, no. 10, pp. 2517-2529, 2007.

[43] A. C. Smith, D. H. Won, V. Braun et al., "A network of Rab GTPases controls phagosome maturation and is modulated by Salmonella enterica serovar Typhimurium," Journal of Cell Biology, vol. 176, no. 3, pp. 263-268, 2007.

[44] O. Steele-Mortimer, L. A. Knodler, S. L. Marcus et al., "Activation of Akt/protein kinase B in epithelial cells by the Salmonella typhimurium effector SigD," The Journal of Biological Chemistry, vol. 275, no. 48, pp. 37718-37724, 2000.

[45] M. R. Terebiznik, O. V. Vieira, S. L. Marcus et al., "Elimination of host cell Ptdlns(4,5)P2 by bacterial SigD promotes membrane fission during invasion by Salmonella," Nature Cell Biology, vol. 4, no. 10, pp. 766-773, 2002.

[46] M. A. Bakowski, V. Braun, G. Y. Lam et al., "The phosphoinositide phosphatase SopB manipulates membrane surface charge and trafficking of the Salmonella-containing vacuole," Cell Host \& Microbe, vol. 7, no. 6, pp. 453-462, 2010.
[47] G. V. Mallo, M. Espina, A. C. Smith et al., "SopB promotes phosphatidylinositol 3-phosphate formation on Salmonella vacuoles by recruiting Rab5 and Vps34," Journal of Cell Biology, vol. 182, no. 4, pp. 741-752, 2008.

[48] V. Braun, A. Wong, M. Landekic, W. J. Hong, S. Grinstein, and J. H. Brumell, "Sorting nexin 3 (SNX3) is a component of a tubular endosomal network induced by Salmonella and involved in maturation of the Salmonella-containing vacuole," Cellular Microbiology, vol. 12, no. 9, pp. 1352-1367, 2010.

[49] M. V. Bujny, P. A. Ewels, S. Humphrey, N. Attar, M. A. Jepson, and P. J. Cullen, "Sorting nexin-1 defines an early phase of Salmonella-containing vacuole-remodeling during Salmonella infection," Journal of Cell Science, vol. 121, no. 12, pp. 2027-2036, 2008.

[50] F. Garcia-del Portillo and B. B. Finlay, "Targeting of Salmonella typhimurium to vesicles containing lysosomal membrane glycoproteins bypasses compartments with mannose 6-phosphate receptors," Journal of Cell Biology, vol. 129, no. 1, pp. 81-97, 1995.

[51] D. Drecktrah, L. A. Knodler, D. Howe, and O. SteeleMortimer, "Salmonella trafficking is defined by continuous dynamic interactions with the endolysosomal system," Traffic, vol. 8, no. 3, pp. 212-225, 2007.

[52] O. H. Yu-Kyoung, C. Alpuche-Aranda, E. Berthiaume, T. Jinks, S. I. Miller, and J. A. Swanson, "Rapid and complete fusion of macrophage lysosomes with phagosomes containing Salmonella typhimurium," Infection and Immunity, vol. 64, no. 9, pp. 3877-3883, 1996.

[53] D. Humphreys, P. J. Hume, and V. Koronakis, "The Salmonella effector SptP dephosphorylates host AAA+ ATPase VCP to promote development of its intracellular replicative niche," Cell Host \& Microbe, vol. 5, no. 3, pp. 225233, 2009.

[54] J. A. Wasylnka, M. A. Bakowski, J. Szeto et al., "Role for myosin II in regulating positioning of Salmonella-containing vacuoles and intracellular replication," Infection and Immunity, vol. 76, no. 6, pp. 2722-2735, 2008.

[55] D. Drecktrah, S. Levine-Wilkinson, T. Dam et al., "Dynamic behavior of Salmonella-induced membrane tubules in epithelial cells," Traffic, vol. 9, no. 12, pp. 2117-2129, 2008.

[56] R. Rajashekar, D. Liebl, A. Seitz, and M. Hensel, "Dynamic remodeling of the endosomal system during formation of Salmonella-induced filaments by intracellular Salmonella enterica," Traffic, vol. 9, no. 12, pp. 2100-2116, 2008.

[57] O. Steele-Mortimer, "The Salmonella-containing vacuolemoving with the times," Current Opinion in Microbiology, vol. 11 , no. 1, pp. 38-45, 2008.

[58] L. J. Mota, A. E. Ramsden, M. Liu, J. D. Castle, and D. W. Holden, "SCAMP3 is a component of the Salmonellainduced tubular network and reveals an interaction between bacterial effectors and post-Golgi trafficking," Cellular Microbiology, vol. 11, no. 8, pp. 1236-1253, 2009.

[59] N. Schroeder, T. Henry, C. de Chastellier et al., "The virulence protein SopD2 regulates membrane dynamics of Salmonellacontaining vacuoles," PLoS pathogens, vol. 6, no. 7, Article ID e1001002, 2010.

[60] J. Deiwick, S. P. Salcedo, E. Boucrot et al., "The translocated Salmonella effector proteins SseF and SseG interact and are required to establish an intracellular replication niche," Infection and Immunity, vol. 74, no. 12, pp. 6965-6972, 2006.

[61] P. Malik-Kale, S. Winfree, and O. Steele-Mortimer, "The bimodal lifestyle of intracellular Salmonella in epithelial 
cells: replication in the cytosol obscures defects in vacuolar replication," PLoS ONE, vol. 7, no. 6, 2012.

[62] J. Szeto, A. Namolovan, S. E. Osborne, B. K. Coombes, and J. H. Brumell, "Salmonella-containing vacuoles display centrifugal movement associated with cell-to-cell transfer in epithelial cells," Infection and Immunity, vol. 77, no. 3, pp. 996-1007, 2009.

[63] L. A. Knodler, B. A. Vallance, J. Celli et al., "Dissemination of invasive Salmonella via bacterial-induced extrusion of mucosal epithelia," Proceedings of the National Academy of Sciences of the United States of America, vol. 107, no. 41, pp. 17733-17738, 2010.

[64] D. G. Guiney, "The role of host cell death in Salmonella infections," Current Topics in Microbiology and Immunology, vol. 289, pp. 131-150, 2005.

[65] S. L. Fink and B. T. Cookson, "Pyroptosis and host cell death responses during Salmonella infection," Cellular Microbiology, vol. 9, no. 11, pp. 2562-2570, 2007.

[66] J. M. Kim, L. Eckmann, T. C. Savidge, D. C. Lowe, T. Witthöft, and M. F. Kagnoff, "Apoptosis of human intestinal epithelial cells after bacterial invasion," Journal of Clinical Investigation, vol. 102, no. 10, pp. 1815-1823, 1998.

[67] G. Paesold, D. G. Guiney, L. Eckmann, and M. F. Kagnoff, "Genes in the Salmonella pathogenicity island 2 and the Salmonella virulence plasmid are essential for Salmonellainduced apoptosis in intestinal epithelial cells," Cellular Microbiology, vol. 4, no. 11, pp. 771-781, 2002.

[68] J. Bernal-Bayard, E. Cardenal-Muñoz, and F. RamosMorales, "The Salmonella type III secretion effector, Salmonella Leucine-rich Repeat Protein (SlrP), targets the human chaperone ERdj3," The Journal of Biological Chemistry, vol. 285, no. 21, pp. 16360-16368, 2010.

[69] J. Bernal-Bayard and F. Ramos-Morales, "Salmonella type III secretion effector SlrP is an E3 ubiquitin ligase for mammalian thioredoxin," The Journal of Biological Chemistry, vol. 284, no. 40, pp. 27587-27595, 2009.

[70] H. Wu, R. M. Jones, and A. S. Neish, "The Salmonella effector AvrA mediates bacterial intracellular survival during infection in vivo," Cellular Microbiology, vol. 14, no. 1, pp. 28-39, 2011.

[71] L. A. Knodler and O. Steele-Mortimer, "The Salmonella effector PipB2 affects late endosome/lysosome distribution to mediate sif extension," Molecular Biology of the Cell, vol. 16, no. 9, pp. 4108-4123, 2005.

[72] M. A. Brennan and B. T. Cookson, "Salmonella induces macrophage death by caspase-1-dependent necrosis," Molecular Microbiology, vol. 38, no. 1, pp. 31-40, 2000.

[73] S. L. Fink and B. T. Cookson, "Apoptosis, pyroptosis, and necrosis: mechanistic description of dead and dying eukaryotic cells," Infection and Immunity, vol. 73, no. 4, pp. 1907-1916, 2005.

[74] B. T. Cookson and M. A. Brennan, "Pro-inflammatory programmed cell death," Trends in Microbiology, vol. 9, no. 3, pp. 113-114, 2001.

[75] D. M. Monack, W. W. Navarre, and S. Falkow, "Salmonellainduced macrophage death: the role of caspase- 1 in death and inflammation," Microbes and Infection, vol. 3, no. 14-15, pp. 1201-1212, 2001.

[76] A. W. M. van der Velden, M. Velasquez, and M. N. Starnbach, "Salmonella rapidly kill dendritic cells via a caspase-1dependent mechanism," Journal of Immunology, vol. 171, no. 12, pp. 6742-6749, 2003.

[77] D. Hersh, D. M. Monack, M. R. Smith, N. Ghori, S. Falkow, and A. Zychlinsky, "The Salmonella invasin SipB induces macrophage apoptosis by binding to caspase-1," Proceedings of the National Academy of Sciences of the United States of America, vol. 96, no. 5, pp. 2396-2401, 1999.

[78] L. Franchi, A. Amer, M. Body-Malapel et al., "Cytosolic flagellin requires Ipaf for activation of caspase- 1 and interleukin $1 \beta$ in Salmonella-infected macrophages," Nature Immunology, vol. 7, no. 6, pp. 576-582, 2006.

[79] E. A. Miao, C. M. Alpuche-Aranda, M. Dors et al., "Cytoplasmic flagellin activates caspase- 1 and secretion of interleukin $1 \beta$ via Ipaf," Nature Immunology, vol. 7, no. 6, pp. 569-575, 2006.

[80] E. A. Miao, D. P. Mao, N. Yudkovsky et al., "Innate immune detection of the type III secretion apparatus through the NLRC4 inflammasome," Proceedings of the National Academy of Sciences of the United States of America, vol. 107, no. 7, pp. 3076-3080, 2010.

[81] Y. Zhao, J. Yang, J. Shi, Y. N. Gong, Q. Lu et al., "The NLRC4 inflammasome receptors for bacterial flagellin and type III secretion apparatus," Nature, vol. 477, no. 7366, pp. 596-600, 2011.

[82] Y. Qu, S. Misaghi, A. Izrael-Tomasevic, K. Newton, L. L. Gilmour et al., "Phosphorylation of NLRC4 is critical for inflammasome activation," Nature, vol. 490, no. 7421, pp. 539-542, 2012.

[83] M. C. Schlumberger and W. D. Hardt, "Salmonella type III secretion effectors: pulling the host cell's strings," Current Opinion in Microbiology, vol. 9, no. 1, pp. 46-54, 2006.

[84] M. K. Stewart, L. A. Cummings, M. L. Johnson, A. B. Berezow, and B. T. Cookson, "Regulation of phenotypic heterogeneity permits Salmonella evasion of the host caspase-1 inflammatory response," Proceedings of the National Academy of Sciences of the United States of America, vol. 108, no. 51, pp. 20742-20747, 2011.

[85] S. J. Libby, M. Lesnick, P. Hasegawa, E. Weidenhammer, and D. G. Guiney, "The Salmonella virulence plasmid spv genes are required for cytopathology in human," Cellular Microbiology, vol. 2, no. 1, pp. 49-58, 2000.

[86] D. M. Monack, C. S. Detweiler, and S. Falkow, "Salmonella pathogenicity island 2-dependent macrophage death is mediated in part by the host cysteine protease caspase-1," Cellular Microbiology, vol. 3, no. 12, pp. 825-837, 2001.

[87] A. W. M. van der Velden, S. W. Lindgren, M. J. Worley, and F. Heffron, "Salmonella pathogenicity island 1independent induction of apoptosis in infected macrophages by Salmonella enterica serotype typhimurium," Infection and Immunity, vol. 68, no. 10, pp. 5702-5709, 2000.

[88] A. Rytkönen, J. Poh, J. Garmendia et al., "SseL, a Salmonella deubiquitinase required for macrophage killing and virulence," Proceedings of the National Academy of Sciences of the United States of America, vol. 104, no. 9, pp. 3502-3507, 2007.

[89] P. Broz, K. Newton, M. Lamkanfi, S. Mariathasan, V. M. Dixit, and D. M. Monack, "Redundant roles for inflammasome receptors NLRP3 and NLRC4 in host defense against Salmonella," Journal of Experimental Medicine, vol. 207, no. 8, pp. 1745-1755, 2010.

[90] A. R. Shenoy, D. A. Wellington, P. Kumar, H. Kassa, C. J. Booth et al., "GBP5 promotes NLRP3 inflammasome assembly and immunity in mammals," Science, vol. 336, no. 6080, pp. 481-485, 2012.

[91] D. G. Guiney and J. Fierer, "The role of the spv genes in Salmonella pathogenesis," Frontiers in Microbiology, vol. 2, p. 129, 2011.

[92] C. M. Pickart, "Mechanisms underlying ubiquitination," Annual Review of Biochemistry, vol. 70, pp. 503-533, 2001. 
[93] M. B. Metzger, V. A. Hristova, and A. M. Weissman, "HECT and RING finger families of E3 ubiquitin ligases at a glance," Journal of Cell Science, vol. 125, pp. 531-537, 2012.

[94] V. Nagy and I. Dikic, "Ubiquitin ligase complexes: from substrate selectivity to conjugational specificity," Biological Chemistry, vol. 391, no. 2-3, pp. 163-169, 2010.

[95] D. Komander, M. J. Clague, and S. Urbé, "Breaking the chains: structure and function of the deubiquitinases," Nature Reviews Molecular Cell Biology, vol. 10, no. 8, pp. 550563, 2009.

[96] C. A. Collins and E. J. Brown, "Cytosol as battleground: ubiquitin as a weapon for both host and pathogen," Trends in Cell Biology, vol. 20, no. 4, pp. 205-213, 2010.

[97] O. Steele-Mortimer, "Exploitation of the ubiquitin system by invading bacteria," Traffic, vol. 12, no. 2, pp. 162-169, 2011.

[98] T. Kubori and J. E. Galán, "Temporal regulation of Salmonella virulence effector function by proteasome-dependent protein degradation," Cell, vol. 115, no. 3, pp. 333-342, 2003.

[99] L. A. Knodler, S. Winfree, D. Drecktrah, R. Ireland, and O. Steele-Mortimer, "Ubiquitination of the bacterial inositol phosphatase, SopB, regulates its biological activity at the plasma membrane," Cellular Microbiology, vol. 11, no. 11, pp. 1652-1670, 2009.

[100] Y. Zhang, W. Higashide, S. Dai, D. M. Sherman, and D. Zhou, "Recognition and ubiquitination of Salmonella type III effector SopA by a ubiquitin E3 ligase, HsRMA1," The Journal of Biological Chemistry, vol. 280, no. 46, pp. 3868238688, 2005.

[101] D. Y. Lin, J. Diao, and J. Chen, "Crystal structures of two bacterial HECT-like E3 ligases in complex with a human E2 reveal atomic details of pathogen-host interactions," Proceedings of the National Academy of Sciences of the United States of America, vol. 109, no. 6, pp. 1925-1930, 2012.

[102] Y. Zhang, W. M. Higashide, B. A. McCormick, J. Chen, and D. Zhou, "The inflammation-associated Salmonella SopA is a HECT-like E3 ubiquitin ligase," Molecular Microbiology, vol. 62, no. 3, pp. 786-793, 2006.

[103] C. M. Quezada, S. W. Hicks, J. E. Galán, and C. Erec Stebbins, "A family of Salmonella virulence factors functions as a distinct class of autoregulated E3 ubiquitin ligases," Proceedings of the National Academy of Sciences of the United States of America, vol. 106, no. 12, pp. 4864-4869, 2009.

[104] A. Haraga and S. I. Miller, "A Salmonella type III secretion effector interacts with the mammalian serine/threonine protein kinase PKN1," Cellular Microbiology, vol. 8, no. 5, pp. 837-846, 2006.

[105] G. Le Negrate, B. Faustin, K. Welsh et al., "Salmonella secreted factor L deubiquitinase of Salmonella typhimurium inhibits NF- $\kappa \mathrm{B}$, suppresses $\mathrm{IkB} \alpha$ ubiquitination and modulates innate immune responses," Journal of Immunology, vol. 180, no. 7, pp. 5045-5056, 2008.

[106] J. Sun, M. E. Hobert, A. S. Rao, A. S. Neish, and J. L. Madara, "Bacterial activation of $\beta$-catenin signaling in human epithelia," American Journal of Physiology, vol. 287, no. 1, pp. G220-G227, 2004.

[107] Z. Ye, E. O. Petrof, D. Boone, E. C. Claud, and J. Sun, "Salmonella effector AvrA regulation of colonic epithelial cell inflammation by deubiquitination," American Journal of Pathology, vol. 171, no. 3, pp. 882-892, 2007.

[108] T. L. Thurston, M. P. Wandel, N. von Muhlinen, A. Foeglein, and F. Randow, "Galectin 8 targets damaged vesicles for autophagy to defend cells against bacterial invasion," Nature, vol. 482, no. 7385, pp. 414-418, 2012.
[109] A. J. Perrin, X. Jiang, C. L. Birmingham, N. S. Y. So, and J. H. Brumell, "Recognition of bacteria in the cytosol of mammalian cells by the ubiquitin system," Current Biology, vol. 14, no. 9, pp. 806-811, 2004.

[110] T. L. Thurston, G. Ryzhakov, S. Bloor, N. von Muhlinen, and F. Randow, "The TBK1 adaptor and autophagy receptor NDP52 restricts the proliferation of ubiquitin-coated bacteria," Nature Immunology, vol. 10, no. 11, pp. 1215-1221, 2009.

[111] P. Wild, H. Farhan, D. G. McEwan, S. Wagner, V. V. Rogov et al., "Phosphorylation of the autophagy receptor optineurin restricts Salmonella growth," Science, vol. 333, no. 6039, pp. 228-233, 2011.

[112] Y. T. Zheng, S. Shahnazari, A. Brech, T. Lamark, T. Johansen, and J. H. Brumell, "The adaptor protein p62/SQSTM1 targets invading bacteria to the autophagy pathway," Journal of Immunology, vol. 183, no. 9, pp. 5909-5916, 2009.

[113] L. D. Hernandez, M. Pypaert, R. A. Flavell, and J. E. Galán, "A Salmonella protein causes macrophage cell death by inducing autophagy," Journal of Cell Biology, vol. 163, no. 5, pp. 11231131,2003

[114] C. L. Birmingham and J. H. Brumell, "Autophagy recognizes intracellular Salmonella enterica serovar typhimurium in damaged vacuoles," Autophagy, vol. 2, no. 3, pp. 156-158, 2006.

[115] F. S. Mesquita, M. Thomas, M. Sachse, A. J. Santos, R. Figueira et al., "The Salmonella deubiquitinase SseL inhibits selective autophagy of cytosolic aggregates," PLOS Pathogens, vol. 8, no. 6, Article ID 100274, 2012.

[116] R. G. Jenner and R. A. Young, "Insights into host responses against pathogens from transcriptional profiling," Nature Reviews Microbiology, vol. 3, no. 4, pp. 281-294, 2005.

[117] C. M. Rosenberger, M. G. Scott, M. R. Gold, R. E. W. Hancock, and B. B. Finlay, "Salmonella typhimurium infection and lipopolysaccharide stimulation induce similar changes in macrophage gene expression," Journal of Immunology, vol. 164, no. 11, pp. 5894-5904, 2000.

[118] C. S. Detweiler, D. B. Cunanan, and S. Falkow, "Host microarray analysis reveals a role for the Salmonella response regulator phoP in human macrophage cell death," Proceedings of the National Academy of Sciences of the United States of America, vol. 98, no. 10, pp. 5850-5855, 2001.

[119] L. Eckmann, J. R. Smith, M. P. Housley, M. B. Dwinell, and M. F. Kagnoff, "Analysis by high density cDNA arrays of altered gene expression in human intestinal epithelial cells in response to infection with the invasive enteric bacteria Salmonella," The Journal of Biological Chemistry, vol. 275, no. 19, pp. 14084-14094, 2000.

[120] H. I. Chiang, C. L. Swaggerty, M. H. Kogut et al., "Gene expression profiling in chicken heterophils with Salmonella enteritidis stimulation using a chicken $44 \mathrm{~K}$ Agilent microarray," BMC Genomics, vol. 9, article 526, 2008.

[121] Y. Wang, O. P. Couture, L. Qu et al., "Analysis of porcine transcriptional response to Salmonella enterica serovar Choleraesuis suggests novel targets of NFkappaB are activated in the mesenteric lymph node," BMC Genomics, vol. 9, article 437, 2008.

[122] W. Rodenburg, I. M. J. Bovee-Oudenhoven, E. Kramer, R. van der Meer, and J. Keijer, "Gene expression response of the rat small intestine following oral Salmonella infection," Physiological Genomics, vol. 30, no. 2, pp. 123-133, 2007.

[123] S. K. Khoo, D. Petillo, M. Parida, A. C. Tan, J. H. Resau, and S. K. Obaro, "Host response transcriptional profiling reveals extracellular components and ABC (ATP-binding 
cassette) transporters gene enrichment in typhoid feverinfected Nigerian children," BMC Infectious Diseases, vol. 11, p. 241, 2011.

[124] V. M. Bruno, S. Hannemann, M. Lara-Tejero, R. A. Flavell, S. H. Kleinstein, and J. E. Galán, "Salmonella typhimurium type III secretion effectors stimulate innate immune responses in cultured epithelial cells," PLoS Pathogens, vol. 5, no. 8, Article ID e1000538, 2009.

[125] S. D. Lawhon, S. Khare, C. A. Rossetti, R. E. Everts, C. L. Galindo et al., "Role of SPI-1 secreted effectors in acute bovine response to Salmonella enterica Serovar Typhimurium: a systems biology analysis approach," PLoS ONE, vol. 6, no. 11, Article ID e26869, 2011.

[126] F. Du and J. E. Galán, "Selective inhibition of type III secretion activated signaling by the Salmonella effector AvrA," PLoS Pathogens, vol. 5, no. 9, Article ID e1000595, 2009.

[127] X. Liu, R. Lu, Y. Xia, S. Wu, and J. Sun, "Eukaryotic signaling pathways targeted by Salmonella effector protein AvrA in intestinal infection in vivo," BMC Microbiology, vol. 10, p. 326,2010 .

[128] S. Wu, Z. Ye, X. Liu et al., "Salmonella typhimurium infection increases p53 acetylation in intestinal epithelial cells," American Journal of Physiology, vol. 298, no. 5, pp. G784-G794, 2010.

[129] S. Zhang, H. S. Lillehoj, C. H. Kim, C. L. Keeler, U. Babu, and M. Z. Zhang, "Transcriptional response of chicken macrophages to Salmonella enterica serovar Enteritidis infection," Developments in Biologicals, vol. 132, pp. 141-151, 2008.

[130] I. Mellman and R. M. Steinman, "Dendritic cells: specialized and regulated antigen processing machines," Cell, vol. 106, no. 3, pp. 255-258, 2001.

[131] I. Mellman, "Antigen processing and presentation by dendritic cells: cell biological mechanisms," Advances in Experimental Medicine and Biology, vol. 560, pp. 63-67, 2005.

[132] M. J. Wick, "The role of dendritic cells during Salmonella infection," Current Opinion in Immunology, vol. 14, no. 4, pp. 437-443, 2002.

[133] F. G. D. Portillo, H. Jungnitz, M. Rohde, and C. A. Guzmán, "Interaction of Salmonella enterica serotype typhimurium with dendritic cells is defined by targeting to compartments lacking lysosomal membrane glycoproteins," Infection and Immunity, vol. 68, no. 5, pp. 2985-2991, 2000.

[134] J. Jantsch, C. Cheminay, D. Chakravortty, T. Lindig, J. Hein, and M. Hensel, "Intracellular activities of Salmonella enterica in murine dendritic cells," Cellular Microbiology, vol. 5, no. 12, pp. 933-945, 2003.

[135] F. Niedergang, J. C. Sirard, C. T. Blanc, and J. P. Kraehenbuhl, "Entry and survival of Salmonella typhimurium in dendritic cells and presentation of recombinant antigens do not require macrophage-specific virulence factors," Proceedings of the National Academy of Sciences of the United States of America, vol. 97, no. 26, pp. 14650-14655, 2000.

[136] C. Cheminay, A. Möhlenbrink, and M. Hensel, "Intracellular Salmonella inhibit antigen presentation by dendritic cells," Journal of Immunology, vol. 174, no. 5, pp. 2892-2899, 2005.

[137] J. A. Tobar, L. J. Carreño, S. M. Bueno et al., "Virulent Salmonella enterica serovar typhimurium evades adaptive immunity by preventing dendritic cells from activating $\mathrm{T}$ cells," Infection and Immunity, vol. 74, no. 11, pp. 6438-6448, 2006.

[138] S. Halici, S. F. Zenk, J. Jantsch, and M. Hensel, "Functional analysis of the Salmonella pathogenicity island 2-mediated inhibition of antigen presentation in dendritic cells," Infection and Immunity, vol. 76, no. 11, pp. 4924-4933, 2008.

[139] E. K. Mitchell, P. Mastroeni, A. P. Kelly, and J. Trowsdale, "Inhibition of cell surface MHC class II expression by Salmonella," European Journal of Immunology, vol. 34, no. 9, pp. 2559-2567, 2004.

[140] N. Lapaque, J. L. Hutchinson, D. C. Jones et al., "Salmonella regulates polyubiquitination and surface expression of $\mathrm{MHC}$ class II antigens," Proceedings of the National Academy of Sciences of the United States of America, vol. 106, no. 33, pp. 14052-14057, 2009.

[141] M. J. Worley, K. H. L. Ching, and F. Heffron, "Salmonella SsrB activates a global regulon of horizontally acquired genes," Molecular Microbiology, vol. 36, no. 3, pp. 749-761, 2000.

[142] E. A. Miao and S. I. Miller, "A conserved amino acid sequence directing intracellular type III secretion by Salmonella typhimurium," Proceedings of the National Academy of Sciences of the United States of America, vol. 97, no. 13, pp. 7539$7544,2000$.

[143] K. Geddes, M. Worley, G. Niemann, and F. Heffron, "Identification of new secreted effectors in Salmonella enterica serovar typhimurium," Infection and Immunity, vol. 73, no. 10, pp. 6260-6271, 2005.

[144] M. P. Sory and G. R. Cornelis, "Translocation of a hybrid YopE-adenylate cyclase from Yersinia enterocolitica into HeLa cells," Molecular Microbiology, vol. 14, no. 3, pp. 583-594, 1994.

[145] G. S. Niemann, R. N. Brown, J. K. Gustin et al., "Discovery of novel secreted virulence factors from Salmonella enterica serovar typhimurium by proteomic analysis of culture supernatants," Infection and Immunity, vol. 79, no. 1, pp. 33-43, 2011.

[146] R. Boonyom, M. H. Karavolos, D. M. Bulmer, and C. M. A. Khan, "Salmonella pathogenicity island 1 (SPI-1) type III secretion of SopD involves $\mathrm{N}$ - and C-terminal signals and direct binding to the InvC ATPase," Microbiology, vol. 156, no. 6 , pp. 1805-1814, 2010.

[147] I. Hautefort, A. Thompson, S. Eriksson-Ygberg et al., "During infection of epithelial cells Salmonella enterica serovar Typhimurium undergoes a time-dependent transcriptional adaptation that results in simultaneous expression of three type 3 secretion systems," Cellular Microbiology, vol. 10, no. 4, pp. 958-984, 2008.

[148] J. E. Button and J. E. Galan, "Regulation of chaperone/effector complex synthesis in a bacterial type III secretion system," Molecular Microbiology, vol. 81, no. 6, pp. 1474$1483,2011$.

[149] M. Lara-Tejero, J. Kato, S. Wagner, X. Liu, and J. E. Galán, “A sorting platform determines the order of protein secretion in bacterial type III systems," Science, vol. 331, no. 6021, pp. 1188-1191, 2011.

[150] S. Schleker, J. Sun, B. Raghavan, M. Srnec, N. Muller et al., "The current Salmonella-host interactome," PROTEOMICS Clinical Applications, vol. 6, pp. 117-133, 2012.

[151] P. Dean, "Functional domains and motifs of bacterial type III effector proteins and their roles in infection," FEMS Microbiology Reviews, vol. 35, no. 6, pp. 1100-1125, 2011.

[152] A. Alemán, P. Fernández-Piñar, D. Pérez-Núñez, R. Rotger, H. Martín et al., "A yeast-based genetic screen for identification of pathogenic Salmonella proteins," FEMS Microbiology Letters, vol. 296, no. 2, pp. 167-77, 2009.

[153] I. Rodríguez-Escudero, R. Rotger, V. J. Cid, and M. Molina, "Inhibition of Cdc42-dependent signalling in Saccharomyces cerevisiae by phosphatase-dead SigD/SopB from Salmonella 
typhimurium," Microbiology, vol. 152, no. 11, pp. 3437-3452, 2006.

[154] S. D. Auweter, A. P. Bhavsar, C. L. De Hoog et al., "Quantitative mass spectrometry catalogues Salmonella pathogenicity island-2 effectors and identifies their cognate host binding partners," The Journal of Biological Chemistry, vol. 286, no. 27, pp. 24023-24035, 2011.

[155] R. Arnold, K. Boonen, M. G. Sun, and P. M. Kim, "Computational analysis of interactomes: current and future perspectives for bioinformatics approaches to model the host-pathogen interaction space," Methods, vol. 57, no. 4, pp. 508-518, 2012.

[156] B. J. Burkinshaw, G. Prehna, L. J. Worrall, and N. C. Strynadka, "Structure of Salmonella effector protein SopB Nterminal domain in complex with host Rho GTPase Cdc42," The Journal of Biological Chemistry, vol. 287, no. 16, pp. 13348-13355, 2012.

[157] A. Ordas, Z. Hegedus, C. V. Henkel, O. W. Stockhammer, D. Butler et al., "Deep sequencing of the innate immune transcriptomic response of zebrafish embryos to Salmonella infection," Fish and Shellfish Immunology, vol. 31, no. 5, pp. 716-724, 2011.

[158] F. García-del Portillo, "Heterogeneity in tissue culture infection models: a source of novel host-pathogen interactions?" Microbes and Infection, vol. 10, no. 9, pp. 1063-1066, 2008.

[159] H. K. de Jong, C. M. Parry, T. van der Poll, and W. J. Wiersinga, "Host-pathogen interaction in invasive salmonellosis," PLOS Pathogens, vol. 8, no. 10, Article ID e100293, 2012.

[160] M. E. Jennings, L. N. Quick, N. Ubol, S. Shrom, N. Dollahon et al., "Characterization of Salmonella type III secretion hyper-activity which results in biofilm-like cell aggregation," PLoS ONE, vol. 7, no. 3, Article ID e33080, 2012.

[161] D. M. Widmaier and C. A. Voigt, "Quantification of the physiochemical constraints on the export of spider silk proteins by Salmonella type III secretion," Microbial Cell Factories, vol. 9, article 78, 2010.

[162] W. A. Hegazy, X. Xu, L. Metelitsa, and M. Hensel, "Evaluation of Salmonella enterica type III secretion system effector proteins as carriers for heterologous vaccine antigens," Infection and Immunity, vol. 80, no. 3, pp. 1193-1202, 2012.

[163] N. Holden, L. Pritchard, and I. Toth, "Colonization outwith the colon: plants as an alternative environmental reservoir for human pathogenic enterobacteria: review article," FEMS Microbiology Reviews, vol. 33, no. 4, pp. 689-703, 2009.

[164] J. D. Barak and B. K. Schroeder, "Interrelationships of food safety and plant pathology: the life cycle of human pathogens on plants," Annual Review of Phytopathology, vol. 50, pp. 241266, 2012.

[165] A. Schikora, A. V. Garcia, and H. Hirt, "Plants as alternative hosts for Salmonella," Trends in Plant Science, vol. 17, no. 5, pp. 245-249, 2012.

[166] M. M. Klerks, M. Van Gent-Pelzer, E. Franz, C. Zijlstra, and A. H. C. van Bruggen, "Physiological and molecular responses of Lactuca sativa to colonization by Salmonella enterica serovar Dublin," Applied and Environmental Microbiology, vol. 73, no. 15, pp. 4905-4914, 2007.

[167] A. Schikora, A. Carreri, E. Charpentier, and H. Hirt, "The dark side of the salad: Salmonella typhimurium overcomes the innate immune response of arabidopsis thaliana and shows an endopathogenic lifestyle," PLoS ONE, vol. 3, no. 5, Article ID e2279, 2008.

[168] J. D. G. Jones and J. L. Dangl, "The plant immune system," Nature, vol. 444, no. 7117, pp. 323-329, 2006.
[169] A. L. Iniguez, Y. Dong, H. D. Carter, B. M. M. Ahmer, J. M. Stone, and E. W. Triplett, "Regulation of enteric endophytic bacterial colonization by plant defenses," Molecular PlantMicrobe Interactions, vol. 18, no. 2, pp. 169-178, 2005.

[170] A. Schikora, I. Virlogeux-Payant, E. Bueso, A. V. Garcia, T. Nilau et al., "Conservation of Salmonella infection mechanisms in plants and animals," PLoS ONE, vol. 6, no. 9, Article ID e24112, 2011.

[171] N. Shirron and S. Yaron, "Active suppression of early immune response in tobacco by the human pathogen Salmonella typhimurium," PLoS ONE, vol. 6, no. 4, Article ID e18855, 2011.

[172] J. D. Barak, L. C. Kramer, and L. Y. Hao, "Colonization of tomato plants by Salmonella enterica is cultivar dependent, and type trichomes are preferred colonization sites," Applied and Environmental Microbiology, vol. 77, no. 2, pp. 498-504, 2011.

[173] S. Ustun, P. Muller, R. Palmisano, M. Hensel, and F. Bornke, "SseF, a type III effector protein from the mammalian pathogen Salmonella enterica, requires resistancegene-mediated signalling to activate cell death in the model plant Nicotiana benthamiana," New Phytologist, vol. 194, no. 4, pp. 1046-1060, 2012.

[174] W. D. Hardt and J. E. Galán, "A secreted Salmonella protein with homology to an avirulence determinant of plant pathogenic bacteria," Proceedings of the National Academy of Sciences of the United States of America, vol. 94, no. 18, pp. 9887-9892, 1997.

[175] L. S. Collier-Hyams, H. Zeng, J. Sun et al., "Cutting edge: Salmonella AvrA effector inhibits the key proinflammatory, anti-apoptotic NF- $\kappa$ B pathway," Journal of Immunology, vol. 169, no. 6, pp. 2846-2850, 2002.

[176] R. M. Jones, H. Wu, C. Wentworth, L. Luo, L. Collier-Hyams, and A. S. Neish, "Salmonella AvrA coordinates suppression of host immune and apoptotic defenses via JNK pathway blockade," Cell Host \& Microbe, vol. 3, no. 4, pp. 233-244, 2008.

[177] X. Liu, R. Lu, S. Wu, and J. Sun, "Salmonella regulation of intestinal stem cells through the Wnt/ $\beta$-catenin pathway," FEBS Letters, vol. 584, no. 5, pp. 911-916, 2010.

[178] X. Liu, R. Lu, S. Wu et al., "Wnt2 inhibits enteric bacterialinduced inflammation in intestinal epithelial cells," Inflammatory Bowel Diseases, vol. 18, no. 3, pp. 418-429, 2012.

[179] R. Mittal, S. Y. Peak-Chew, R. S. Sade, Y. Vallis, and H. T. McMahon, "The acetyltransferase activity of the bacterial toxin YopJ of Yersinia is activated by eukaryotic host cell inositol hexakisphosphate," The Journal of Biological Chemistry, vol. 285, no. 26, pp. 19927-19934, 2010.

[180] R. Lu, X. Liu, S. Wu, Y. Xia, Y. G. Zhang et al., "Consistent activation of the $\beta$-catenin pathway by Salmonella typethree secretion effector protein AvrA in chronically infected intestine," American Journal of Physiology, vol. 303, no. 10, pp. G1113-G1125, 2012.

[181] N. Figueroa-Bossi, S. Uzzau, D. Maloriol, and L. Bossi, "Variable assortment of prophages provides a transferable repertoire of pathogenic determinants in Salmonella," Molecular Microbiology, vol. 39, no. 2, pp. 260-271, 2001.

[182] B. K. Coombes, M. E. Wickham, N. F. Brown et al., "Genetic and molecular analysis of GogB, a phage-encoded type III-secreted substrate in Salmonella enterica serovar typhimurium with autonomous expression from its associated phage," Journal of Molecular Biology, vol. 348, no. 4, pp. 817-830, 2005. 
[183] A. V. C. Pilar, S. A. Reid-Yu, C. A. Cooper, D. T. Mulder, and B. K. Coombes, "GogB is an anti-inflammatory effector that limits tissue damage during Salmonella infection through interaction with human FBXO22 and Skp1," PLOS Pathogens, vol. 8, no. 6, Article ID e1002773, 2012.

[184] M. W. Wood, M. A. Jones, P. R. Watson, S. Hedges, T. S. Wallis, and E. E. Galyov, "Identification of a pathogenicity island required for Salmonella enteropathogenicity," Molecular Microbiology, vol. 29, no. 3, pp. 883-891, 1998.

[185] C. G. Pfeifer, S. L. Marcus, O. Steele-Mortimer, L. A. Knodler, and B. B. Finlay, "Salmonella typhimurium virulence genes are induced upon bacterial invasion into phagocytic and nonphagocytic cells," Infection and Immunity, vol. 67, no. 11, pp. 5690-5698, 1999.

[186] L. A. Knodler, J. Celli, W. D. Hardt, B. A. Vallance, C. Yip, and B. B. Finlay, "Salmonella effectors within a single pathogenicity island are differentially expressed and translocated by separate type III secretion systems," Molecular Microbiology, vol. 43 , no. 5 , pp. 1089-1103, 2002.

[187] F. Garcia-del Portillo, M. B. Zwick, Ka Yin Leung, and B. B. Finlay, "Salmonella induces the formation of filamentous structures containing lysosomal membrane glycoproteins in epithelial cells," Proceedings of the National Academy of Sciences of the United States of America, vol. 90, no. 22, pp. 10544-10548, 1993.

[188] L. A. Knodler, B. A. Vallance, M. Hensel, D. Jäckel, B. B. Finlay, and O. Steele-Mortimer, "Salmonella type III effectors PipB and PipB2 are targeted to detergent-resistant microdomains on internal host cell membranes," Molecular Microbiology, vol. 49, no. 3, pp. 685-704, 2003.

[189] E. Morgan, J. D. Campbell, S. C. Rowe et al., "Identification of host-specific colonization factors of Salmonella enterica serovar Typhimurium," Molecular Microbiology, vol. 54, no. 4, pp. 994-1010, 2004.

[190] S. Li, Z. Zhang, L. Pace, H. Lillehoj, and S. Zhang, "Functions exerted by the virulence-associated type-three secretion systems during Salmonella enterica serovar Enteritidis invasion into and survival within chicken oviduct epithelial cells and macrophages," Avian Pathology, vol. 38, no. 2, pp. 97-106, 2009.

[191] K. L. Ebers, C. Y. Zhang, M. Z. Zhang, R. H. Bailey, and S. Zhang, "Transcriptional profiling avian beta-defensins in chicken oviduct epithelial cells before and after infection with Salmonella enterica serovar Enteritidis," BMC Microbiology, vol. 9, article 153, 2009.

[192] S. Li, M. Z. Zhang, L. Yan, H. Lillehoj, L. W. Pace, and S. Zhang, "Induction of CXC chemokine messenger-RNA expression in chicken oviduct epithelial cells by Salmonella enterica serovar enteritidis via the type three secretion system-1," Avian Diseases, vol. 53, no. 3, pp. 396-404, 2009.

[193] L. A. Knodler and O. Steele-Mortimer, "Taking possession: biogenesis of the Salmonella-containing vacuole," Traffic, vol. 4, no. 9, pp. 587-599, 2003.

[194] S. Eriksson, S. Lucchini, A. Thompson, M. Rhen, and J. C. D. Hinton, "Unravelling the biology of macrophage infection by gene expression profiling of intracellular Salmonella enterica," Molecular Microbiology, vol. 47, no. 1, pp. 103-118, 2003.

[195] T. Henry, C. Couillault, P. Rockenfeller et al., “The Salmonella effector protein PipB2 is a linker for kinesin-1," Proceedings of the National Academy of Sciences of the United States of America, vol. 103, no. 36, pp. 13497-13502, 2006.

[196] F. Baison-Olmo, E. Cardenal-Munoz, and F. Ramos-Morales, "PipB2 is a substrate of the Salmonella pathogenicity island 1-encoded type III secretion system," Biochemical and Biophysical Research Communications, vol. 423, no. 2, pp. 240 246, 2012.

[197] M. A. Stein, K. Y. Leung, M. Zwick, F. Garcia-del Portillo, and B. B. Finlay, "Identification of a Salmonella virulence gene required for formation of filamentous structures containing lysosomal membrane glycoproteins within epithelial cells," Molecular Microbiology, vol. 20, no. 1, pp. 151-164, 1996.

[198] C. R. Beuzon, S. Meresse, K. E. Unsworth et al., "Salmonella maintains the integrity of its intracellular vacuole through the action of SifA," The EMBO Journal, vol. 19, no. 13, pp. 3235-3249, 2000.

[199] J. H. Brumell, C. M. Rosenberger, G. T. Gotto, S. L. Marcus, and B. B. Finlay, "SifA permits survival and replication of Salmonella typhimurium in murine macrophages," Cellular Microbiology, vol. 3, no. 2, pp. 75-84, 2001.

[200] I. Hansen-Wester, B. Stecher, and M. Hensel, "Type III secretion of Salmonella enterica serovar typhimurium translocated effectors and SseFG," Infection and Immunity, vol. 70, no. 3, pp. 1403-1409, 2002.

[201] C. R. Beuzón, S. P. Salcedo, and D. W. Holden, "Growth and killing of a Salmonella enterica serovar Typhimurium sifA mutant strain in the cytosol of different host cell lines," Microbiology, vol. 148, no. 9, pp. 2705-2715, 2002.

[202] J. H. Brumell, D. L. Goosney, and B. B. Finlay, "SifA, a type III secreted effector of Salmonella typhimurium, directs Salmonella-induced filament (Sif) formation along microtubules," Traffic, vol. 3, no. 6, pp. 407-415, 2002.

[203] J. Guignot, E. Caron, C. Beuzón et al., "Microtubule motors control membrane dynamics of Salmonella-containing vacuoles," Journal of Cell Science, vol. 117, no. 7, pp. 1033-1045, 2004.

[204] R. E. Harrison, J. H. Brumell, A. Khandani et al., "Salmonella impairs RILP recruitment to Rab7 during maturation of invasion vacuoles," Molecular Biology of the Cell, vol. 15, no. 7, pp. 3146-3154, 2004.

[205] J. H. Brumell, P. Tang, M. L. Zaharik, and B. B. Finlay, "Disruption of the Salmonella-containing vacuole leads to increased replication of Salmonella enterica serovar typhimurium in the cytosol of epithelial cells," Infection and Immunity, vol. 70, no. 6, pp. 3264-3270, 2002.

[206] E. A. Roark and K. Haldar, "Effects of lysosomal membrane protein depletion on the Salmonella-containing vacuole," PLoS ONE, vol. 3, no. 10, Article ID e3538, 2008.

[207] J. Ruiz-Albert, X. J. Yu, C. R. Beuzón, A. N. Blakey, E. E. Galyov, and D. W. Holden, "Complementary activities of SseJ and SifA regulate dynamics of the Salmonella typhimurium vacuolar membrane," Molecular Microbiology, vol. 44, no. 3, pp. 645-661, 2002.

[208] E. Boucrot, C. R. Beuzón, D. W. Holden, J. P. Gorvel, and S. Méresse, "Salmonella typhimurium SifA effector protein requires its membrane-anchoring C-terminal hexapeptide for its biological function," The Journal of Biological Chemistry, vol. 278, no. 16, pp. 14196-14202, 2003.

[209] A. T. Reinicke, J. L. Hutchinson, A. I. Magee, P. Mastroeni, J. Trowsdale, and A. P. Kelly, "A Salmonella typhimurium effector Protein SifA is modified by host cell prenylation and S-acylation machinery," The Journal of Biological Chemistry, vol. 280, no. 15, pp. 14620-14627, 2005.

[210] E. Boucrot, T. Henry, J. P. Borg, J. P. Gorvel, and S. Méresse, "The intracellular fate of Salmonella depends on the recruitment of kinesin," Science, vol. 308, no. 5725, pp. 11741178,2005 
[211] L. Diacovich, A. Dumont, D. Lafitte et al., "Interaction between the SifA virulence factor and its host target SKIP is essential for Salmonella pathogenesis," The Journal of Biological Chemistry, vol. 284, no. 48, pp. 33151-33160, 2009.

[212] M. B. Ohlson, Z. Huang, N. M. Alto et al., "Structure and function of Salmonella SifA indicate that its interactions with SKIP, SseJ, and RhoA family GTPases induce endosomal tubulation," Cell Host \& Microbe, vol. 4, no. 5, pp. 434-446, 2008.

[213] A. Dumont, E. Boucrot, S. Drevensek et al., "SKIP, the host target of the Salmonella virulence factor SifA, promotes kinesin-1-dependent vacuolar membrane exchanges," Traffic, vol. 11, no. 7, pp. 899-911, 2010.

[214] N. M. Alto, F. Shao, C. S. Lazar et al., "Identification of a bacterial type III effector family with $\mathrm{G}$ protein mimicry functions," Cell, vol. 124, no. 1, pp. 133-145, 2006.

[215] R. C. Orchard and N. M. Alto, "Mimicking GEFs: a common theme for bacterial pathogens," Cellular Microbiology, vol. 14, no. 1, pp. 10-18, 2012.

[216] D. B. N. Vinh, D. C. Ko, R. A. Rachubinski, J. D. Aitchison, and S. I. Miller, "Expression of the Salmonella spp. virulence factor SifA in yeast alters Rhol activity on peroxisomes," Molecular Biology of the Cell, vol. 21, no. 20, pp. 3567-3577, 2010.

[217] A. Arbeloa, J. Garnett, J. Lillington et al., "EspM2 is a RhoA guanine nucleotide exchange factor," Cellular Microbiology, vol. 12, no. 5, pp. 654-664, 2010.

[218] L. K. Jackson, P. Nawabi, C. Hentea, E. A. Roark, and K. Haldar, "The Salmonella virulence protein SifA is a G protein antagonist," Proceedings of the National Academy of Sciences of the United States of America, vol. 105, no. 37, pp. 1414114146, 2008.

[219] J. A. Freeman, M. E. Ohl, and S. I. Miller, "The Salmonella enterica serovar typhimurium translocated effectors SseJ and SifB are targeted to the Salmonella-containing vacuole," Infection and Immunity, vol. 71, no. 1, pp. 418-427, 2003.

[220] K. Kaniga, D. Trollinger, and J. E. Galan, "Identification of two targets of the type III protein secretion system encoded by the inv and spa loci of Salmonella typhimurium that have homology to the Shigella IpaD and IpaA proteins," Journal of Bacteriology, vol. 177, no. 24, pp. 7078-7085, 1995.

[221] M. A. Jepson, B. Kenny, and A. D. Leard, "Role of sipA in the early stages of Salmonella typhimurium entry into epithelial cells," Cellular Microbiology, vol. 3, no. 6, pp. 417-426, 2001.

[222] M. Raffatellu, Y. H. Sun, R. P. Wilson et al., "Host restriction of Salmonella enterica serotype typhi is not caused by functional alteration of SipA, SopB, or SopB," Infection and Immunity, vol. 73, no. 12, pp. 7817-7826, 2005.

[223] M. C. Schlumberger, R. Käppeli, M. Wetter et al., "Two newly identified SipA domains (F1, F2) steer effector protein localization and contribute to Salmonella host cell manipulation," Molecular Microbiology, vol. 65, no. 3, pp. 741-760, 2007.

[224] C. A. Lee, M. Silva, A. M. Siber, A. J. Kelly, E. Galyov, and B. A. McCormick, "A secreted Salmonella protein induces a proinflammatory response in epithelial cells, which promotes neutrophil migration," Proceedings of the National Academy of Sciences of the United States of America, vol. 97, no. 22, pp. 12283-12288, 2000.

[225] M. Silva, C. Song, W. J. Nadeau, J. B. Matthews, and B. A. McCormick, "Salmonella typhimurium SipA-induced neutrophil transepithelial migration: involvement of a PKC$\alpha$-dependent signal transduction pathway," American Journal of Physiology, vol. 286, no. 6, pp. G1024-G1031, 2004.
[226] D. M. Wall, W. J. Nadeau, M. A. Pazos, H. N. Shi, E. E. Galyov, and B. A. Mccormick, "Identification of the Salmonella enterica serotype Typhimurium SipA domain responsible for inducing neutrophil recruitment across the intestinal epithelium," Cellular Microbiology, vol. 9, no. 9, pp. 22992313, 2007.

[227] T. A. Agbor, Z. C. Demma, K. L. Mumy, J. D. Bien, and B. A. McCormick, "The ERM protein, ezrin, regulates neutrophil transmigration by modulating the apical localization of MRP2 in response to the SipA effector protein during Salmonella typhimurium infection," Cellular Microbiology, vol. 13, no. 12, pp. 2007-2021, 2011.

[228] S. Hapfelmeier, K. Ehrbar, B. Stecher, M. Barthel, M. Kremer, and W. D. Hardt, "Role of the Salmonella pathogenicity island 1 effector proteins SipA, SopB, SopE, and SopE2 in Salmonella enterica subspecies 1 serovar Typhimurium colitis in streptomycin-pretreated mice," Infection and Immunity, vol. 72, no. 2, pp. 795-809, 2004.

[229] S. Zhang, R. L. Santos, R. M. Tsolis et al., "The Salmonella enterica serotype Typhimurium effector proteins SipA, SopA, SopB, SopD, and SopE2 act in concert to induce diarrhea in calves," Infection and Immunity, vol. 70, no. 7, pp. 3843-3855, 2002.

[230] A. M. Keestra, M. G. Winter, D. Klein-Douwel, M. N. Xavier, S. E. Winter et al., "A Salmonella virulence factor activates the NOD1/NOD2 signaling pathway," mBio, vol. 2, no. 6, Article ID e00266-11, 2011.

[231] J. F. Figueiredo, S. D. Lawhon, K. Gokulan et al., "Salmonella enterica Typhimurium SipA induces CXCchemokine expression through p38MAPK and JUN pathways," Microbes and Infection, vol. 11, no. 2, pp. 302-310, 2009.

[232] L. C. Brawn, R. D. Hayward, and V. Koronakis, "Salmonella SPI1 effector SipA persists after entry and cooperates with a SPI2 effector to regulate phagosome maturation and intracellular replication," Cell Host \& Microbe, vol. 1, no. 1, pp. 63-75, 2007.

[233] M. N. Giacomodonato, S. Uzzau, D. Bacciu et al., "SipA, SopA, SopB, SopD, and SopE2 effector proteins of Salmonella enterica serovar Typhimurium are synthesized at late stages of infection in mice," Microbiology, vol. 153, no. 4, pp. 12211228, 2007.

[234] D. Hermant, R. Menard, N. Arricau, C. Parsot, and M. Y. Popoff, "Functional conservation of the Salmonella and Shigella effectors of entry into epithelial cells," Molecular Microbiology, vol. 17, no. 4, pp. 781-789, 1995.

[235] K. Kaniga, S. Tucker, D. Trollinger, and J. E. Galan, "Homologs of the Shigella IpaB and IpaC invasins are required for Salmonella typhimurium entry into cultured epithelial cells," Journal of Bacteriology, vol. 177, no. 14, pp. 3965-3971, 1995.

[236] C. M. Collazo and J. E. Galán, "The invasion-associated type III system of Salmonella typhimurium directs the translocation of Sip proteins into the host cell," Molecular Microbiology, vol. 24, no. 4, pp. 747-756, 1997.

[237] M. Lara-Tejero and J. E. Galán, "Salmonella enterica serovar Typhimurium pathogenicity island 1-encoded type III secretion system translocases mediate intimate attachment to nonphagocytic cells," Infection and Immunity, vol. 77, no. 7, pp. 2635-2642, 2009.

[238] S. Chatterjee, D. Zhong, B. A. Nordhues, K. P. Battaile, S. Lovell, and R. N. De Guzman, "The crystal structures of the Salmonella type III secretion system tip protein SipD in 
complex with deoxycholate and chenodeoxycholate," Protein Science, vol. 20, no. 1, pp. 75-86, 2011.

[239] M. Lunelli, R. Hurwitz, J. Lambers, and M. Kolbe, "Crystal structure of PrgI-SipD: insight into a secretion competent state of the type three secretion system needle tip and its interaction with host ligands," PLOS Pathogens, vol. 7, no. 8, Article ID e1002163, 2011.

[240] Y. Wang, B. A. Nordhues, D. Zhong, and R. N. De Guzman, "NMR characterization of the interaction of the Salmonella type III secretion system protein $\mathrm{SipD}$ and bile salts," Biochemistry, vol. 49, no. 19, pp. 4220-4226, 2010.

[241] A. M. Prouty and J. S. Gunn, "Salmonella enterica serovar typhimurium invasion is repressed in the presence of bile," Infection and Immunity, vol. 68, no. 12, pp. 6763-6769, 2000.

[242] D. Dreher, M. Kok, C. Obregon, S. G. Kiama, P. Gehr, and L. P. Nicod, "Salmonella virulence factor SipB induces activation and release of IL-18 in human dendritic cells," Journal of Leukocyte Biology, vol. 72, no. 4, pp. 743-751, 2002.

[243] C. Obregon, D. Dreher, M. Kok, L. Cochand, G. S. Kiama, and L. P. Nicod, "Human alveolar macrophages infected by virulent bacteria expressing SipB are a major source of active interleukin-18," Infection and Immunity, vol. 71, no. 8, pp. 4382-4388, 2003.

[244] R. D. Hayward and V. Koronakis, "Direct nucleation and bundling of actin by the SipC protein of invasive Salmonella," The EMBO Journal, vol. 18, no. 18, pp. 4926-4934, 1999.

[245] S. A. Carlson, M. B. Omary, and B. D. Jones, "Identification of cytokeratins as accessory mediators of Salmonella entry into eukaryotic cells," Life Sciences, vol. 70, no. 12, pp. 1415-1426, 2002.

[246] C. A. Scherer, E. Cooper, and S. I. Miller, "The Salmonella type III secretion translocon protein SspC is inserted into the epithelial cell plasma membrane upon infection," Molecular Microbiology, vol. 37, no. 5, pp. 1133-1145, 2000.

[247] R. Madan, R. Rastogi, S. Parashuraman, and A. Mukhopadhyay, "Salmonella acquires lysosome-associated membrane protein 1 (LAMP1) on phagosomes from Golgi via SipC protein-mediated recruitment of host Syntaxin6," The Journal of Biological Chemistry, vol. 287, no. 8, pp. 5574-5587, 2012.

[248] R. M. Tsolis, L. G. Adams, T. A. Ficht, and A. J. Bäumler, "Contribution of Salmonella typhimurium virulence factors to diarrheal disease in calves," Infection and Immunity, vol. 67, no. 9, pp. 4879-4885, 1999.

[249] E. A. Miao, C. A. Scherer, R. M. Tsolis et al., "Salmonella typhimurium leucine-rich repeat proteins are targeted to the SPl1 and SPl2 type III secretion systems," Molecular Microbiology, vol. 34, no. 4, pp. 850-864, 1999.

[250] B. Kobe and A. V. Kajava, "The leucine-rich repeat as a protein recognition motif," Current Opinion in Structural Biology, vol. 11, no. 6, pp. 725-732, 2001.

[251] J. R. Rohde, A. Breitkreutz, A. Chenal, P. J. Sansonetti, and C. Parsot, "Type III secretion effectors of the IpaH family are E3 ubiquitin ligases," Cell Host \& Microbe, vol. 1, no. 1, pp. 77-83, 2007.

[252] A. U. Singer, J. R. Rohde, R. Lam et al., "Structure of the Shigella T3SS effector IpaH defines a new class of E3 ubiquitin ligases," Nature Structural and Molecular Biology, vol. 15, no. 12, pp. 1293-1301, 2008.

[253] Y. Zhu, H. Li, L. Hu et al., "Structure of a Shigella effector reveals a new class of ubiquitin ligases," Nature Structural and Molecular Biology, vol. 15, no. 12, pp. 1302-1308, 2008.

[254] M. W. Wood, M. A. Jones, P. R. Watson et al., "The secreted effector protein of Salmonella dublin, SopA, is translocated into eukaryotic cells and influences the induction of enteritis," Cellular Microbiology, vol. 2, no. 4, pp. 293-303, 2000.

[255] A. N. Layton, P. J. Brown, and E. E. Galyov, "The Salmonella translocated effector SopA is targeted to the mitochondria of infected cells," Journal of Bacteriology, vol. 187, no. 10, pp. 3565-3571, 2005.

[256] M. Raffatellu, R. P. Wilson, D. Chessa et al., "SipA, SopA, SopB, SopD, and SopE2 contribute to Salmonella enterica serotype typhimurium invasion of epithelial cells," Infection and Immunity, vol. 73, no. 1, pp. 146-154, 2005.

[257] J. Diao, Y. Zhang, J. M. Huibregtse, D. Zhou, and J. Chen, "Crystal structure of SopA, a Salmonella effector protein mimicking a eukaryotic ubiquitin ligase," Nature Structural and Molecular Biology, vol. 15, no. 1, pp. 65-70, 2008.

[258] K. H. Hong and V. L. Miller, "Identification of a novel Salmonella invasion locus homologous to Shigella ipgDE," Journal of Bacteriology, vol. 180, no. 7, pp. 1793-1802, 1998.

[259] E. E. Galyov, M. W. Wood, R. Rosqvist et al., "A secreted effector protein of Salmonella dublin is translocated into eukaryotic cells and mediates inflammation and fluid secretion in infected ileal mucosa," Molecular Microbiology, vol. 25, no. 5, pp. 903-912, 1997.

[260] F. A. Norris, M. P. Wilson, T. S. Wallis, E. E. Galyov, and P. W. Majerus, "SopB, a protein required for virulence of Salmonella dublin, is an inositol phosphate phosphatase," Proceedings of the National Academy of Sciences of the United States of America, vol. 95, no. 24, pp. 14057-14059, 1998.

[261] S. L. Marcus, M. R. Wenk, O. Steele-Mortimer, and B. B. Finlay, "A synaptojanin-homologous region of Salmonella typhimurium SigD is essential for inositol phosphatase activity and Akt activation," FEBS Letters, vol. 494, no. 3, pp. 201-207, 2001.

[262] D. Zhou, L. M. Chen, L. Hernandez, S. B. Shears, and J. E. Galán, "A Salmonella inositol polyphosphatase acts in conjunction with other bacterial effectors to promote host cell actin cytoskeleton rearrangements and bacterial internalization," Molecular Microbiology, vol. 39, no. 2, pp. 248-259, 2001.

[263] L. D. Hernandez, K. Hueffer, M. R. Wenk, and J. E. Galán, "Salmonella modulates vesicular traffic by altering phosphoinositide metabolism," Science, vol. 304, no. 5678, pp. 1805-1807, 2004.

[264] L. A. Knodler, B. Finlay, and O. Steele-Mortimer, "The Salmonella effector protein SopB protects epithelial cells from apoptosis by sustained activation of Akt," The Journal of Biological Chemistry, vol. 280, no. 10, pp. 9058-9064, 2005.

[265] L. D. Rogers, N. F. Brown, Y. Fang, S. Pelech, and L. J. Foster, "Phosphoproteomic analysis of Salmonella-infected cells identifies key kinase regulators and SopB-dependent host phosphorylation events," Science Signaling, vol. 4, no. 191, p. rs9, 2011.

[266] L. S. Bertelsen, G. Paesold, S. L. Marcus, B. B. Finlay, L. Eckmann, and K. E. Barrett, "Modulation of chloride secretory responses and barrier function of intestinal epithelial cells by the Salmonella effector protein SigD," American Journal of Physiology, vol. 287, no. 4, pp. C939-C948, 2004.

[267] A. Alemán, I. Rodríguez-Escudero, G. V. Mallo, V. J. Cid, M. Molina, and R. Rotger, "The amino-terminal noncatalytic region of Salmonella typhimurium SigD affects actin organization in yeast and mammalian cells," Cellular Microbiology, vol. 7, no. 10, pp. 1432-1446, 2005.

[268] L. D. Rogers, A. R. Kristensen, E. C. Boyle et al., "Identification of cognate host targets and specific ubiquitylation 
sites on the Salmonella SPI-1 effector SopB/SigD," Journal of Proteomics, vol. 71, no. 1, pp. 97-108, 2008.

[269] I. Rodríguez-Escudero, N. L. Ferrer, R. Rotger, V. J. Cid, and M. Molina, "Interaction of the Salmonella typhimurium effector protein SopB with host cell Cdc42 is involved in intracellular replication," Molecular Microbiology, vol. 80, no. 5, pp. 1220-1240, 2011.

[270] S. L. Marcus, L. A. Knodler, and B. B. Finlay, "Salmonella enterica serovar Typhimurium effector SigD/SopB is membrane-associated and ubiquitinated inside host cells," Cellular Microbiology, vol. 4, no. 7, pp. 435-446, 2002.

[271] J. C. Patel, K. Hueffer, T. T. Lam, and J. E. Galán, "Diversification of a Salmonella virulence protein function by ubiquitindependent differential localization," Cell, vol. 137, no. 2, pp. 283-294, 2009.

[272] J. H. Brumell, S. Kujat-Choy, N. F. Brown, B. A. Vallance, L. A. Knodler, and B. B. Finlay, "SopD2 is a novel type III secreted effector of Salmonella typhimurium that targets late endocytic compartments upon delivery into host cells," Traffic, vol. 4, no. 1, pp. 36-48, 2003.

[273] M. A. Jones, M. W. Wood, P. B. Mullan, P. R. Watson, T. S. Wallis, and E. E. Galyov, "Secreted effector proteins of Salmonella dublin act in concert to induce enteritis," Infection and Immunity, vol. 66, no. 12, pp. 5799-5804, 1998.

[274] M. A. Bakowski, J. T. Cirulis, N. F. Brown, B. B. Finlay, and J. H. Brumell, "SopD acts cooperatively with SopB during Salmonella enterica serovar Typhimurium invasion," Cellular Microbiology, vol. 9, no. 12, pp. 2839-2855, 2007.

[275] X. Jiang, O. W. Rossanese, N. F. Brown et al., "The related effector proteins SopD and SopD2 from Salmonella enterica serovar Typhimurium contribute to virulence during systemic infection of mice," Molecular Microbiology, vol. 54, no. 5, pp. 1186-1198, 2004.

[276] M. W. Wood, R. Rosqvist, P. B. Mullan, M. H. Edwards, and E. E. Galyov, "SopE, a secreted protein of Salmonella dublin, is translocated into the target eukaryotic cell via a sip-dependent mechanism and promotes bacterial entry," Molecular Microbiology, vol. 22, no. 2, pp. 327-338, 1996.

[277] R. J. Cain, R. D. Hayward, and V. Koronakis, "The target cell plasma membrane is a critical interface for Salmonella cell entry effector-host interplay," Molecular Microbiology, vol. 54, no. 4, pp. 887-904, 2004.

[278] M. G. Rudolph, C. Weise, S. Mirold et al., "Biochemical analysis of SopE from Salmonella typhimurium, a highly efficient guanosine nucleotide exchange factor for RhoGTPases," The Journal of Biological Chemistry, vol. 274, no. 43, pp. 3050130509, 1999.

[279] D. Humphreys, A. Davidson, P. J. Hume, and V. Koronakis, "Salmonella virulence effector SopE and Host GEF ARNO cooperate to recruit and activate WAVE to trigger bacterial invasion," Cell Host \& Microbe, vol. 11, no. 2, pp. 129-139, 2012.

[280] A. J. Müller, C. Hoffmann, M. Galle et al., "The $S$. typhimurium effector SopE induces caspase-1 activation in stromal cells to initiate gut inflammation," Cell Host \& Microbe, vol. 6, no. 2, pp. 125-136, 2009.

[281] W. D. Hardt, H. Urlaub, and J. E. Galán, "A substrate of the centisome 63 type III protein secretion system of Salmonella typhimurium is encoded by a cryptic bacteriophage," Proceedings of the National Academy of Sciences of the United States of America, vol. 95, no. 5, pp. 2574-2579, 1998.

[282] S. Mirold, W. Rabsch, M. Rohde et al., "Isolation of a temperate bacteriophage encoding the type III effector protein SopE from an epidemic Salmonella typhimurium strain,"
Proceedings of the National Academy of Sciences of the United States of America, vol. 96, no. 17, pp. 9845-9850, 1999.

[283] K. Ehrbar and W. D. Hardt, "Bacteriophage-encoded type III effectors in Salmonella enterica subspecies 1 serovar Typhimurium," Infection, Genetics and Evolution, vol. 5, no. 1, pp. 1-9, 2005.

[284] C. A. Lopez, S. E. Winter, F. Rivera-Chávez et al., "Phagemediated acquisition of a type III secreted effector protein boosts growth of Salmonella by nitrate respiration," mBio, vol. 3, no. 3, Article ID e00143-12, 2012.

[285] C. S. Bakshi, V. P. Singh, M. W. Wood, P. W. Jones, T. S. Wallis, and E. E. Galyov, "Identification of SopE2, a Salmonella secreted protein which is highly homologous to SopE and involved in bacterial invasion of epithelial cells," Journal of Bacteriology, vol. 182, no. 8, pp. 2341-2344, 2000.

[286] A. Friebel, H. Ilchmann, M. Aepfelbacher, K. Ehrbar, W. Machleidt, and W. D. Hardt, "SopE and SopE2 from Salmonella typhimurium activate different sets of RhoGTPases of the host cell," The Journal of Biological Chemistry, vol. 276, no. 36, pp. 34035-34040, 2001.

[287] B. J. Cherayil, B. A. McCormick, and J. Bosley, "Salmonella enterica serovar typhimurium-dependent regulation of inducible nitric oxide synthase expression in macrophages by invasins SipB, SipC, and SipD and effector SopE2," Infection and Immunity, vol. 68, no. 10, pp. 5567-5574, 2000.

[288] F. C. Huang, A. Werne, Q. Li, E. E. Galyov, W. A. Walker, and B. J. Cherayil, "Cooperative interactions between flagellin and SopE2 in the epithelial interleukin-8 response to Salmonella enterica serovar typhimurium infection," Infection and Immunity, vol. 72, no. 9, pp. 5052-5062, 2004.

[289] M. Hensel, J. E. Shea, S. R. Waterman et al., "Genes encoding putative effector proteins of the type III secretion system of Salmonella pathogenicity island 2 are required for bacterial virulence and proliferation in macrophages," Molecular Microbiology, vol. 30, no. 1, pp. 163-174, 1998.

[290] K. I. Uchiya, M. A. Barbieri, K. Funato, A. H. Shah, P. D. Stahl, and E. A. Groisman, "A Salmonella virulence protein that inhibits cellular trafficking," The EMBO Journal, vol. 18, no. 14, pp. 3924-3933, 1999.

[291] A. H. Lee, M. P. Zareei, and S. Daefler, "Identification of a NIPSNAP homologue as host cell target for Salmonella virulence protein SpiC," Cellular Microbiology, vol. 4, no. 11, pp. 739-750, 2002.

[292] Y. Shotland, H. Krämer, and E. A. Groisman, "The Salmonella SpiC protein targets the mammalian Hook3 protein function to alter cellular trafficking," Molecular Microbiology, vol. 49, no. 6, pp. 1565-1576, 2003.

[293] C. Buechler, M. Bodzioch, S. M. Bared et al., "Expression pattern and raft association of NIPSNAP3 and NIPSNAP4, highly homologous proteins encoded by genes in close proximity to the ATP-binding cassette transporter A1," Genomics, vol. 83, no. 6, pp. 1116-1124, 2004.

[294] A. M. Verhagen, T. K. Kratina, C. J. Hawkins, J. Silke, P. G. Ekert, and D. L. Vaux, "Identification of mammalian mitochondrial proteins that interact with IAPs via $\mathrm{N}$ terminal IAP binding motifs," Cell Death and Differentiation, vol. 14, no. 2, pp. 348-357, 2007.

[295] L. Xu, M. E. Sowa, J. Chen, X. Li, S. P. Gygi, and J. W. Harper, "An FTS/Hook/p107FHIP complex interacts with and promotes endosomal clustering by the homotypic vacuolar protein sorting complex," Molecular Biology of the Cell, vol. 19, no. 12, pp. 5059-5071, 2008.

[296] X. Ge, C. L. Frank, F. Calderon de Anda, and L. H. Tsai, "Hook3 interacts with PCM1 to regulate pericentriolar 
material assembly and the timing of neurogenesis," Neuron, vol. 65 , no. 2, pp. 191-203, 2010.

[297] J. A. Freeman, C. Rappl, V. Kuhle, M. Hensel, and S. I. Miller, "SpiC is required for translocation of Salmonella pathogenicity island 2 effectors and secretion of translocon proteins SseB and SseC," Journal of Bacteriology, vol. 184, no. 18, pp. 4971-4980, 2002.

[298] X. J. Yu, J. Ruiz-Albert, K. E. Unsworth, S. Garvis, M. Liu, and D. W. Holden, "SpiC is required for secretion of Salmonella pathogenicity Island 2 type III secretion system proteins," Cellular Microbiology, vol. 4, no. 8, pp. 531-540, 2002.

[299] X. J. Yu, M. Liu, and D. W. Holden, "SsaM and SpiC interact and regulate secretion of Salmonella pathogenicity Island 2 type III secretion system effectors and translocators," Molecular Microbiology, vol. 54, no. 3, pp. 604-619, 2004.

[300] X. J. Yu, K. McGourty, M. Liu, K. E. Unsworth, and D. W. Holden, "pH sensing by intracellular Salmonella induces effector translocation," Science, vol. 328, no. 5981, pp. 1040 1043, 2010.

[301] K. Kaniga, J. Uralil, J. B. Bliska, and J. E. Galán, "A secreted protein tyrosine phosphatase with modular effector domains in the bacterial pathogen Salmonella typhimurium," Molecular Microbiology, vol. 21, no. 3, pp. 633-641, 1996.

[302] Y. Fu and J. E. Galán, "The Salmonella typhimurium tyrosine phosphatase SptP is translocated into host cells and disrupts the actin cytoskeleton," Molecular Microbiology, vol. 27, no. 2, pp. 359-368, 1998.

[303] S. L. Lin, T. X. Le, and D. S. Cowen, "SptP, a Salmonella typhimurium type III-secreted protein, inhibits the mitogenactivated protein kinase pathway by inhibiting Raf activation," Cellular Microbiology, vol. 5, no. 4, pp. 267-275, 2003.

[304] A. Haraga and S. I. Miller, "A Salmonella enterica serovar Typhimurium translocated leucine-rich repeat effector protein inhibits NF- $\kappa \mathrm{B}-$ dependent gene expression," Infection and Immunity, vol. 71, no. 7, pp. 4052-4058, 2003.

[305] Y. Ye, "Diverse functions with a common regulator: ubiquitin takes command of an AAA ATPase," Journal of Structural Biology, vol. 156, no. 1, pp. 29-40, 2006.

[306] R. Rotger and J. Casadesus, "The virulence plasmids of Salmonella," International Microbiology, vol. 2, no. 3, pp. 177184, 1999.

[307] E. F. Boyd and D. L. Hartl, "Salmonella virulence plasmid: modular acquisition of the spv virulence region by an Fplasmid in Salmonella enterica subspecies I and insertion into the chromosome of subspecies II, IIIa, IV and VII isolates," Genetics, vol. 149, no. 3, pp. 1183-1190, 1998.

[308] H. Hochmann, S. Pust, G. Von Figura, K. Aktories, and H. Barth, "Salmonella enterica SpvB ADP-ribosylates actin at position arginine-177-characterization of the catalytic domain within the SpvB protein and a comparison to binary clostridial actin-ABP-ribosylating toxins," Biochemistry, vol. 45, no. 4, pp. 1271-1277, 2006.

[309] M. L. Lesnick, N. E. Reiner, J. Fierer, and D. G. Guiney, "The Salmonella spvB virulence gene encodes an enzyme that ADP-ribosylates actin and destabilizes the cytoskeleton of eukaryotic cells," Molecular Microbiology, vol. 39, no. 6, pp. 1464-1470, 2001.

[310] S. M. Margarit, W. Davidson, L. Frego, and C. E. Stebbins, "A steric antagonism of actin polymerization by a Salmonella virulence protein," Structure, vol. 14, no. 8, pp. 1219-1229, 2006.

[311] D. Tezcan-Merdol, T. Nyman, U. Lindberg, F. Haag, F. Koch-Nolte, and M. Rhen, "Actin is ADP-ribosylated by the Salmonella enterica virulence-associated protein SpvB," Molecular Microbiology, vol. 39, no. 3, pp. 606-619, 2001.

[312] E. A. Miao, M. Brittnacher, A. Haraga, R. L. Jeng, M. D. Welch, and S. I. Miller, "Salmonella effectors translocated across the vacuolar membrane interact with the actin cytoskeleton," Molecular Microbiology, vol. 48, no. 2, pp. 401415, 2003.

[313] C. L. Birmingham, X. Jiang, M. B. Ohlson, S. I. Miller, and J. H. Brumell, "Salmonella-induced filament formation is a dynamic phenotype induced by rapidly replicating Salmonella enterica serovar typhimurium in epithelial cells," Infection and Immunity, vol. 73, no. 2, pp. 1204-1208, 2005.

[314] S. H. Browne, M. L. Lesnick, and D. G. Guiney, "Genetic requirements for Salmonella-induced cytopathology in human monocyte-derived macrophages," Infection and Immunity, vol. 70, no. 12, pp. 7126-7135, 2002.

[315] A. Kurita, H. Gotoh, M. Eguchi et al., "Intracellular expression of the Salmonella plasmid virulence protein, SpvB, causes apoptotic cell death in eukaryotic cells," Microbial Pathogenesis, vol. 35, no. 1, pp. 43-48, 2003.

[316] H. Gotoh, N. Okada, Y. G. Kim et al., "Extracellular secretion of the virulence plasmid-encoded ADP-ribosyltransferase SpvB in Salmonella," Microbial Pathogenesis, vol. 34, no. 5, pp. 227-238, 2003.

[317] S. H. Browne, P. Hasegawa, S. Okamoto, J. Fierer, and D. G. Guiney, "Identification of Salmonella SPI-2 secretion system components required for SpvB-mediated cytotoxicity in macrophages and virulence in mice," FEMS Immunology and Medical Microbiology, vol. 52, no. 2, pp. 194-201, 2008.

[318] P. Mazurkiewicz, J. Thomas, J. A. Thompson et al., "SpvC is a Salmonella effector with phosphothreonine lyase activity on host mitogen-activated protein kinases," Molecular Microbiology, vol. 67, no. 6, pp. 1371-1383, 2008.

[319] T. Haneda, Y. Ishii, H. Shimizu, K. Ohshima, N. Iida et al., "Salmonella type III effector SpvC, a phosphothreonine lyase, contributes to reduction in inflammatory response during intestinal phase of infection," Cellular Microbiology, vol. 14, no. 4, pp. 485-499, 2012.

[320] H. Li, H. Xu, Y. Zhou et al., "The phosphothreonine lyase activity of a bacterial type III effector family," Science, vol. 315, no. 5814, pp. 1000-1003, 2007.

[321] D. F. Brennan and D. Barford, "Eliminylation: a posttranslational modification catalyzed by phosphothreonine lyases," Trends in Biochemical Sciences, vol. 34, no. 3, pp. 108114, 2009.

[322] L. Chen, H. Wang, J. Zhang et al., "Structural basis for the catalytic mechanism of phosphothreonine lyase," Nature Structural and Molecular Biology, vol. 15, no. 1, pp. 101-102, 2008.

[323] Z. Ke, G. K. Smith, Y. Zhang, and H. Guo, "Molecular mechanism for eliminylation, a newly discovered posttranslational modification," Journal of the American Chemical Society, vol. 133, no. 29, pp. 11103-11105, 2011.

[324] G. K. Smith, Z. Ke, A. C. Hengge, D. Xu, D. Xie, and H. Guo, "Active-site dynamics of SpvC virulence factor from Salmonella typhimurium and density functional theory study of phosphothreonine lyase catalysis," Journal of Physical Chemistry B, vol. 113, no. 46, pp. 15327-15333, 2009.

[325] Y. Zhu, H. Li, C. Long et al., "Structural insights into the enzymatic mechanism of the pathogenic MAPK phosphothreonine lyase," Molecular Cell, vol. 28, no. 5, pp. 899-913, 2007.

[326] M. Cordero-Alba, J. Bernal-Bayard, and F. Ramos-Morales, "Srf): a Salmonella type III secretion system effector regulated 
by PhoP, RcsB and IolR," Journal of Bacteriology, vol. 194, no. 16, pp. 4226-4236, 2012.

[327] D. Canals, D. M. Perry, R. W. Jenkins, and Y. A. Hannun, "Drug targeting of sphingolipid metabolism: sphingomyelinases and ceramidases," British Journal of Pharmacology, vol. 163, no. 4, pp. 694-712, 2011.

[328] C. Kröger and T. M. Fuchs, "Characterization of the myoinositol utilization island of Salmonella enterica serovar Typhimurium," Journal of Bacteriology, vol. 191, no. 2, pp. 545-554, 2009.

[329] C. R. Beuzón, G. Banks, J. Deiwick, M. Hensel, and D. W. Holden, "pH-dependent secretion of $\mathrm{SseB}$, a product of the SPI-2 type III secretion system of Salmonella typhimurium," Molecular Microbiology, vol. 33, no. 4, pp. 806-816, 1999.

[330] J. R. Klein and B. D. Jones, "Salmonella pathogenicity island 2-encoded proteins SseC and SseD are essential for virulence and are substrates of the type III secretion system," Infection and Immunity, vol. 69, no. 2, pp. 737-743, 2001.

[331] T. Nikolaus, J. Deiwick, C. Rappl et al., "SseBCD proteins are secreted by the type III secretion system of Salmonella pathogenicity island 2 and function as a translocon," Journal of Bacteriology, vol. 183, no. 20, pp. 6036-6045, 2001.

[332] V. Kuhle and M. Hensel, "SseF and SseG are translocated effectors of the type III secretion system of Salmonella pathogenicity island 2 that modulate aggregation of endosomal compartments," Cellular Microbiology, vol. 4, no. 12, pp. 813-824, 2002.

[333] R. L. Guy, L. A. Gonias, and M. A. Stein, "Aggregation of host endosomes by Salmonella requires SPI2 translocation of SseFG and involves SpvR and the fms-aroE intragenic region," Molecular Microbiology, vol. 37, no. 6, pp. 14171435, 2000.

[334] P. Müller, D. Chikkaballi, and M. Hensel, "Functional dissection of SseF, a membrane-integral effector protein of intracellular Salmonella enterica," PLOS ONE, vol. 7, no. 4, Article ID e35004, 2012.

[335] V. Kuhle, D. Jäckel, and M. Hensel, "Effector proteins encoded by Salmonella pathogenicity island 2 interfere with the microtubule cytoskeleton after translocation into host cells," Traffic, vol. 5, no. 5, pp. 356-370, 2004.

[336] G. L. Abrahams, P. Müller, and M. Hensel, "Functional dissection of SseF, a type III effector protein involved in positioning the Salmonella-containing vacuole," Traffic, vol. 7, no. 8, pp. 950-965, 2006.

[337] S. P. Salcedo and D. W. Holden, "SseG, a virulence protein that targets Salmonella to the Golgi network," The EMBO Journal, vol. 22, no. 19, pp. 5003-5014, 2003.

[338] V. Kuhle, G. L. Abrahams, and M. Hensel, "Intracellular Salmonella enterica redirect exocytic transport processes in a Salmonella pathogenicity island 2-dependent manner," Traffic, vol. 7, no. 6, pp. 716-730, 2006.

[339] A. E. Ramsden, D. W. Holden, and L. J. Mota, "Membrane dynamics and spatial distribution of Salmonella-containing vacuoles," Trends in Microbiology, vol. 15, no. 11, pp. 516524, 2007.

[340] T. Henry, J. P. Gorvel, and S. Méresse, "Molecular motors hijacking by intracellular pathogens," Cellular Microbiology, vol. 8, no. 1, pp. 23-32, 2006.

[341] X. Wang, D. Li, D. Qu, and D. Zhou, "Involvement of TIP60 acetyltransferase in intracellular Salmonella replication," BMC Microbiology, vol. 10, article 228, 2010.

[342] M. J. Worley, G. S. Nieman, K. Geddes, and F. Heffron, "Salmonella typhimurium disseminates within its host by manipulating the motility of infected cells," Proceedings of the
National Academy of Sciences of the United States of America, vol. 103, no. 47, pp. 17915-17920, 2006.

[343] L. M. McLaughlin, G. R. Govoni, C. Gerke et al., "The Salmonella SPI2 effector SseI mediates long-term systemic infection by modulating host cell migration," PLoS Pathogens, vol. 5, no. 11, Article ID e1000671, 2009.

[344] J. M. Thornbrough and M. J. Worley, "A naturally occurring single nucleotide polymorphism in the Salmonella SPI2 type III effector $\mathrm{srfH} / \mathrm{sseI}$ controls early extraintestinal dissemination," PLoS ONE, vol. 7, no. 9, Article ID e45245, 2012.

[345] S. W. Hicks, G. Charron, H. C. Hang, and J. E. Galán, "Subcellular targeting of Salmonella virulence proteins by host-mediated S-palmitoylation," Cell Host \& Microbe, vol. 10, no. 1, pp. 9-20, 2011.

[346] N. S. Lossi, N. Rolhion, A. I. Magee, C. Boyle, and D. W. Holden, "The Salmonella SPI-2 effector SseJ exhibits eukaryotic activator-dependent phospholipase A and glycerophospholipid: cholesterol acyltransferase activity," Microbiology, vol. 154, no. 9, pp. 2680-2688, 2008.

[347] P. Nawabi, D. M. Catron, and K. Haldar, "Esterification of cholesterol by a type III secretion effector during intracellular Salmonella infection," Molecular Microbiology, vol. 68, no. 1, pp. 173-185, 2008.

[348] M. B. Ohlson, K. Fluhr, C. L. Birmingham, J. H. Brumell, and S. I. Miller, "SseJ deacylase activity by Salmonella enterica serovar typhimurium promotes virulence in mice," Infection and Immunity, vol. 73, no. 10, pp. 6249-6259, 2005.

[349] M. Christen, L. H. Coye, J. S. Hontz et al., "Activation of a bacterial virulence protein by the GTPase RhoA," Science Signaling, vol. 2, no. 95, p. ra71, 2009.

[350] D. L. LaRock, P. S. Brzovic, I. Levin, M. P. Blanc, and S. I. Miller, "A Salmonella typhimurium-translocated glycerophospholipid:cholesterol acyltransferase promotes virulence by binding to the RhoA protein switch regions," The Journal of Biological Chemistry, vol. 287, no. 35, pp. 2965429663, 2012.

[351] S. L. Kujat Choy, E. C. Boyle, O. Gal-Mor et al., "SseK1 and SseK2 are novel translocated proteins of Salmonella enterica serovar Typhimurium," Infection and Immunity, vol. 72, no. 9, pp. 5115-5125, 2004.

[352] N. F. Brown, B. K. Coombes, J. L. Bishop et al., "Salmonella phage ST64B encodes a member of the SseK/NleB effector family," PLoS ONE, vol. 6, no. 3, Article ID e17824, 2011.

[353] B. K. Coombes, M. J. Lowden, J. L. Bishop et al., "SseL is a Salmonella-specific translocated effector integrated into the SsrB-controlled Salmonella pathogenicity island 2 type III secretion system," Infection and Immunity, vol. 75, no. 2, pp. 574-580, 2007.

[354] S. D. Auweter, H. B. Yu, E. T. Arena, J. A. Guttman, and B. B. Finlay, "Oxysterol-binding protein (OSBP) enhances replication of intracellular Salmonella and binds the Salmonella SPI2 effector SseL via its N-terminus," Microbes and Infection, vol. 14, no. 2, pp. 148-154, 2011.

[355] E. T. Arena, S. D. Auweter, L. C. Antunes, A. W. Vogl, J. Han et al., "The deubiquitinase activity of the Salmonella pathogenicity island 2 effector, SseL, prevents accumulation of cellular lipid droplets," Infection and Immunity, vol. 79, no. 11, pp. 4392-4400, 2011.

[356] R. Singh and A. M. Cuervo, "Lipophagy: connecting autophagy and lipid metabolism," International Journal of Cell Biology, vol. 2012, Article ID 282041, 12 pages, 2012.

[357] S. G. S. C. Buchanan and N. J. Gay, "Structural and functional diversity in the leucine-rich repeat family of proteins," 
Progress in Biophysics and Molecular Biology, vol. 65, no. 12, pp. 1-44, 1996.

[358] I. Levin, C. Eakin, M. P. Blanc, R. E. Klevit, S. I. Miller, and P. S. Brzovic, "Identification of an unconventional E3 binding surface on the $\mathrm{UbcH} 5 \sim \mathrm{Ub}$ conjugate recognized by a pathogenic bacterial E3 ligase," Proceedings of the National Academy of Sciences of the United States of America, vol. 107, no. 7, pp. 2848-2853, 2010.

[359] E. Cardenal-Munoz and F. Ramos-Morales, "Analysis of the expression, secretion and translocation of the Salmonella enterica type III secretion system effector SteA," PLoS ONE, vol. 6, no. 10, Article ID e26930, 2011.

[360] S. B. Van Engelenburg and A. E. Palmer, "Imaging typeIII secretion reveals dynamics and spatial segregation of Salmonella effectors," Nature Methods, vol. 7, no. 4, pp. 325330, 2010.

[361] J. Poh, C. Odendall, A. Spanos et al., "SteC is a Salmonella kinase required for SPI-2-dependent F-actin remodelling," Cellular Microbiology, vol. 10, no. 1, pp. 20-30, 2008.

[362] P. Fernandez-Pinar, A. Aleman, J. Sondek, H. G. Dohlman, M. Molina et al., "The Salmonella typhimurium effector SteC inhibits Cdc42-mediated signaling through binding to the exchange factor Cdc24 in Saccharomyces cerevisiae," Molecular Biology of the Cell, vol. 23, no. 22, pp. 4430-4443, 2012.

[363] A. B. Blanc-Potard, F. Solomon, J. Kayser, and E. A. Groisman, "The SPI-3 pathogenicity island of Salmonella enterica," Journal of Bacteriology, vol. 181, no. 3, pp. 9981004, 1999.

[364] T. D. Ho, N. Figueroa-Bossi, M. Wang, S. Uzzau, L. Bossi, and J. M. Slauch, "Identification of GtgE, a novel virulence factor encoded on the Gifsy-2 bacteriophage of Salmonella enterica serovar typhimurium," Journal of Bacteriology, vol. 184, no. 19, pp. 5234-5239, 2002.

[365] S. Spanò, X. Liu, and J. E. Galán, "Proteolytic targeting of Rab29 by an effector protein distinguishes the intracellular compartments of human-adapted and broad-host Salmonella," Proceedings of the National Academy of Sciences of the United States of America, vol. 108, no. 45, pp. 18418 $18423,2011$.

[366] R. Samudrala, F. Heffron, and J. E. McDermott, "Accurate prediction of secreted substrates and identification of a conserved putative secretion signal for type iii secretion systems," PLoS Pathogens, vol. 5, no. 4, Article ID e1000375, 2009. 

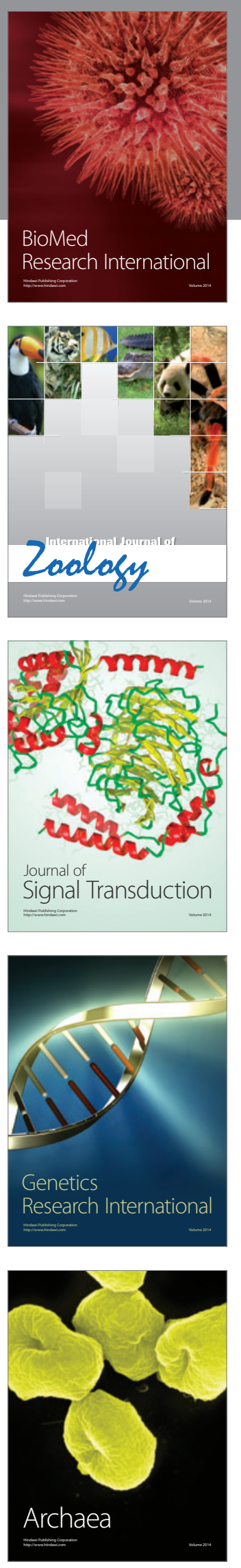
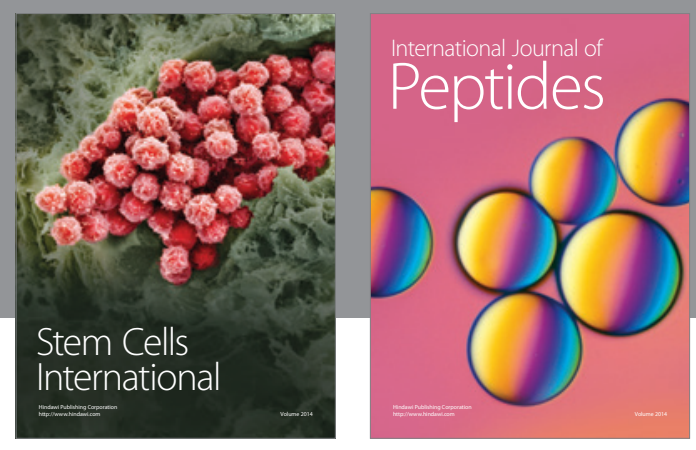

Submit your manuscripts at

http://www.hindawi.com
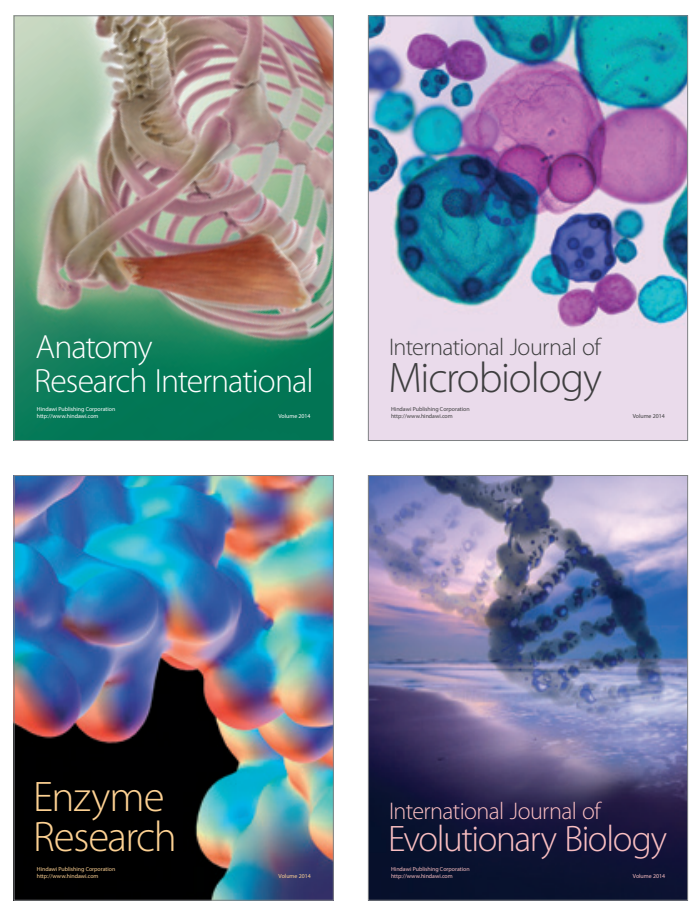
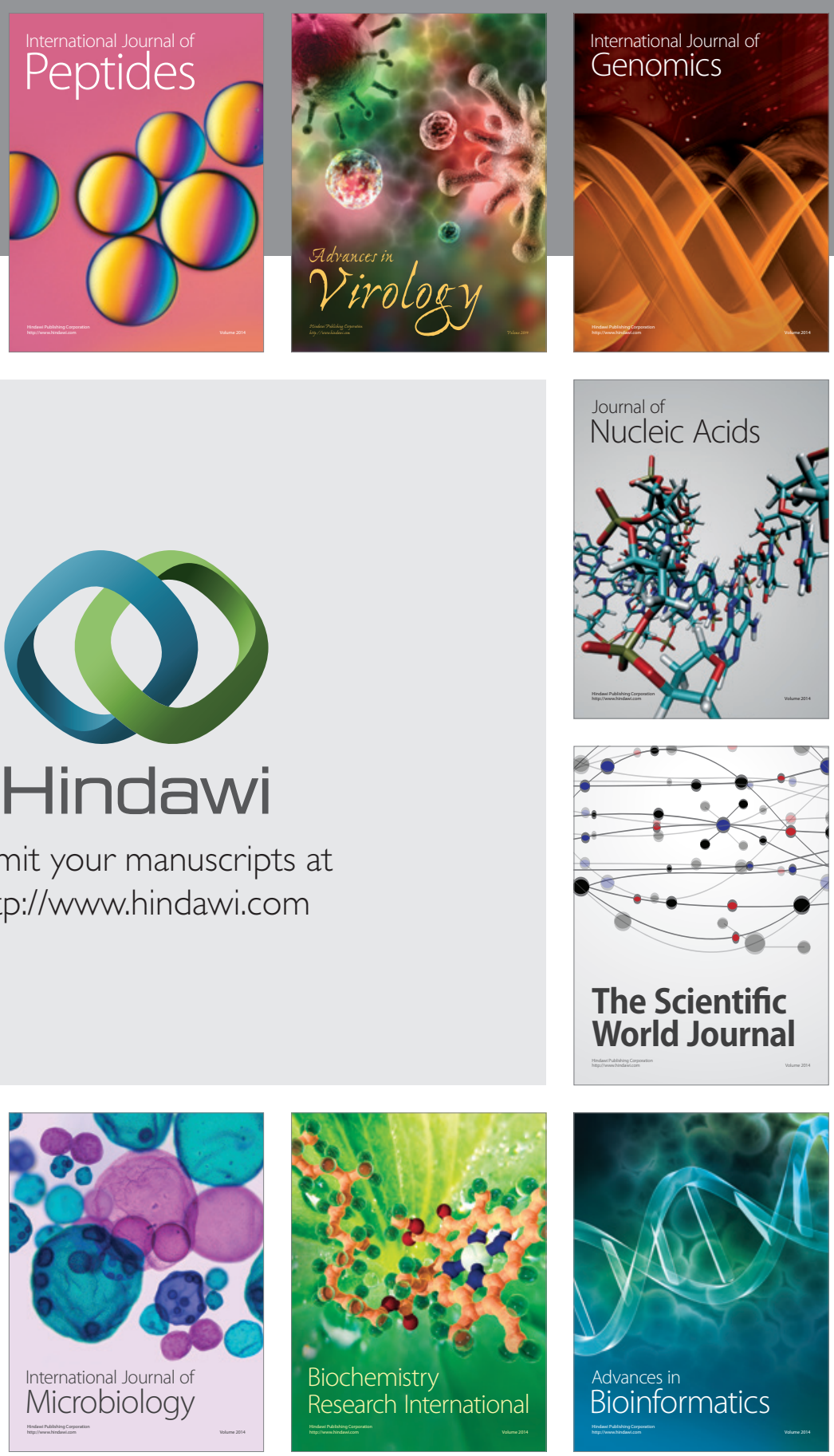

The Scientific World Journal
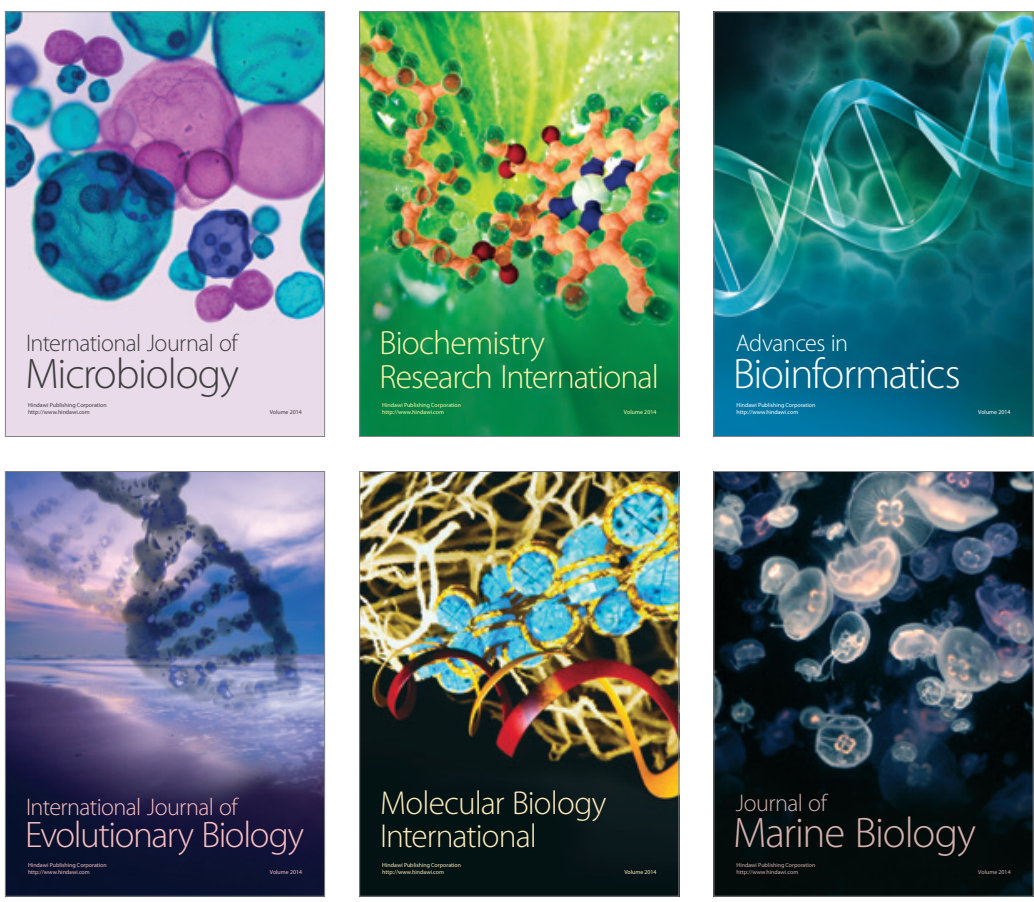